Francisco Bernardini Tancredi

\title{
Aspectos Epidemiológicos do Consumo de Medicamentos Psicotrópicos pela População de Adultos do Distrito de São Paulo
}

\author{
Dissertação apresentada à Faculdade de \\ Saúde Pública da Universidade de São de \\ Paulo, Departamento de Prática de Saúde \\ Pública, para a obtenção do título de \\ "Mestre em Saúde Pública". \\ Orientador: Profa. Aracy Witt de Pinho Spinola
}

\footnotetext{
BIBLIOTECA

Faculuade de saúde pública

UNIVERSILADE DE SAO PALLO

$S P-8$
}

São Paulo

1979 
rạa.

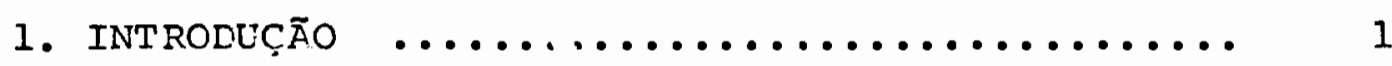

1.1 o desenvolvimento da Esicofarmacclooia... 4

1.2 Aspectos psico-sociais da ansiedade e a ação cos medicamentos psicotrōnicos ..... 14

1.3 Aspectos epidemiológicos co consuro de me dicamentos psicotrópicos ............ 29

1.4 Algumas particularidades do mercado brasi leiro de medicamentos psicotrópicos ..... 54

3. MATERIAL E METODO .................... 65

3.1 Amostra $\ldots \ldots \ldots \ldots \ldots \ldots \ldots \ldots \ldots \ldots \ldots \ldots . \ldots \ldots$

3.2 Levartamento de dados ............... 66

3.2.1 Fase de rastreamento.......... 67

3.2.2 Avaliação da entrevista de rastrea mento ..................... 69

3.3 Análise dos resultados .............. 70

3.3.1 Anālise do tipc de redicamentos utilizados ................. 71

3.3.2 Anālise dos pacrōes de corsuro ... 73

3.4 Apuração dos resultadcs .............. 75

3.5 Tratamento estatístico .............. 75

3.6 Estimativa do indice ce correçãc para informaçōes incompletas ............. 76 
4. RESULTADOS E DISCUSS $\widetilde{O} O \ldots \ldots \ldots \ldots \ldots \ldots \ldots$ pāo.

4. I Prevalência em um ano do consumo de medicamentos psicotrópicos ..............

4.2 Incidência e prevalência do consumo de me dicamentos psicotrópicos er 30 dias .....

4.3 Distribuição geogrãfica da prevalência do consumo de redicamentos psicctrópiccs ...

4.4 Padrões de consumo de redicarentcs psico-

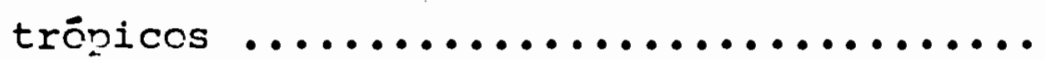

4.5 Tipos de redicamentos consumidos ........

4.6 Motivos para o uso de medicamentos psicotrópicos $\quad \ldots \ldots \ldots \ldots \ldots \ldots \ldots \ldots \ldots \ldots \ldots$

4.7 Fontes de indicação do uso dos medicamentos psicotrópicos .................

4.8 Estudo das características de idade e sexo dos consumidores de redicamentos psico

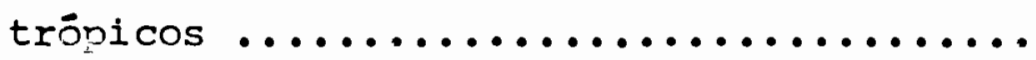

4.9 Consumo de medicamentos psicotrópicos e

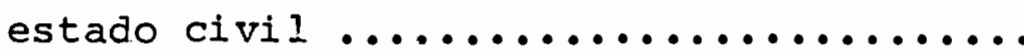

4.10 Consumo de medicamentos psicotrópicos e condições de habitação ...............

4.11 Consumo de medicamentos psicotrópicos e srau de instrução

5. CONCLUSÕES

6. REFERENCIAS RIBLIOGRAFICAS

7. ANEXOS 
RESUMO

o autor faz uma anālise crítica do consumo de medicamentos psicotröpicos e apresenta os resultados de um inquérito epidemiológico realizaco no Distrito de são Paulo com vistas a determinar os nĩveis de prevalência e incidência do consumo destes redicamentos, os padrões de consumo, os tipos de medicamentos mais frequentemente utilizados e a associação do uso de psicotrōpicos a algumas variāveis sōcio-derocráficas.

Inicialmente discute os aspectos psico-so ciais da ansiedade chamando a atenção para o risco da utiliza ção de ansiolíticos, hipnóticos e sedativos para o alívio da an siedade objetiva, a qual representa uma resposta de defesa do indivíduo frente ao seu reio ambiente; defende a idéia de que esta forma de ansiedade é útil e necessária ao Homem e que a utilização indiscriminada de medicamentos psicotrópicos para o seu alívio representa um prejuĩzo para o desenvolvimento emocio nal individual e para a prođressão teleológica da sociedade.

Discute aspectos do mercado destes medicamen tos apontando os papēis desempenhados pelos principais envolvidos em uma complexa relação de interesses: a indústria farmacêutica, a classe mēdica, os pacientes e os proprietārios de farmā cias. Em relação ao mercado brasileiro, discute o importante segmento ocupado pelos produtos classificados cono "antidistôni cos" que, a seu ver, representam uma forma disfarçada de coloca ção no mercado de produtos psicotrōpicos cuja venda escapa aos rigores da legislação que regula a prescrição e aquisição de me dicamentos contendo substâncias psicotrōpicas. 
O inquérito enidemiológico realizado em 1976-1978 indica que entre 3690 indivíuos de 16 ou mais anos de idade pertencentes a 1345 familias a prevalência de consumo no ültimo ano foi de $122,2,1000$ habitantes $(75,7 / 1000$ para o sexo masculino e 163,2/1000 para o sexo feminino). A incidência de no vos consuridores nos últimos 30 dias foi $7,6 / 1000$ habitantes $(5,8 / 1000$ para o sexo masculino e 9,2/1000 para o sexo feminino). Observou-se uma tendência ao crescimento dos niveis de consumo com a idade e valores de prevalência de consumo sempre maiores entre as mulheres do que entre os homens (produto cruzado igual a 2,38$)$. A icade média dos consumicores de psicotrópicos é 5,13 anos superior a dos não consumicores. A prevalência de consumo nas āreas geogräficas de melhor qualidade de vida é $62 \%$ sunerior àquela das āreas de menor qualidade de vida.

Foram observados três oađrões característicos de consumo: o uso regular $(56,18$ dos consumidores), o uso esporā dico $(38,1 \%$ dos consumicores $)$ e o uso episōdico $(4,48$ dos consumidores). Os consumidores esporädicos tendem a ser mais constantes no seu comportamento do que os consumidores regulares e episōdicos.

Os medicamentos ansioliticos, hipnōticos e sedativos são os mais frequentemente usados $(86,5$ cos casos) e, pelo menos, $62,6 \%$ deles podem ser adquiricos sem a apresentação de receita nédica. Somente os derivados da benzodiazenina lansio liticos e hipnóticos) representam $72,8 \%$ de todos os produtos con sumicos.

Em $81,6 \%$ dos casos o uso se deu por indicação médica, em 2,78 dos casos a indicação foi do "farmacêutico", em 4,48 dos casos a indicação foi de um parente ou conhecido e em 
10,28 dos casos foi o prōprio usuário que decidiu a indicação. Dentre os médicos, são os clínicos gerals os que mais prescrevem psicotrópicos $(57,4$ \&o total) e eles têm clara preferência pelos produtos livres de contr. le de receituārio.

Há indícios de que possa haver maiores ni veis de consumo entre mulheres com vinculo matrimonial rompido (viūvas, separadas e desquitadas) na faixa etāria de 30 a 50 anos. Outrossim, foram observados maiores niveis de consumo em pessoas com menor grau de instrução. Não foi encontrada qualquer relação entre consumo de medicamentos e as condições de habitação (medidas pelo incice de aglomeração). 
SUMMARY 
SUMMARY

The ruthor critically analyzes the consumption of psychotropic drugs and also presents the results of an epicemiolooical survey taken within the District of são Paulo, which was performed in order to determine the prevalence and incidence of the consumption of such erugs, the consumption patterns, the types of medications most frequently taken, and to determine a relation between the use of psychotropics and socialdemographic variables.

First, some psycho-social aspects of anxiety are presented, emphasizing the risks involved when minor tranquilizers, hypnotics, and sedatives are used to relieve objective anxiety, which is the normal individual's defense reaction against the acressions of his environment. It sunports the icea that such anxiety is constructive and necessary for man and that the carefree utilization of psychotropic medications will thus harm, both the individual's emotional developrent and the teleolocical progress of society.

The psychopharmaceutical market is then discussed, pointing out the complex relationships among those involved and their various interests: the pharmaceutical industry, the medical class, the patients, and the pharmacy proprietors. In respect to the Brazilian market, those products classified as "antidistônicos", (hidden psychotronics), are discussec as a disguised way to legally sell psychotropic drugs over the counter and escape laws applying to their purchase and prescrintion.

The epidemiological survey taken curine the years 1976-1978 indicates that 3690 participants, 16 years or older and distributed among 1345 farilies, showed a consumption 
prevalence in the last year of $122.2 / 1000$ inhabitants, (75.7/ 1000 for males and $163.2 / 1000$ for females). In the last 30 days the incidence of new consumers was $7.6 / 1000$ inhabitants. There is an increasing tendency observed in corresnondence to the consumption level and age. Furthermore, the prevalence values are always higher for females than for males, (cross product is equivalent to 2.38 ); the mean age of psychotronic consumers is 5.13 years higher than nonconsumers.

In the geographic areas with a higher standard of living, the consumption prevalence is $62 \%$ greater than in those areas with a lower standard of living.

Three consumption patterns are characterized: the regular use (56.1\% of the consumers), the sporadic use (39.1\% of the consumers), and the episodic use (4.48 of the consumers). The sporadic consumers tend to have a rore consistent behavior compared to those considered recular or episodic consurers. Minor tranquilizers, hypnotics, and sedatives are found as heinc the medications most frequently used, ( 86.58 of the cases), with at least 62.68 of them purchasable over the counter. Those drugs derived from benzodiazepine, (i.e., minor tranquilizers and hypnotics), alone represent $72.8 \%$ of all the medications consured. In 81.68 of the cases, the medications were taken under a doctor's prescription, $2.7 \%$ of the cases occurred due to a pharmacist's indication, in $4.4 \%$ of the cases a relative or friend had suggested the use of the medication, and in 10.28 of the cases the user himself had prescribed the medication. Arong physicians, psychotropics are more ofter prescribed by ceneral practitioners, (57.48 of the total cases), whose preference is clearly given to those products freely sold over the counter. 
There is incication oiven that women with broken marriages, (widowed, seperated, or divorced), within the age group of 30 to 50 years, have a higher consumption level. High levels of consumption are also observed among less educated persons. No association was found between the consumption of psychotropics and habitation conditions, (reasured by the conglomeration index). 
1. INTRODUÇÃO 
Em 1974 o Programa de Saúde Mental da Fạ culdade de Saúde Pública da Universidade de são Paulo deu iní cio ao "Estudo dos Transtornos Mentais e suas Caracteristicas no Distrito de São Paulo" (*); trata-se de estudo epidemioló gico de largo porte realizado através de inquérito domiciliar com objetivo geral de analisar as caracteristicas da distribui ção dos transtornos mentais na população residente nos 48 subdistritos que compõem o Distrito de são Paulo.

Uma das informações solicitadas no inquérito referia-se ao uso de medicamentos psicotrópicos no perīo do de 12 meses que antecediam a data da entrevista na medida em que, como se supôs, este representava um dos possiveis ele mentos indicadores da presença de transtorno mental no indiví duo. A partir do início do trabalho de campo, em 1975, chamou a nossa atenção o número, aparentemente grande, de pessoas que acusarain o uso destes medicamentos, inclusive aquelas que, pe lo conjunto de informações, não aparentavam ser portadores de um transtorno mental; isto $\bar{e}$, aparentemente, o uso de medica-

(*) O Programa de Saüde Mental é decorrente de convênio entre a Coordenadoria de Saüde Mental da Secretaria de Estado da Saúde e o Departamento de Saúde Pública da Universidade de São Paulo28. A supervisāo do Programa está a cargo do Dr. Cid Guimarães e sua execução a cargo do Dr. Francís co Bernardini Tancredi. 0 "Estudo dos Transtornos Mentais e suas Caracteristicas no Distrito de São Paulo" está sen do desenvolvido em colaboração com o Departamento de Ep $\bar{i}$ demiologia; o Grupo de Planejamento do estudo foi compos= to pelos seguintes membros do corpo docente da Faculdade de Saüde Püblica: Prof. Ruy Laurenti, Dr. Cid Guimarēs, Dra. Eunice Pinho de Castro Silva, Dr. José Maria Pacheco de Souza, Dra. Sabina Léa Davidson Gotlieb, Dra. Maria He lena de Mello Jorge e Dr. Francisco Bernardini Tancredi. A execução do estudo ficou a cargo dos Drs. Francisco Ber nardini Tancredi, Paulo César Sandler e Ernesto BaptistaFilho. 
mentos psicotrōpicos não podia, isoladamente, ser considerado um indício da presença de um transtorno mental e aparecia co mo um padrão de comportamento mais extenso do que se poderia imaginar. Ficou-nos a impressão de que os medicamentos ansio liticos, hipnóticos e sedativos, em particular aqueles de aqu sição livre, estavam sendo objeto de uma atitude permissiva por parte da população e consumidos não somente para o alívio da ansiedade associada a estados mentais caracteristicamente mórbidos como, também, para o alívio da ansiedade, mesmo que transitōria, decorrente de situações do dia a dia e com uma conotação claramente não-médica; assim, por exemplo, o luto, dificuldades no trabalho ou negōcios, as mais diversas dificul dades de relacionamento interpessoal, o medo diante de uma do ença, o excesso de tensões acumuladas no trabalho ou no deslo camento urbano, a frustação de projetos de vida ou, simplesmen te, o desejo de obter tranquilidade ou um sono repousante, to dos apareceram. como motivos que levavam ao consumo esporádico ou regular de medicamentos tranquilizantes.

Outrossim, além de uma aparente liberalidade da classe médica na prescrição de psicotrópicos, ficounos a impressão de que, um nümero significativo de pessoas os utilizava sem orientação médica, seja por indicação de "farma cêuticos", parentes ou conhecidos ou por conta própria.

Diante de tais observações tomamos a decí são de estudar a extensão do problema. Tanto os índices de pre valência do consumo, como os padrões de consumo, as fontes de indicação e os motivos para o uso pareciam aspectos dignos de uma anālise mals profunda. Além disso, a anālise das caractẹ rísticas do mercado de medicamentos, das condiçōes de prestação de serviços médicos e das atitudes da população frente à ansiedade e seus mecanismos de alỉvio parece necessāria para 
a compreensão global do problema.

o número e a complexidade das variáveis envolvidas não nos permitiam uma anālise ampla da questão. Con tudo, pareceu-nos indicado, num primeiro estudo realizar uma abordagem descritiva a partir da qual fossem levantadas hipóteses explicativas do fenômeno as quais, por sua vez, poderiam dar origem a estudos analíticos que viessem a incursionar so bre terreno tão complexo.

A execução do projeto foi possível graças ao aproveitamento da infra-estrutura do "Estudo dos Transtornos Mentais e Suas Características no Distrito de são Paulo" . Ampliamos o nưmero de questões relativas ao uso de medicamentos psicotrópicos e, a partir de julho de 1976, os entrevista dores domiciliares foram treinados com o objetivo de, a par da entrevista que jā vinha sendo feita, obter informações que conduzissem a conclusões sobre o padrão de utilização de medi camentos psicotrópicos, tipos de medicamentos utilizados, fon tes de indicação e motivos para o uso. Estas informações adi cionais e aquelas que foram objeto do "Estudo dos Transtornos Mentais e Suas Características no Distrito de são Paulo" per mitiram a realização deste estudo.

$\mathrm{Na}$ medida em que este trabalho se preocupa com os aspectos epidemiológicos do consumo de medicamentos que atuam sobre o comportamento humano e que seu uso indevido pode ter reflexos na organização social, julgamos conveniente abordar, num primeiro momento, alguns aspectos psico-sociais da ansiedade, emoção que com maior frequência tem sido alvo da utilização dos psicotrópicos. Alēm disso, para facilitar a compreensão de todo o trabalho, damos inicialmente uma sucinta descrição do desenvolvimento da psicofarmacologia. 
Se bem que o campo de interesse da psicofarmacologia possa ser entendido, I'um sentido amplo, como o estudo de todas as substâncias com ação predominante sobre o sistema nervoso central que alteram as funções cognitivas e conativas, limitar-nos-emos a abordar somente o desenvolvimen to das drogas utilizadas com objetivos terapêuticos. Assim, ficam excluidas as referências sobre o ópio, a maconha, a co ca, o peiote e outras diversas drogas empregadas em diversas culturas desde há séculos e ainda hoje utilizadas marginalmen te por alguns segmentos das sociedades modernas.

A utilização terapêutica de psicofārmacos não è recente. As infusōes de raizes de Rauwolfia serpentina eram empregadas desde hā sēculos na India para o tratamento da loucura e diversas tribos indigenas da América Latina que dominavam a técnica de preparação de vegetais com o fim de ob ter tranquilização. O lítio foi utilizado esporadicamente no século XIX para o tratamento da mania; logo foi abandonado por receio de seus efeitos tóxicos e, há cerca de tres décạ das, seu uso foi retomado. Ainda no século passado foram sin tetizados e utilizados os brometos, o hidrato de cloral e 0 paraldeido, hoje em dia, parcamente consumidos.

Em 1903 passa a fazer parte do arsenal te rapêutico do médico o primeiro barbitūrico, o Veronal. A respeito deste curioso nome, conta-se que houve intenção do fabri cante em associar a imagem do novo medicamento à cidade de Ve rona, sede da tragédia "Romeu e Julieta", onde a jovem toma uma poção māgica que a faz dormir profunda e longamente para, depois, despertar completamente lúcida. Nos anos seguintes surgem novos derivados barbitūricos empregados largamente até 
hoje (Luminal em 1912 e Amytal em 1923). Mais de 2.000 substân cias correlatas foram sintetizadas e diversas delas entraram para o receituārio médico ${ }^{32}$.

Os barbitüricos representar.'n importante aquisição pelas suas excepcionais qualidades como hipnōticos ou como sedativos, quando utilizados em menores doses; além disso, também entraram largamente no campo da Neurologia o Gardenal e o Prominal pelas suas propriedades anticonvulsivan tes. Em $1920 \mathrm{Kläse}$ introduz o tratamento pela narcose continua ou sonoterapia, o qual durante algum tempo gozou de prestígio pela eficácia em estudos agudos de tensão, excitação e angústia e diante da falta de outras terapias alternativas ${ }^{32}$. Por volta de 1930 a narcose contínua foi eclipsada por outros pro cedimentos, mas voltou a ter popularidade limitada no tratamen to das neuroses agudas de combate durante a segunda guerra mun dial. Na década de 1930 surgiram os tratamentos pelo choque insulínico e a convulsoterapia que preencheram o espaço anteriormente ocupado pelos barbitúricos nos tratamentos dos esta dos psicóticos, principalmente as psicoses esquizofrênicas. Assim, aqueles compostos tiveram suas indicações limitadas aos estados de ansiedade e tensão associados mais frequentemente às neuroses. Finalmente, com o surgimento dos neurolépticos e dos tranquilizantes derivados da benzodiazepina, nas décadas de 1950-1960, os tratamentos à base de barbitüricos cairam de finitivamente em ostracismo, exceto o seu emprego nas epilepsias como eficientes moderadores das disritmias cerebrais e como hipnóticos ou sedativos coadjuvantes de outros tratamentos farmacológicos.

Pode se afirmar que os barbitúricos repre sentaram a primeira grande conquista da psicofarmacologia. Mesmo sem que se tivesse um conhecimento claro dos seus meca 
nismos de ação (o que veio acontecer mais tarde com os estudos de neurofisiologia), eles foram bastante populares tanto entre a classe médica com entre os consumidores. Com a posterior ob servação de que causavam dependência e tolerância e que podiam ser utilizados com sucesso por pacientes suicidas, foram esta belecidas normas rígidas de controle do seu consumo, dificultando a sua comercialização.

A débacle definitiva dos barbitūricos, con tudo, ocorreu a partir da década de 1950. Em 1952 foi lançada no mercado a cloropromazina, droga-mãe de uma extensa lista de medicamentos com a propriedade de controlar os estados psicótị cos (chamadas de neurolēpticos) e pouco depois, em 1954, é lan çado o meprobamato, o qual, sem ser capaz de atuar eficazmente sobre os estados psicóticos, era, contudo, capaz de reduzir a ansiedade e angústia; se bem que de reinado efêmero, o meprobamato teve o mérito de ser o primeiro de uma longa lista de psicofármacos denominados ansioliticos ou, simplesmente, tran quilizantes.

En 1957 e 1958 surgem os primeiros antide pressivos e em 1960 foi posto à venda o Librium, sucedâneo $\underline{i}$ mediato do meprobamato pertencente à familia das benzodiazepí nicos, sem dúvida, a mais prolífica e comercialmente bem suce dida de todas entre os psicofármacos; rapidamente surgiram no vos derivados de benzodiazepina, dos quais o diazepam (Valium) - introduzido em 1963 - è até hoje o mais largamente empregado. Praticamente a cada 2 anos é colocado à disposição do mer cado um novo derivado da benzodiazepina, seja ele possuidor de efeito tranquilizante (medazepan, oxazepan, lorazepan, clo bazan) seja de efeito hipnótico (nitrazepan, flurazepan e flū netrazepan).

o impacto causado pelos neurolépticos, 
tranquilizantes e antidepressivos sobre a Psiquiatria foi espe tacular, inclusive a ponto de diversos autores considerarem a década de 1950 o início da moderna psicofarmacologia 32,49. Em diversos paises o tempo médio de permanência nos hospitais psi quiātricos ? o número de leitos psiquiātricos declinaram acen tuadamente (Figuras 1 e 2); o número de pacientes que passaram a obter reintegração social aumentou significativamente 24,49 , ; os tratamentos por choque insulínico e pela convulsoterapia ti veram suas indicações restringidas, principalmente o primeiro deles, que hoje estā praticamente em desuso. Com os novos medi camentos, tornou-se viāvel, se não atuar sobre os fatores etio lógicos da esquizofrenia, da psicose maníaco-depressiva e das neuroses, pelo menos, intervir diretamente sobre seus sintomas cardinais sem ter, para isso, que provocar sedação acentuada como ocorria com os barbitúricos. Além disso, a margem de segu rança (relação entre a dose ũtil e a dose letal) era bem maior para as novas drogas permitindo uma maleabilidade e segurança até então inimaginadas para os tratamentos psiquiátricos.

o Quadro 1 mostra os principais grupos psi cofarmacológicos modernos litilizados com finalidade terapêuti ca. Ela não pretende englobar todos os psicofármacos à disposi ção do mercado; sua finalidade é servir como um simples guia da exposição que se seguirá e, para facilitar sua compreensão, foram omitidos aqueles fármacos pouco utilizados atualmente. A classificação em Neurolēpticos, Antidepressivos, Tranquilizañtes e Hipnōticos baseia-se na ação principal de cada grupo de fārmacos, mas contēm forçosamente certas arbitrariedades pois uma mesma droga pode ter mais de um efeito na dependência da dose em que é utilizada, ou mesmo em doses uniformes $23,24,49$. Assim, por exemplo, quase todos os tranquilizantes são também hipnóticos em altas doses e todos os hipnóticos podem, em doses baixas, ser utilizados para sedação diurna. 
-FIGURA 1 - ADMISSÕES E DURAÇÃO MẼDIA DA ESTADIA DOS DOENTES NA CLINICA UINVERSITÁRIA DE PSIQUIATRIA DE BASILEIA, DE 1940 A 1963.

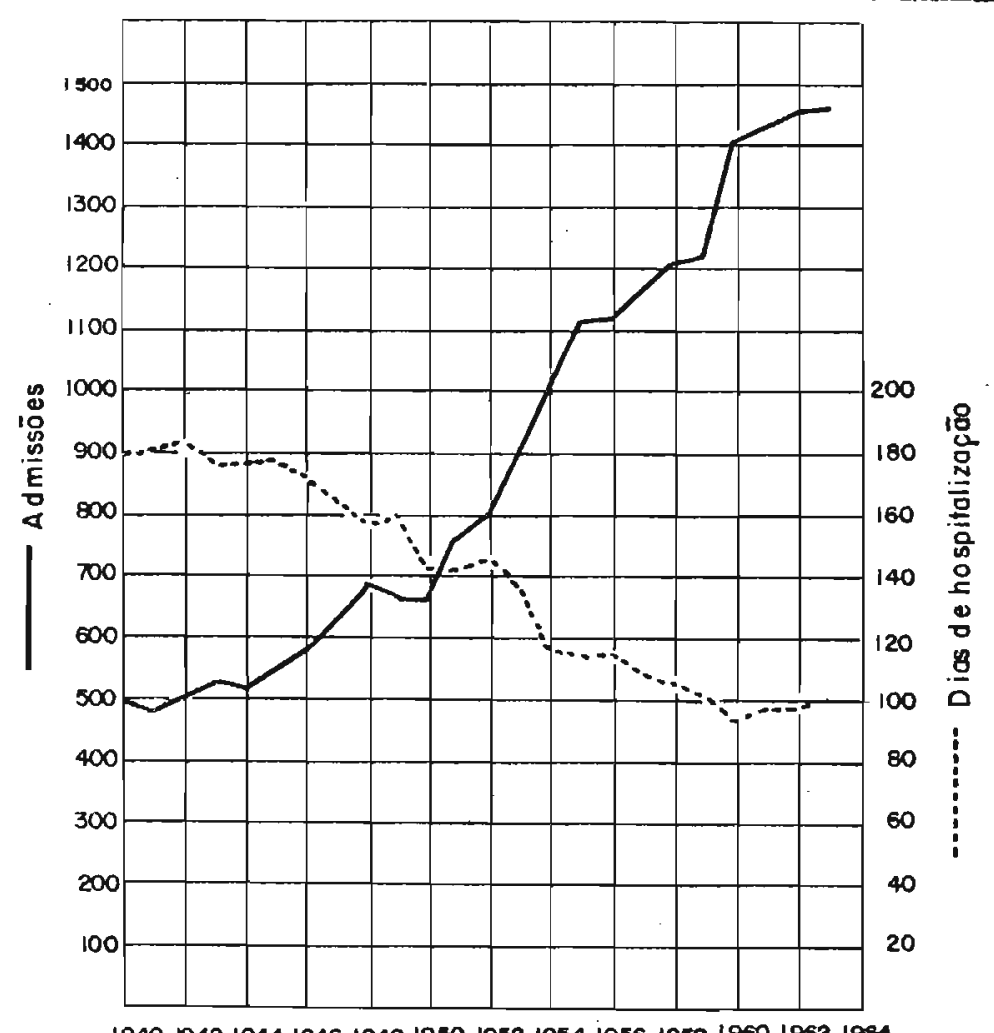

1940194219441946194819501952196419561958196019621984

FONTE: POLDINGER, W. 49 .

OBS: Os nümeros da esquerda dizem respetto à curva a traço cheio e os da direita à curva a ponteado.

FIGURA 2 - POPULAÇÃO DOS HOSPITAIS PSIQUIATRICOS POBLICOS NOS ESTADOS UNIDOS, 1946 - 1967

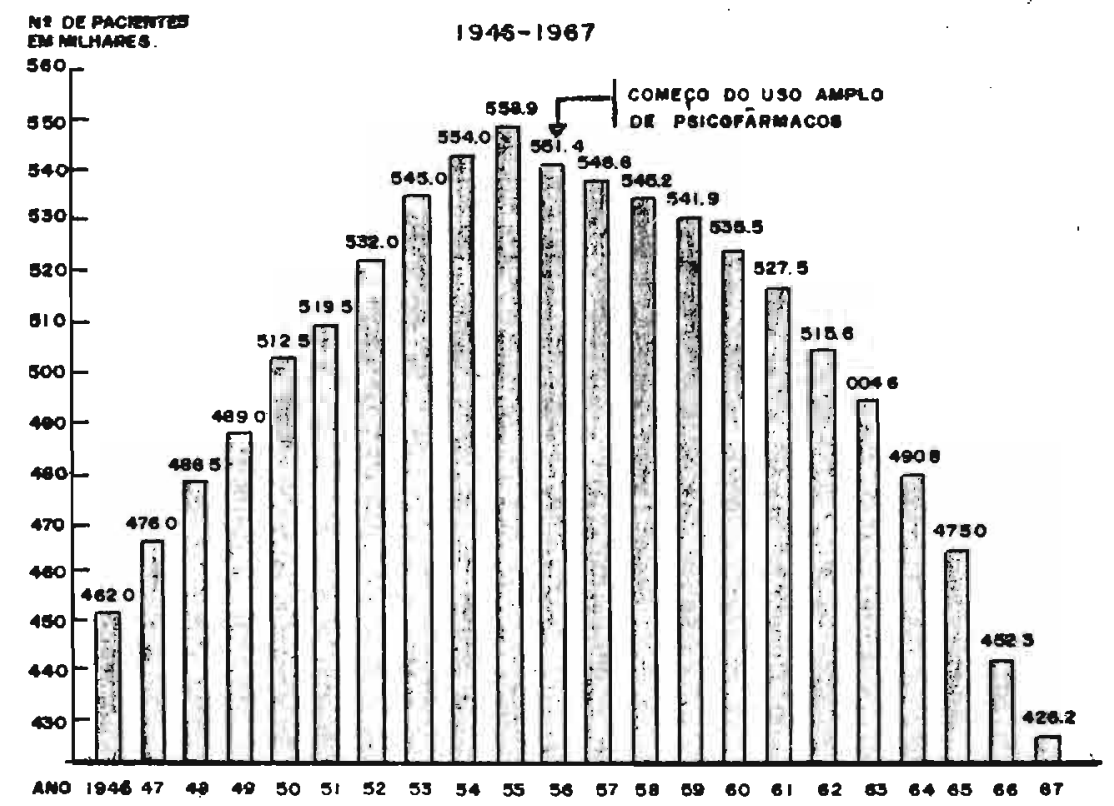

FONTE: FREEDMAN AND KAPLAN ${ }^{24}$ 
QUADRO 1 - SINOPSE DOS PRINCIPAIS DERIVADOS UTILIZADOS EM MEDICAMENTOS PSICOTROPICOS NO BRASTL.

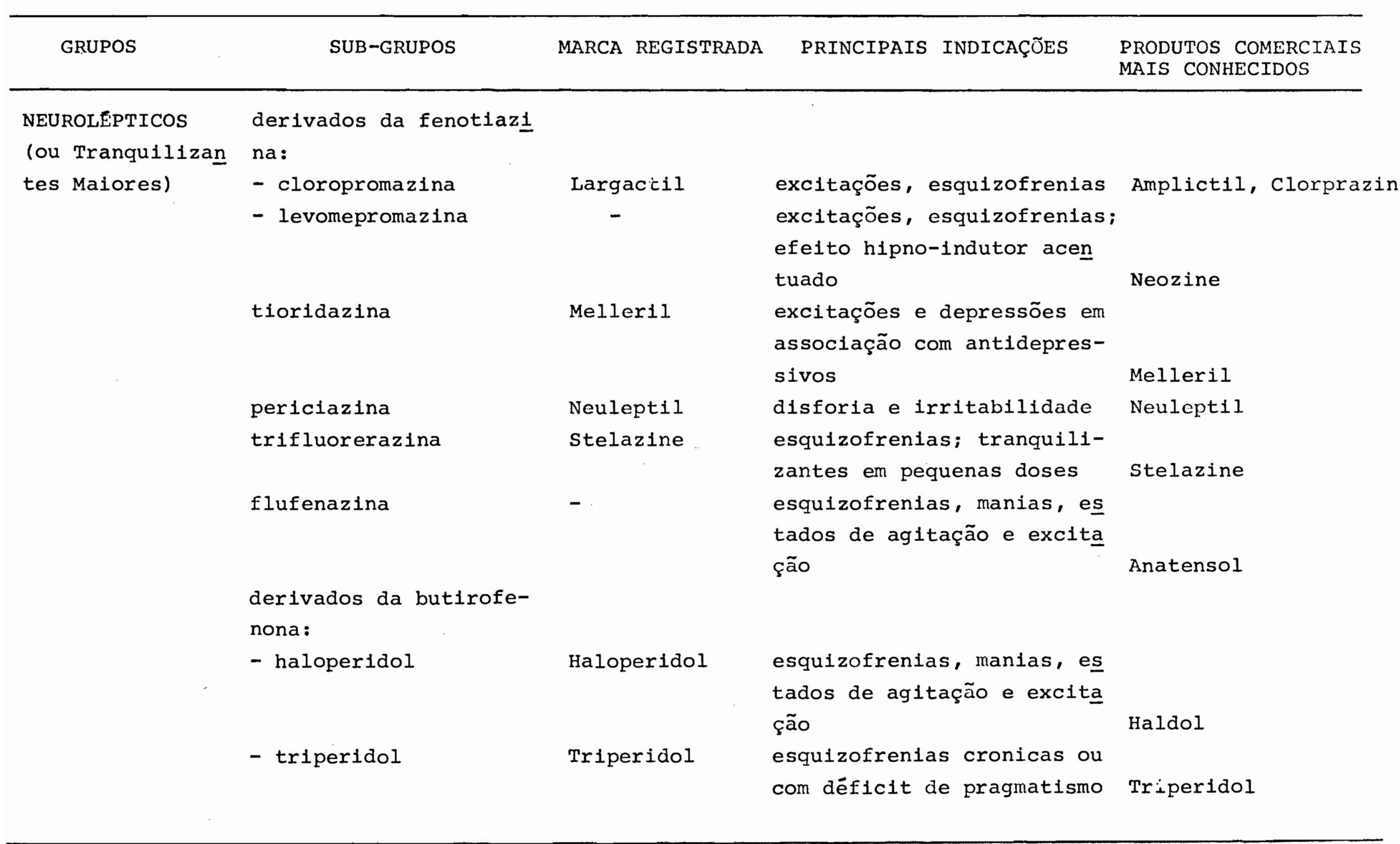




\begin{tabular}{|c|c|c|c|c|}
\hline $\begin{array}{l}\text { TRANQUILIZANTES } \\
\text { (ou Tranquilizan } \\
\text { tes menores ou } \underline{A} \\
\text { taráxicos ou An }\end{array}$ & $\begin{array}{l}\text { derivados do glicol: } \\
\text { - meprobamato } \\
\text { derivados da benzodia } \\
\text { zepina: }\end{array}$ & - & ansiedade & \\
\hline \multirow[t]{7}{*}{ sioliticos) } & - clorodiazepóxido & Librium & ansiedade & $\begin{array}{l}\text { Librium, Psicosedin, } \\
\text { Tensil }\end{array}$ \\
\hline & - diazepam & Valium & ansiedade & $\begin{array}{l}\text { Valium, Dienpax, So } \\
\text { malium }\end{array}$ \\
\hline & - medazepan & - & ansiedade & Medazepol \\
\hline & - oxazepan & - & ansiedade & Nobrium, Oxazepol \\
\hline & - lorazepan & - & ansiedade & Lorax, Lorium \\
\hline & - clobazam & - & ansiedade & Frisium, Urbanil \\
\hline & - bromazepan & Lexotan & ansiedade & Lexotan, Deptran \\
\hline ANTIDEPRESSIVOS & Imipramina & Tofranil & depressões, principalmente & \\
\hline TIMOLEPTICOS (Ou & & & as endógenas & Tofranil \\
\hline $\begin{array}{l}\text { Antidepressivos } \\
\text { triciclicos ou }\end{array}$ & amitriptilina & - & $\begin{array}{l}\text { depressões, princlpalmente } \\
\text { as endógenas }\end{array}$ & Tryptanol \\
\hline \multirow[t]{2}{*}{ Timoanalépticos) } & nortripillina & - & $\begin{array}{l}\text { depressões, principalmente } \\
\text { as endōgenas }\end{array}$ & \\
\hline & protriptilina & - & $\begin{array}{l}\text { depressões, principalmente } \\
\text { as endógenas }\end{array}$ & Concordin \\
\hline
\end{tabular}




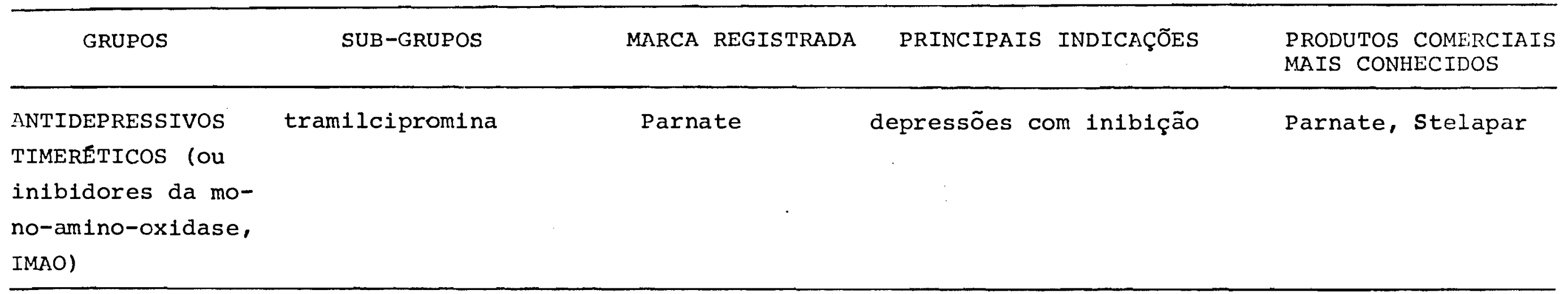

HIPNÓTICOS

derivados barbitüricos:

- fenobarbital Luminal efeito hipnötico de longa

ação; principalmente usado

como anticonvulsionante

Gardenal e diversos outros que o contém em pequenas doses se dativas (Vagostesyl, Sedandromaco)

- amobarbital Amytal efeito hipnótico de dura-

- butabarbital
derivados da benzodiaze pina:

- nitrazepan

- Elurazepan

- flunitrazepan derivados da quinazolinona: ção mediana

Nogadon

hipno-indução

\section{Amytal}

Butisol

Dalmadorm

Ronypnol

hipno-indução

hipno-indução.

metaqualona hipno-indução

\section{Vacotonil}

Mogddon, Nitrenpax, Serenex

Dalmadorm, Insonium Rohypnol

Mequalon, Mandrix

* Retirados do mercado brasileiro (e em diversos outros países) em 1977 devido a seus efeitos psicodislépti cos e por criar dependencia. 
Do ponto de vista da neurofisiologia pode se compreender melhor os efeitos dos psicofármacos estudando-se os seus mecanismos de atuação sobre o sistema nervoso cen tral. Enquanto os barbitūricos agem sobre todo o sistema, de primindo as formaçōes do tronco cerebral e da cōrtex, as ben zodiazepinas tem ação mais seletiva, atuando sobre o sistema límbico mas não sobre o córtex, o que explica o seu menor efei to sedativo. Assim, para se obter o mesmo efeito ansiolítico, - paciente que toma barbitūrico terā suas funçōes psíquicas superiores, de localização na córtex, mais afetadas. Pode se dizer que a ação dos barbitúricos não é seletiva enquanto a dos psicofármacos mais modernos (benzodiazepinas, neurolépticos em geral) è mais específica, isto é, eles atuam principal mente sobre formaçōes localizadas do sistema nervoso central integrantes dos circuitos neurofisiológicos responsāveis pela afetividade, pela agressividade, pela ansiedade, pelo humor,etc. Algumas caracteristicas dos fármacos pertencentes a cada grande grupo são dadas a seguir:

1. Neurolépticos: são as drogas conhecidas como an tipsicóticas ou tranquilizantes maiores por sua capacidade de fazer regredir os estados psicōticos; a maioria deles é capaz de atuar sobre delirios e álucinações, reduzindo-os ou suprimindo-os. são, tambēm, eficazes no controle dos estados de ex citação e agitação psicomotora. Alguns deles produzem sedação marcada enquanto outros, não. Todos podem apresentar efeitos colaterais (sindrome de parkinsonismo), combatidos com relatí va facilidade na maioria das vezes; ultimamente, tem-se descri to alguns casos de descinesias tardias consequentes ao uso dos neurolépticos. A margem de segurança pode ser considerada alta para a maioria deles; alguns, com maior efeito sedativo, tem menor margem de segurançà. Não provocam dependência ou tolerân 
cia.

2. Tranquilizantes: também conhecidos por tranquili zantes menores ou ansioliticos por sua propriedade marcada de reduzir o nível de ansiedade. Por o tro lado, o seu efeito an tipsicōtico è muito pequeno. São indicados em todos os estados (inclusive os psicóticos) onde se objetiva reduzir a ansiedade; dada sua propriedade, são largamente usados em todos os trata mentos médicos. Seus principais efeitos colaterais são a inibi ção dos reflexos e a ataxia. Não provocam tolerância ou depen dência, exceto ocasionalmente quando empregados por largos pe ríodos de tempo. Sua margem de segurança é bastante elevada.

3. Antidepressivos: são divididos em dois grupos: os timerēticos (inibidores da mono-amino-oxidase) que atuam mais sobre a inibição associada às depressões e os timolēpticos (derivados tricíclicos) com atuação mais acentuada sobre a tristeza vital. São, enfim, psicofārmacos que atuem sobre o humor e podem ser indicados para a maioria das formas de de pressões se bem que seus efeitos mais evidentes se fazem sentir nos casos de depressões endógenas. Seus efeitos colaterais são, em geral, de pequena monta e de fácil resolução. A margem de segurança tambēm é boa. Não provocam dependência ou tolerância.

4. Hipnōticos: vamos considerar três grupos:

a) os derivados da benzodiazepina, atualmente os mais utilizados, possuem caracteristicas semelhantes aos tran quilizantes, exceto pelo fato de o efeito hipno-indutor ser mais pronunciado e o efeito ansiolitico, menor; b)os derivados da quinozolinona, proscritos em 1976 por causa de seus efeitos psicodislēpticos* quando usado em doses mais elevadas do que o

* efeito psicodisléptico - capacidade de promover dissociaçāo da personalidade à semelhança do ácido lisérgico e psilocibina. 
recomendado e por provocar dependência; c) os barbitúricos que podem ser empregados como hipnōticos ou, em doses menores, como tranquilizantes sedativos. Afora casos pouco frequentes de alterações da coagulabiliảade sanguínea, seus efeitos ind: sejāveis prendem-se mais ao seu próprio efeito sedativo. Ou trossim, são drogas que apresentam pequena margem de segurança e podem provocar tolerância e dependēncia.

Por fim cabe citar entre as substâncias psicoativas utilizāveis terapeuticamente, os extratos de vege tais preparados a partir da Passiflora incarnata e da Eritrina sp. As publicações versando sobre psicofarmacologia não fá zem menção das propriedades tranquilizantes e sedativas destes vegetais; contudo, os extratos deles estão associados a peque nas doses de barbitúricos (fenobarbetal) em diversas preparações disponíveis no mercado brasileiro.

1.2. ASPECTOS PSICO-SOCIAIS DA ANSIEDADE E A AÇÃO DOS MEDI CAMENTOS PSICOTRÓPICOS.

Como jā mencionado, a introdução dos medị camentos psicotrōpicos modernos teve papel lapidar na terapêu tica psiquiātrica. Os grandes quadros mórbidos passaram a ter um prognóstico mais favorável com recuperações mais numerosas e duradouras. De um lado, na medida em que era possivel contro lar ou fazer regredir completamente os estados psicóticos com o uso dos neurolépticos, os hospitais psiquiātricos deixaram de ser o único ponto de referência para inúmeros pacientes. De outro lado, o manejo dos estados ansiosos associados a diversas patologias psiquiātricas tornou-se bem mais fācil com os tranquilizantes que foram - e ainda o são - largamente em 
pregados como auxiliares no tratamento de estados neuróticos e diversos sindromes ansiosos da mais variada etiologia.

Contudo, se é obrigatório reconhecer seu alto valor terapéutico, necessário, também, preocupar-se com o seu uso indiscriminado ou, mesmo, indevido.

Afinal, se os derivados da benzodiazepina - e, em graus diferentes, outros psicofārmacos - são capazes de atuar sobre os mecanismos neurofisiológicos envolvidos com uma emoção tão vital, frequente e importante como a ansiedade, perguntamos até que ponto e em quais situações ela deve ser $\underline{e}$ liminada ou combatida. mister perguntar se a ansiedade é sempre um distúrbio psicopatológico que exprime um transtorno do equílibrio psiquíco, se o seu aparecimento e percepção são nocivos ao indivíduo.

HINSIE e CAMPBELI ${ }^{31}$, assim definem a ansie dade:

"Um afeto que difere de outros afetos pela sua especifica característica de desprazer. A ansiedade consis te de um aspecto fisiolōgico, somātico (alterações respiratōrias, aumento da atividade cardíaca, alteraçōes vasomotoras, distūrbios mūsculo-esquelēticos como tremores ou paralisia, aumento da sudorese, etc.) e de um aspecto psicológico. Este último inclue'... uma atitude consciente especifica e um sentimento peculiar caracterizado: (1) por uma percepção física e mentalmente dolorosa de ser impotente para fazer alguma coi sa a Isspeito de uma situação pessoal; (2) pelo ressentimento de um perigo eminente e quase inevitável; (3) por um estado de alerta tenso e fisicamente extenuante como se estivesse frente a uma emergência; (4) por uma auto-absorção apreensiva que interfere com a solução efetiva e vantajosa dos problemas reais; (5) por uma dúvida insolúvel acerca da natureza do mal ameaçador, acerca da probabilidade do verdadeiro aparecimento 
da ameaça, acerca dos melhores meios objetivos de reduzir ou remover o mal, e acerca da sua própria capacidade subjetiva de fazer uso efetivo daqueles meios se e quando a emergência aparecer' 'Piotrowski, Z. Perceptanalysis, MacMillan, New York, 1957). A ansiedade deve ser diferenciada do medo ao qual faltam as características (4) e (5). O medo é uma reação fren te a um perigo ameaçador e real, enquanto a ansiedade é mais tipicamente uma reação frente a um perigo irreal ou imaginado..."

Nesta definição os autores não deixam claro se se trata de um distúrbio psico-patológico ou não, isto é, se se trata de um afeto anormal ou uma reação fisiológica do ser. Alēm disso, pretendem criar uma distinção clara entre an siedade e medo, o que nem sempre é possivel ou verdadeiro 29,54 . Para RYCROFT 54 é preciso "descartar a idéia, amplamente aceita atualmente, de que toda ansiedade é irracional, anormal e neu rótica e mostrar que, pelo conträrio, a capacidade de ficar ansioso é uma função biológica necessāria para a sobrevivência.

Os estudos da etiologia mostram como os a nimais tem necessidade de ansiedade para sua sobrevivēncia ${ }^{29}$. Seu mundo é cercado de ameaças, dos mais diversos tipos de $\underline{i}$ nimigos e perigos; é preciso estar em constante estado de aler ta a fim de não sucumbir. Desta forma, a imagem do inimigo é apreendida rapidamente ou mesmo estabelecida arquetipicamente; quem não aprende a tempo sucumbe à inexorável seleção e pode se dizer que "a tendência à fuga, o medo ante o inimigo, a an gústia ante a ameaça geral ou como quer que se chame este fe nōmeno que domina toda a organização corporal e toda a conduta é, portanto, o afeto que tem o predomínio absoluto no reino animal" 29 .

HEDIGER 29 ainda propõe que, na medida em 
que o homem se livrou muito rapidamente da necessidade de evi tar o inimigo, jā que contava com o fogo e as armas, a ansieda de relacionada à ameaça vital provinda do meio ambiente se di luiu, mas a emoção em si não deixa de existir, passando a se relacionar à ameaça do sobrenatural, produção da própria fan tasia humana. Mas o sobrenatural - algo projetado no mundo ex terior - passa a adquirir nas culturas ocidentais um carāter de internalidade; os deuses, com suas ameaças e castigo, pas sam a fazer parte da estrutura intima de cada um e cada um car rega dentro de si a culpa e o castigo. O homen ocidental jā não tem mais necessidade da figura exterior do deus para se punir e sofrer; è sua própria consciēncia moral - o deus inter nalizado - que o castiga e o angustia.

$$
\text { FREUD } 25,26 \text { sugere que hä dois tipos de an }
$$
siedade, que ele chamou de objetiva e neurötica. A ansiedade objetiva estaria relacionada a situações concretas que ameaçam a integridade (física ou psiquica) do ser, enquanto que a an siedade neurōtica estaria ligada a mecanismos patológicos do psiquismo, ou seja, a medos irracionais provenientes da utili zação de mecanismos inadequados de defesa do ego. Assim, de a cordo com esta concepção, a ansiedade objetiva seria aquela $\underline{\text { e }}$ moção que encontra paralelo em todo o reino aminal, ao passo que a ansiedade neurótica restaria como peculiaridade do ser humano.

Contudo, esta classificação não nos permi te entender a ansiedade em todos os seus aspectos. Como enten der a ansiedade do Homem frente ao desconhecimento do seu fü turo? A partir do momento em que possui consciência, o Homem se torna ansioso, pois questiona a sua existència e interroga se sobre o seu futuro. E este tipo de ansiedade tem sido obje to, desde sempre, de filósofos, cientistas sociais, teológos 
e artistas. Não se pode admitir que esta "ansiedade vital" se ja patológica (neurótica) ou semelhante à ansiedade do animal que procura a sobrevivência em um meio hostil. Outrossim, é certamente ela a responsāvel pela progressão teleológica do Homer. Como entender a evolução científica ou espiritual do Homem se ele estivesse destituido desta emoção?

De outro lado, é obrigatório entender que toda a organização social - qualquer que seja a forma que ela assuma - traz consigo inümeros fatores ansiogènicos para cada individuo em particular ou para seu grupo. De tal sorte, que podemos traçar um paralelo entre a hostilidade do meio ambien te dos animais e a hostilidade que a organização social huma na representa para cada um.

Frente à agressividade deste meio - cujas expressões mais atuais são o consumismo, a crescente massificação, a criminalidade crescente, o culto à produtividade e ao econômico, a limitação da liberdade de expressão, a competi tividade e o terror ${ }^{14,39}$ - o indivíduo experimenta uma desagra dável sensação de ansiedade; e o alívio desta só é possível de duas maneiras: ou o conformismo ou a busca de alguma forma de intervenção no sentido de modificar o meio ambiente. O con formismo, como solução radical e duradoura da ansiedade, colo caria o individuo à serviço daqueles fatores apontados e leva ria à estagnação do processo evolutivo das estruturas sociais. A busca da mudança estabelece uma relação dinâmica de ajustes que somados traduzem a progressão das sociedades.

Sem dúvida, a busca de mudanças implica em maior sofrimento, na medida em que os processos de mudança são mais lentos e a capacidade individual de intervenção é pequena - e torna-se menor quanto maior for o corpo social. Contudo, qualquer que seja o prisma utilizado - filosófico, psicológico, 
teológico ou sociológico - este parece ser um papel do qual o Homem não pode ou não deve abdicar. A respeito destas duas po sições possíveis de serem assumidas pelo individuo e seu gru po e das relações com as forças hostis do meio social, George Orwell, em "1984"46 e Aldous Huxley" ${ }^{3}$, em "O admirāvel Mundo Novo" produziram fantasias que chegaram a marcar época.

E, sem dúvida, no campo da Psiquiatria e da Psicanálise que a ansiedade è profundamente investigada, quer pela frequência com que aparece associada aos transtornos mentais, quer pela intensidade marcante com que se manifesta em certos estados patológicos. Assim, a nosografia psiquiātri ca consagrou a expressão "neurose" para descrever quadros onde a ansiedade aparece como transtorno principal, seja de forma pura (neurose de ansiedade), mascarada (neurose histérica, or ganoneuroses), associada a simbolos (neurose obsessiva, neuro se fóbica) ou a transtornos do humor (neurose depressiva). A lém disso, a maioria dos transtornos mentais pode vir acompanhada da ansiedade - esquizofrenias, depressões endógenas, transtornos orgânicos cerebrais.

Em que pese o seu caráter eminentemente fisiológico, observa-se no transcorrer do século, um processo de psiquiatrização da ansiedade - ultrapassando, mesmo, todo - processo de medicalização da sociedade - levando a un alarga mento, muitas vezes indevido, co conceito de transtorno neurō tico. A época em que Kraepelin assentou as bases da atual noso grafia psiquiātrica, no princípio do sēculo, o conceito de neu rose restringia-se a alguns clássicos quadros bastante delimi tados; posteriormente, por influência das escolas psicanalíti C̈as, o conceito se alarga sobremaneira, passando a incluir di versos transtornos do relacionamento interpessoal, até entāo não considerados. Quando CAPLAN ${ }^{15}$ expöe sua teoria das crises 
na dēcada de 1960, aponta situações como o luto, o casamento, a aposentadoria, a perda de um emprego ou a aquisição de um novo emprego como geradoras de ansiedade e potencialmente de sencadeadoras de um transtorno mental e, portan $\circ$, passiveis de intervenção médica com objetivos preventivos. Hoje em dia, com frequência, os "psicanalistas da familia" incluem os mais diversos processos sociais, dentre os geradores de "neuroses familiares" e efetuam intervenções mēdicas sobre tais situações.

Observando os estudos de epidemiologia dos transtornos mentais PLUNKETT e GORDON ${ }^{48}$ constatam que as taxas de prevalència encontradas em diversos levantamentos realizados na primeira metade do século são bastante inferiores às taxas referidas em estudos efetuados a partir de 1950. Explicam que estas diferenças certamente não se devem a um real au mento dos transtornos mentais, mas, tão somente, a um alargamento das fronteiras do conceito de transtornos neuróticos. Que esta imprecisão de limites existe, pode ser constatado no inquérito epidemiológico de LANGNER et al ${ }^{37}$ realizado em New York onde os autores confundem o conceito de felicidade pes soal com transtorno mental, chegando à conclusão de que cerca de $80 \%$ dos habitantes sofriam de um transtorno mental.

Este alargamento de fronteiras chega a tal ponto que se torna difícil para alguns deixar de dar um rótulo médico às mais variadas situações levando-os a admitir todas as expressões de ansiedade como patológicas ou potencialmente patogènicas.

Vemos como, através deste processo, se es tabelece a falsa concepção de que a ansiedade é sempre um fe nomeno patológico. Definitivamente a ansiedade e a enfermidade psíquica não são a mesma coisa ${ }^{8}$. Constatamos como a ansiecade oriunda, seja de experiēncias tão naturais como o luto, 
a doença ou o questionamento sobre o futuro, seja de processos sociais e econōmicos acaba por ser confundida com a ansiedade oriunda de um funcionamento inadequado do processo psicodināmico.

Como responder a situações como a violên cia e criminalidade, ou ao tempo excessivo gasto em transporte urbano, ou à competição por uma oportunidade de trabalho, ou à ameaça da guerra, ou, enfim, a um sem nümero de situações comuns à existência, a não ser com ansiedade? A ansiedade é certamente necessāria a fim de que o indivíduo não sucumba da mesma forma que o cervo da fābula de Tolstoi devia manter-se ansioso para não sucumbir ao leão ${ }^{29}$. VON GEBSATELL ${ }^{65}$ assume posição clara ao afirmar: "O que surpreende hoje no que se tem escrito sobre este fenōmeno è uma opinião sumamente duvidosa e sumária que equipara angūstia e enfermidade. Esta equiparação deve ser rejeitada da maneira mais radical em favor de uma visão mais ampla. Ainda que sempre seja um 'patos', um estado de sofrimento de algum tipo, a angūstia não é em absoluto, uma enfermidade e, portanto, tampouco objeto da patologia a não ser que se ceda à malévola simplicidade que vê uma disposição patológica no destino fundamental do Homem de ter de sofrer". Como então, distinguir a ansiedade patolō gica da ansiedade natural e ütil ao indivíduo? Que parâmetros utilizar? A intensidade, a frequência ou suas causas? Atuando de forma contínua e/ou em intensidade elevada ela pode levar à morte por esgotamento 29,57 ou lesões irreversiveis de órgãos; pode se, então, admitir que, nesta conjuntura, ela é patológi ca na medida em que pode provocar a morte do organismo. Quan to às causas, admitimos um retorno às primeiras postulações de FREUD que a classificava em objetiva e neurótica; a ansie dade objetiva $\bar{e}$, qualquer que seja sua intensidade e frequẹn 
cia, ütil na medida em que representa a resposta a situações externas hostis e prepara o individuo para a defesa e o predis fõe à intervenção; jā a ansiedade neurótica pode - ainda que numa visão simplista - ser considerada indesejável. Para as duas é admissivel alguma forma de intervenção que a alivie; a intervenção médica é justificada para a ansiedade neurōtica, mas, de forma alguma, se justifica para a ansiedade objetiva que só deve ser aliviada pela modificação das condições do meio ambiente (ou pela mobilização do potencial intimo prove niente da experiência existencial).

Não se trata, aqui, de assumir uma posição "calvinista" que pregue o sofrimento, mas tampouco, admitimos uma atitude permissiva que entenda a ansiedade como uma emoção sempre indesejāvel e pregue a sua erradicação por quaisquer meios e a busca do bem-estar a qualquer custo. Nossa posição tem seu interesse muito mais voltado para o coletivo do que para o individual; preocupa-se muito mais com as consequências que podem advir para a progressão teleológica da organização social se a tendência a encarar a ansiedade como emoção pato lógica e indesejável seguir o curso atual.

Pois esta preocupação deixa de parecer ab surda ou exagerada a partir da descoberta e comercialização dos modernos medicamentos psicotrópicos. E, dentre elas, des tacam-se os derivados da benzodiazepina comercializados a par tir de 1960 pela sua particular pripriedade ansiolitica. Eles possuem pronunciada capacidade de agir sobre os mecanismos neurofisiológicos responsáveis pela ansiedade, reduzindo sobre maneira sua intensidade.

A respeito dos efeitos destas drogas è dig no transcrever um trecho de uma publicação científica do Labo ratório Roche ${ }^{53}$, responsável pela sintese e introdução no mex 
cado das duas primeiras e principais benzodiazepinas, o Librium e o Valium (os grifos são nossos):

"... Para determinar os efeitos psicofarma cológicos de una droga, certos padrões básicos do comportamento, os quais podem ser demonstra dos tanto em animais como em homens, são exami nados. Por exemplo, o medo é uma reação emocio nal elementar, a qual pode ser observada de uma maneira similar tanto em ratos com em seres hu manos. COMO CANNON e CANNON et BRITTON observa ram muitos anos atrās, toda ameaça ou perigo desencadeia uma "reação de fuga ou luta" instin tiva, a qual, de acordo com as investigações de SELYE sobre o stress, é capaz de mobilizar todos os mecanismos de defesa do organismo. Es ta sindrome de stress tem manifestações tanto emocionais como físicas.

Esta reação combinada de fuga ou luta, que ocor re tanto em seres humanos como em animais, for nece uma valiosa indicação da eficācia de uma droga sobre o sinarome de stress psicossomático. Se animais confinados em uma gaiola não tem oportunidade de empreender a fuga, então eles reagem a uma ameaça ou perigo externo com agressão. A aplicação desse clássico teste de compor tamento torna possível examinar esta reação a uma ameaça ou perigo externo sob a influência de várias drogas psicotrópicas e comparar seus efeitos.

o primeiro passo para examinar as propriedades relaxantes de uma droga é testar seus efeitos 
sobre os "ratos lutadores". O sinal de perigo que provoca um estado de excitação è obtido por um choque elétrico que passa por uma grade no piso da gaiola na qual os animais estão fechados. Depois de alguns momentos de tentativas frustas de fuga, os dois ratos na gaiola come çam a se atacar mutuamente.

Após eliminar-se aqueles ratos que não mostram esta reação tỉpica, o psicofārmaco en teste è administrado em alta dosagem. Se ele prova ser efetivo, isto é, se è capaz de suprimir comple tamente a reação de luta em $100 \%$ dos casos, é possível determinar a dose minima em que se ob tém $100 \%$ de eficácia. Esta dose é, por exemplo, lomg por quilo de peso por via oral para o Va lium Roche, enquanto a DL 50* por via oral é $720 \mathrm{mg}$ por quilo de peso representando uma mar gem de segurança estremamente grande. O Valium Roche provou ser vinte vezes mais efetivo do que o meprobamato neste teste; os neurolépticos de tipo cloropromazina são capazes de antagoni zar a reação de fuga somente em altas doses que são acompanhadas de intensa sedação central. As drogas que provaram ser eficazes sobre os ratos lutadores são, então, submetidas a um tes te posterior, usando ratos com lesões na região septal do sistema límbico. Os animais submetidos a esta cirurgia tornam-se extremamente a gressivos depois de um período de um ou dois 
dias. Eles reagem com extrema intensidade a es timulos externos como estrondos, mexer em seus bigodes com una vareta ou beliscões na cauda. A reação dos animais é avaliada por uma escala variando de $\underline{0}$ a $\underline{4}$ onde o $\underline{0}$ significa nenhuma reação e $\underline{4}$, una reação pronunciada, antes e de pois de $1 / 2$ e 1 hora apōs uma injeção intraperi tonial de uma solução fisiológica (como contro le) e a droga de teste. O Valium Roche também foi testado por este método e comparado com ou tras preparações de ação central, e o resultado mostrou que o "taming effect"* do Valium Ro che foi marcadamente superior àquele de doses equivalentes do meprobamato. Somente aquelas preparações psicotrópicas que provaram ser efe tivas nestes testes prévios são, agora, testados em primatas, comparando-se a influência sobre a agressividade com aquela sobre a atividade em geral. Este teste é o método mais exato para avaliar o "taming effect" de um medicamento, o qual, por sua vez, está relacionado ao : efeito terapêutico desejável. Os psicofārmacos tem un efeito pronunciado so bre o comportamento de macacos normalmente a gressivos em relação ao homem, gritando horrivelmente, arreganhando os dentes e atacando qualquer um ciue se aproxime. Para este teste os investigadores vestem máscaras protetoras e pesadas luvas. Durante a avaliação da sua agres 
sividade os animais são mantidos fora das gaio las, acorrentados ao pé de uma longa mesa onde eles podem ser estreitamente observados. Para a avaliação de sua atividade normal eles são postos em gaiolas onde podem ser observados a travēs de vidros especiais.

Em uma investigação, os macacos foram inicialmente observados sem tratamento e sua ativida de geral anotada em uma escala de comportamen to. o comportamento agressivo dos animais em relação ao investigador foi, então, avaliado. Depois da administração da droga os animais fo ram observados pelos mesmos métodos durante vá rias horas sem que o investigador soubesse se a droga ativa ou um placebo haviam sido dados. Neste experimento o Valium Roche foi notāvel pelo fato de que exerceu um muito marcante efeito sobre a agressividade dos macacos, sem reduzir apreciavelmente a atividade geral. Este "taming effect" è muito diferente da ação das fenotrozinas, sob o efeito das quais estes macacos, embora sedados, ainda se comportam agressivamente en relação a qualquer ser humano que se aproxime..."

Estas observações ressaltam que as benzo diazepinas são capazes de eliminar a agressividade ("taming effect") sem influir na atividade geral. Com todo o cuidado que se deva ter ao fazer inferèncias sobre o efeito de farmá cos no ser humano a partir de experimentos animais é, de toda a forma, digno notar que esta droga é potencialmente capaz de 
inibir reações instintivas de defesa, tornando o individuo a pātico. Se ela é capaz de amansar ratos previamente "neurotizados" ou docilizar macacos naturalmente agressivos, sem, con tudo, reduzir significativamente seu estado de consciência, isto é, sem provocar sedação, o qué esperar do efeito da dro ga sobre o comportamento humano?

Medicamentos de outros grupos psicofarmacológicos são mais raramente utilizados para o tratamento da ansiedade. Eventualmente podem ser empregados neurolēpticos ou barbitūricos, mas a sedação e os efeitos colaterais desagra dáveis que podem provocar, alēm da menor margem de segurança, fizeram com que a preferência recaísse sobre as benzodiazepinas.

Algumas centenas de experimentos clínicos já foram realizados com os derivados da benzodiazepina em pa cientes portadores de ansiedade. A maioria deles aponta uma significativa capacidade de redução da ansiedade, em que pese o fato de os estudos mais seriamente conduzidos, com método duplo-cego, apontarem um ponderável efeito placebo. A par da redução da ansiedade, observa-se que os efeitos sedativos são reduzidos se comparados a outros grupos psicofarmacológicos.

Estas caracteristicas provavelmente as al çaram à categoria das drogas de grande aceitação pela classe médica. Sendo eficientes no manejo da ansiedade de qualquer e tiologia e não oferecendo os riscos e contra-indicaçōes dos neurolépticos e barbitúricos, as benzodiazepinas rapidamente ganharam a preferência de médicos e pacientes. A princípio, seu uso esteve restrito aos casos de neuroses, mas, paulatina mente, passou a ser empregada em situações de ansiedade não neurōtica. Pelo menos, isto é o que indica o crescimento mar cante das prescrições do clorodiazepóxido e do diazepan nas 
décadas de 1960 e 1970.

Existe, sem dúvida, a preocupação de diver sos autores $6,7,10,11,12,14,20,21,30,40,42,44,45,47,60,61,64$ de que estes psicofärmacos vem sendo utilizados de forma exagerada e, pode se supor, que com a finalidade de eliminar a ansiedade objetiva, isto é, com a finalidade de resolver situa ções não médicas.

Ora, se é verdade que são empregadas para o manejo da ansiedade objetiva, então è válida a preocupação que se externa a respeito do significado que isto possa ter para a organização social e a evolução teleológica do Homem. Outrossim, não è verdade que sejam drogas muito seguras. Sabe-se que as benzodiazepinas produzem uma sensação de relaxamento geral e, eventualmente, alguma sonolên cia; a isto se associa em não poucos casos, um problema de a taxia e aumento de tempo das respostas reflexas. BETTS et al ${ }^{9}$, em experimento controlado, constataram que o cloridazepóxido afetou a performance de individuos submetidos a testes de habilidades na condução de veículos a motor e alerta para a pos sibilidade de que seu uso contribua para acidentes de trānsito. Diante de um grupo de fármacos com tais caracteristicas, capazes de inibir a ansiedade - qualquer que seja a sua etiologia - devé-se questionar se os mecanismos de controle sobre sua comercialização não deveriam ser tão rígi dos quanto os controles impostos aos psicofármacos do grupo dos neurolēpticos e barbitúricos.

Em 1966 - apenas 6 anos após o início da comercialização da primeira benzodiazepina - DENIKER ${ }^{20}$, um dos mais importantes investigadores da psicofarmacologia, já aler tava para o "... uso imoderado destas substâncias, fora ge prescrições médicas, com o fim de evitar, graças à sua 
ação rápida, todos os inconvenientes da existência moderna: ansiedade, nervosismo, insonia..." e propunha que se evitasse recorrer a "estas aspirinas dos estados de tensão ou angústia" para todas is situaçōes. WANDREY et LEUTNER ${ }^{62}$ em 1967 referem que tais medicamentos recebiam dos usuārios os apelidos de "happy pills", "modern aspirins", "peace-of-mind pills", "don't-give-a-damm-pill" ou "thoughtless tablets".

\subsection{ASPECTOS EPIDEMIOLOGICOS DO CONSUMO DE MEDICAMENTOS} PSICOTRŌPICOS

Em particular após a introdução dos derí vados benzodiazepínicos, o consumo global de medicamentos con tendo substâncias psicotrópicas experimentou um aumento consi derāvel $7,10,12,42,45,60,61,64$. BURNER ${ }^{12}$ observa que de 1967 a 1971 houve um aumento de $11 \%$ no nümero de prescrições de psí cotrópicos na Inglaterra e País de Gales; este incremento se deve, particularmente, aos hipnóticos não barbitūricos (58\%), antidepressivos (43z) e tranquilizantes (26\%), ao passo que os hipnōticos barbitúricos apresentaram um decrēscimo (27\%). Entre 1964 e 1972 o nümero de receitas de ansiolíticos passou de cerca de 40 milhöes a cerca de 90 milhões nos Estados Uni dos; paralelamente, as prescrições de neurolépticos, antidepressivos tricỉclicos e associaçōes apresentaram crescimento muito pequeno ${ }^{10}$. o grande crescimento das vendas de ansioliti cos deveu-se essencialmente aos benzodiazepínicos, observando se no mesmo período, uma estabilização ou decréscimo nas ven das de outros medicamentos ansiolíticos contenảo meprobamato, barbitūrico e hidroxizinal0. Em 1972 o Valium ( marca registra da do diazepan) foi o medicamento mais vendido nos Estados U nitos, com 50 milhōes de receitas anuajs e o Librium (marca 
registrada do clorodiazepóxido) situou-se en quarto lugar com 20 milhões de receitas anuais ${ }^{61}$; neste mesmo ano, as 144 mi lhōes de receitas de psicotrópicos nos Estados Unidos (sem in cluir os lipnóticos) corresponderam a $6 \%$ do total de medicamen tos éticos lし*. No Brasil, em 1975 um medicamento psicotrópico participava da lista dos 20 medicamentos mais vendidos no ano 52 .

o volume de vendas de medicamentos sofreu um acréscimo de $100 \%$ entre 1960 e 1971 no mercado norte-ameri cano; os medicamentos com ação sobre o sistema nervoso central situam-se em primeiro lugar entre as vendas e foram os que a presentaram um dos maiores crescimentos neste periodo (136\%) 27 .

Este crescimento não está dissociado do fenômeno de medicalização acelerada da sociedade ${ }^{34}$ onde se oḅ serva marcada tendência à alocação de recursos cada vez mais vultosos em gastos com a saūce, chegando alguns países a dispender $10 \%$ do seu Produto Nacional Bruto em gastos com médicos, hospitais, produção de medicamentos e de equipamentos médicos ${ }^{27}$. Os medicamentos psicotrōpicos, por diversas razōes, tẽm, desde há duas dēcadas, representado um segmento bastante significatí vo destes gastos.

\section{Estudos realizados em diversos países tem} mostrado seguidamente altos indices de prevalēncia de consumo. Em 1973 PARRY et al ${ }^{47}$ encontraram, em estudo realizado a nível nacional nos Estados Unidos, um indice de 318 de adultos que haviam se utilizado de psicotrópicos no período de un ano; des te total, 228 haviam consumido medicamentos controlados e os

* Denominam-se "éticos" os medicamentos cuja venda está sujei ta à prescrição médica. "Não éticos" são os produtos de veñ da livre; nos países anglofonicos são, também, conhecidos como "nonprescription drugs" ou "over-the-counter drugs". Entre os produtos não-éticos encontram-se analgésicos e an tipiréticos, antiespasmódicos, desinfetantes locais (produ= tos para curativos externos, gargarejos e inalaçóes), etc. 
restantes $9 \%$ usaram produtos não éticos*. Em estudo semelhante realizado em San Francisco (EUA) em 1971, NELLINGER et al 42 encontraram cifras ainda maiores: $23 \%$ dos homens e $38 \%$ da mu Iheres haviam usado produtos controlados no período de um ano, enquanto 148 dos homens e $13 \%$ das mulheres usaram produtos não controlados ("over-the-counter"). E importante notar que nes tes dois estudos foram incluạdos os estimulantes anfetamínicos os quais, como notam os próprios autores, são frequentemente utilizados em regimes de emagrecimento; seu uso nos tratamen tos psiquiātricos, com raras exceçōes, é contra indicado, mas muitas pessoas ainda os utilizam com o objetivo de obter esti mulação e combater o sono.

\section{o levantamento talvez mais expressivo da} prevalência do consumo de medicamentos psicotrópicos foi aque le que BALTER et $a l^{7}$ levaram a efeito em 1971 em nove países europeus simultaneamente. Os valores encontrados (Tabela l) a pontam $10 \%$ a $17 \%$ da população de 15 ou mais anos de idade da queles países utilizando-se de psicotrópicos no período de um ano. Observa-se que nesse estudo os autores não computaram os medicamentos neurolépticos, antidepressivos, anticomiciais e estimulantes, restringindo sua atenção aos medicamentos que promovem alívio imediato e sintomātico da ansiedade. Poucos estudos têm sido realizados acerca dos níveis de consumo de outros grupos de medicamentos, mas estes valores encontrados e os dados de volume de produção da indústria farmacêutica in dicam que os psicotrópicos são, provavelmente, o grupo de me dicamentos mais largamente consumido em diversos paises, exce

* 0 mercado norte-americano conta com grande nümero de produtos näo-éticos ("over-the-counter drugs") anunciados como "estimulantes", "pílulas para dormir" ou "tranquilizantes" que contém cafeína (nos estimulantes) e escopolamina e/ou metapirilene em baixas doses (nas pilulas para dormir e tranquilizantes). 
TABELA 1 - PORCENTAGEM DE INDIVIDUOS QUE USARAM MEDICAMENTOS ANSIOLITICOS/SEDATIVOS DURANTE O ULTIMO ANO EM NOVE PAISES EUROPEUS POR SEXO E IDADE, 1971.

\begin{tabular}{|c|c|c|c|c|c|c|c|c|c|c|c|}
\hline & & IDADE & BELGICA & DINAMARCA & FRANÇA & ALEMANHA & ITÁLIA & HOLANDA & ESPANHA & SUECIA & REINO UNIDO \\
\hline \multicolumn{12}{|c|}{ HOMENS } \\
\hline & & $15-24$ & 7.0 & 5.8 & 8.1 & 5.8 & $13.5^{*}$ & 4.0 & 7.7 & 6.5 & $4.5^{\star}$ \\
\hline & & $25-34$ & 11.8 & 6.2 & 9.1 & 4.3 & 10.9 & 13.2 & 5.8 & 8.3 & 3.1 \\
\hline & & $35-44$ & 9.3 & 8.7 & 11.1 & 7.3 & 9.2 & 6.0 & 6.9 & 9.5 & 9.2 \\
\hline & & $45-54$ & 14.3 & 16.7 & 18.6 & 9.8 & 10.7 & 8.8 & 7.6 & $1 \% .6$ & 9.6 \\
\hline & & $55+$ & 16.7 & 12.9 & 13.2 & 13.7 & 7.1 & 11.1 & 6.7 & 12.0 & 13.9 \\
\hline TOTAL & $\mathrm{DE}$ & HOMENS & 12.0 & 10.2 & 11.9 & 8.4 & 9.8 & 8.5 & 7.0 & 9.9 & 8.9 \\
\hline \multicolumn{12}{|c|}{ MULHERES } \\
\hline & & $15-24$ & 15.8 & 14.4 & 13.4 & 5.3 & $8.1^{*}$ & 10.8 & 10.3 & 8.9 & $17.2^{\star}$ \\
\hline & & $25-34$ & 21.0 & 8.0 & 21.0 & 19.2 & 14.4 & 13.3 & 10.3 & 14.5 & 20.1 \\
\hline & & $35-44$ & 20.7 & 29.3 & 20.3 & 25.7 & 15.1 & 18.3 & 13.8 & 24.4 & 15.6 \\
\hline & & $45-54$ & 18.6 & 23.7 & 20.3 & 23.7 & 14.2 & 21.7 & 15.3 & 23.0 & 23.6 \\
\hline & & $55+$ & 24.5 & 23.4 & 27.6 & 20.4 & 10.8 & 20.4 & 13.5 & 30.9 & 18.6 \\
\hline TOTAL & $D E$ & MULHERES & 20.9 & 19.9 & 21.4 & 19.2 & 12.6 & 16.8 & 12.5 & 21.5 & 19.1 \\
\hline $\begin{array}{l}\text { TOTAL } \\
\text { SEXOS }\end{array}$ & $D E$ & AMBOS OS & 16.8 & 15.1 & 16.7 & 14.2 & 11.2 & 12.7 & 9.7 & 15.8 & 14.2 \\
\hline
\end{tabular}

* Intervalo de idade, $16-24$. FONTE: BALTER et al ${ }^{7}$. 
tuados os analgésicos cujos niveis poden atingir $28 \%$ da população ${ }^{17}$.

Quanto à distribuição dos consumidores se gundo o s€yo, todos os autores são unânimes ao afirmar que os resultados indicam uma larga predominância do sexo feminino; de uma forma geral dois terços do consumidores são mulheres 7,11 , $16,42,47$. Parece tentador aventar a hipótese de que esta dife rença seria indicativa de um maior stress a que estariam sujei tas as mulheres, talvez pelas rāpidas mudanças observadas em seu papel social. Contudo, como observam BUSH e RABIN ${ }^{13}$ elas são maiores consumidoras de todos os grupos de medicamentos sintomáticos e faltam elementos para se afirmar com segurança que as mulheres estejam submetidas a um maior nivel de stress. Em cuidadoso estudo critico WAGHORN ${ }^{60}$ aponta algumas diretrizes que possam explicar esta diferença. As mulheres frequentam mais os consultórios médicos e costumam apresentar mais sinto mas do que os homens. Outrossim, o médico parece mais predisposto a encarar estes sintomas como "neurōticos" ou como típi cos problemas femininos. Alēm disso, as indústrias farmacêuti cas, em sua propaganda de psicotrópicos dirigida à classe mé dica, tende a utilizar imagens de situações onde a mulher apa rece como uma dona-de-casa insatisfeita, ansiosa e dependente, enfim, vîtima de uma circunstāncia stressante. Entrevistando 68 médicos acerca de imagem típica do paciente queixoso, COOPERSTOCK ${ }^{18}$ verificou que $72 \%$ deles se referiram a mulheres, enquanto 248 não fizeram menção a sexo e, somente 4 g relaciona ram a imagem do paciente queixoso ao sexo masculino. Ainda, segundo este último autor, em relação aos homens, as mulheres tem maior chancela da sociedade para a expressão dos seus sen timentos e maior percepção de seus problemas emocionais; pro curam mais frequentemente o médico por problemas emocionais e 
este tem maior expectativa da sua necessidade de uso de psico trópicos.

No que se refere à idade, em ambos os se xos observa-se uma tendência ao crescimento do $c$ nsumo a par tir dos 25 anos $^{7}$ (Tabela 1), mas deste ponto em diante não são notadas diferenças significativas. PARRY et al 47 e MELLINGER et al 42 observaram, nos Estados Unidos, maior prevalência no grupo etário de 18 a 29 anos, seguidos de perto pelo grupo de 60 a 74 anos; Mellinger chama a atenção para as diferentes preferências nos dois grupos: os mais jovens consomem mais es timulantes enquanto o grupo de 60 a 74 anos consome mais hip nöticos. Na opinião de PARRY et al a prevalência geral entre homens parece crescer rapidamente no grupo etário de 30 a 44 anos para depois cair e, entre as mulheres, este aumento na classe de 30 a 44 anos permanece inalterado nas idades maiores.

Un dos aspectos que mais chama a atenção no estudo do consumo de psicotrópicos è o fato de não serem sempre utilizados com regularidade. Reflexo do que havia sido comentado no item 1.2 è a observação de que parcela significa tiva da população consome estes medicamentos de forma esporádica para o alívio imediato de uma situação desconfortável. BALTER et $a^{7}$ en seu estudo multinacional verificam que de $30 \%$ a $64 \%$ da população de consumidores tem um padrão de consumo definido como regular, isto $\bar{e}$, tomam o medicamento diariamente por um período de um mês ou mais (Tabela 2); em sua opinião - padrão regular é um critério muito mais importante para o estudo dos indices de prevalència de consumo em uma população dada do que o mero uso de um medicamento por uns poucos dias em alguma época do ano. Os dados da Tabela 3 comparados àque les da Tabela 1 mostram que os índices de prevalência caem a centuadamente quando se considera somente os consumidores re 
TABELA 2 - USO DIĀRIO DE MEDICAMENTOS ANSIOLITICOS/SEDATIVOS TRÓPICOS EM NOVE PAISES EUROPEUS EM 1971.

\begin{tabular}{|c|c|c|c|c|c|c|c|c|c|}
\hline \multirow[b]{2}{*}{ SEXO } & \multicolumn{9}{|c|}{ PORCENTAGEM DE CONSUMIDORES USANDO O MEDICAMENTO REGULARMENTE } \\
\hline & BELGICA & DINAMARCA & FRANÇA & ALEMANHA & ITĂLIA & HOLANDA & ESPANHA & SUICCIA & REINO UNIDO \\
\hline HOMENS & 41.7 & 64.0 & 42.3 & 48.1 & 18.9 & 67.8 & 36.1 & 38.2 & 54.8 \\
\hline MULHERES & 50.0 & 51.5 & 39.8 & 40.2 & 37.9 & 62.2 & 44.1 & 29.1 & 62.6 \\
\hline TOTAL & 46.9 & 55.6 & 40.7 & 42.4 & 30.0 & 64.0 & 41.2 & 31.9 & 60.6 \\
\hline
\end{tabular}

FONTE: BALTER et al ${ }^{7}$. 
TABELA 3 - PORCENTAGEM DE INDIVIDUOS QUE USARAM MEDICAMENTOS ANSIOLITICOS/SEDATIVOS DE FORMA REGULAR POR UM MES OU MAIS DURANTE O ULTIMO ANO EM NOVE PAISES EUROPEUS, POR SEXO E IDADE, 1971.

\begin{tabular}{|c|c|c|c|c|c|c|c|c|c|c|}
\hline & IDADE & BELGICA & DINAMARCA & FRANÇA & ALEMANHA & ITALIA & HOLANDA & ESPANHA & SUÉCIA & REINO UNIDO \\
\hline \multirow[t]{6}{*}{ HOMENS } & & & & & & & & . & & \\
\hline & $15-24$ & 4.0 & 1.9 & 1.2 & 1.8 & $0.0 *$ & 1.1 & 2.1 & 2.6 & $0.0 *$ \\
\hline & $25-34$ & 3.9 & 3.1 & 4.0 & 1.9 & 1.6 & 7.0 & 2.6 & 3.6 & 2.5 \\
\hline & $35-44$ & 2.8 & 4.3 & 3.7 & 2.9 & 1.8 & 4.3 & 0.9 & 2.9 & 4.9 \\
\hline & $45-54$ & 2.9 & 15.5 & 11.1 & 3.8 & 3.7 & 5.9 & 3.8 & 1.4 & 4.2 \\
\hline & $55+$ & 9.0 & 7.9 & 6.0 & 8.5 & 1.7 & 10.5 & 3.1 & 7.0 & 9.3 \\
\hline TOTAL DE & HOMENS & 5.0 & 6.5 & 5.0 & 4.1 & 1.9 & 5.8 & 2.5 & 3.8 & 4.8 \\
\hline \multicolumn{11}{|l|}{ MULHERES } \\
\hline & $15-24$ & 4.0 & 6.2 & 4.5 & 1.2 & $0.0 *$ & 6.6 & 3.0 & 2.1 & $12.6^{*}$ \\
\hline & $25-34$ & 12.3 & 5.7 & 9.3 & 7.7 & 5.3 & 6.7 & 5.1 & 5.5 & 10.4 \\
\hline & $35-44$ & 6.5 & 20.0 & 6.2 & 8.4 & 6.8 & 11.3 & 5.8 & 5.5 & 6.4 \\
\hline & $45-54$ & 8.1 & 11.8 & 11.3 & 9.6 & 6.8 & 12.3 & 7.3 & 2.9 & 15.2 \\
\hline & $55+$ & 15.7 & 9.7 & 10.0 & 9.6 & 4.2 & 14.4 & 7.2 & 11.5 & 12.9 \\
\hline TOTAL DE & MULHERES & 10.5 & 10.2 & 8.5 & 7.7 & 4.8 & 10.5 & 5.5 & 6.3 & 11.9 \\
\hline$T \circ T A I$ & & 7.9 & 8.4 & 6.8 & 6.0 & 3.4 & 8.1 & 4.0 & 5.0 & 8.6 \\
\hline
\end{tabular}

* Intervalo de idade: $16-24$. FONTE: BALTER et al ${ }^{7}$. 
gulares.

Não concordamos com os autores quando re legam o uso esporádico a um plano secundārio na avaliação do problema do consumo de psicotrópiccs. Em primeiro lugar, por que o padrão esporādico nem sempre é o "mero uso do medicamen to por uns poucos dias em alguma época do ano" e, em segundo lugar, porque seus valores são mais expressivos como medida da tendência a se usar psicotrōpicos para o manejo de situaçōes anteriormente encaradas como vissicitudes naturais da vida.

E possivel que o padrão regular de consumo seja o mais encontrado entre os usuários de neurolépticos, an ticomiciais e antidepressivos na medida em que, nestas instân cias, não se visa ao alívio imediato de um sintoma e são tra tamentos submetidos a estrito controle médico. Já entre os con sumidores de ansioliticos, hipnōticos e sedativos, seja por indicação médica ou leiga, é possîvel encontrar uma proporção maior de usuārios esporádicos ou episódicos.

Os tipos de medicamentos psicotrópicos mais frequentemente utilizados tem sido os ansiolíticos, hipnóticos e sedativos. Entre os ansioliticos, os derivados da benzodiaze pina são os preferidos desde o seu aparecimento em 1960. Em 1973 BLACKWELL ${ }^{10}$ apontava para o fato de que $97 \%$ dos clínicos gerais usavam o diazepan. A Figura 3 indica a importância cres cente dos tranquilizantes menores (ansioliticos) no conjunto dos psicotrópicos prescritos nos Estádos Unidos e a Figura 4 mostra que o seu crescimento se deve, particularmente, às ben zodiazepinas.

$$
\text { MELIINGER et al }{ }^{42} \text { e PARRY et a } 1^{47} \text { encontra }
$$
ram nos Estados Unidos indices de prevalência de consumo bem menores para os neurolēpticos do que para ansioliticos e hip nóticos. Alēm disso, as diferenças nos Índices de consumo en 
FIGURA 3 - TENDENCIAS DO CONSUMO DOS MEDICAMENTOS PSI COTROPICOS MAIS COMUMENTE PRESCRITOS NOS ESTADOS UNIDOS, 1964 - 1972.

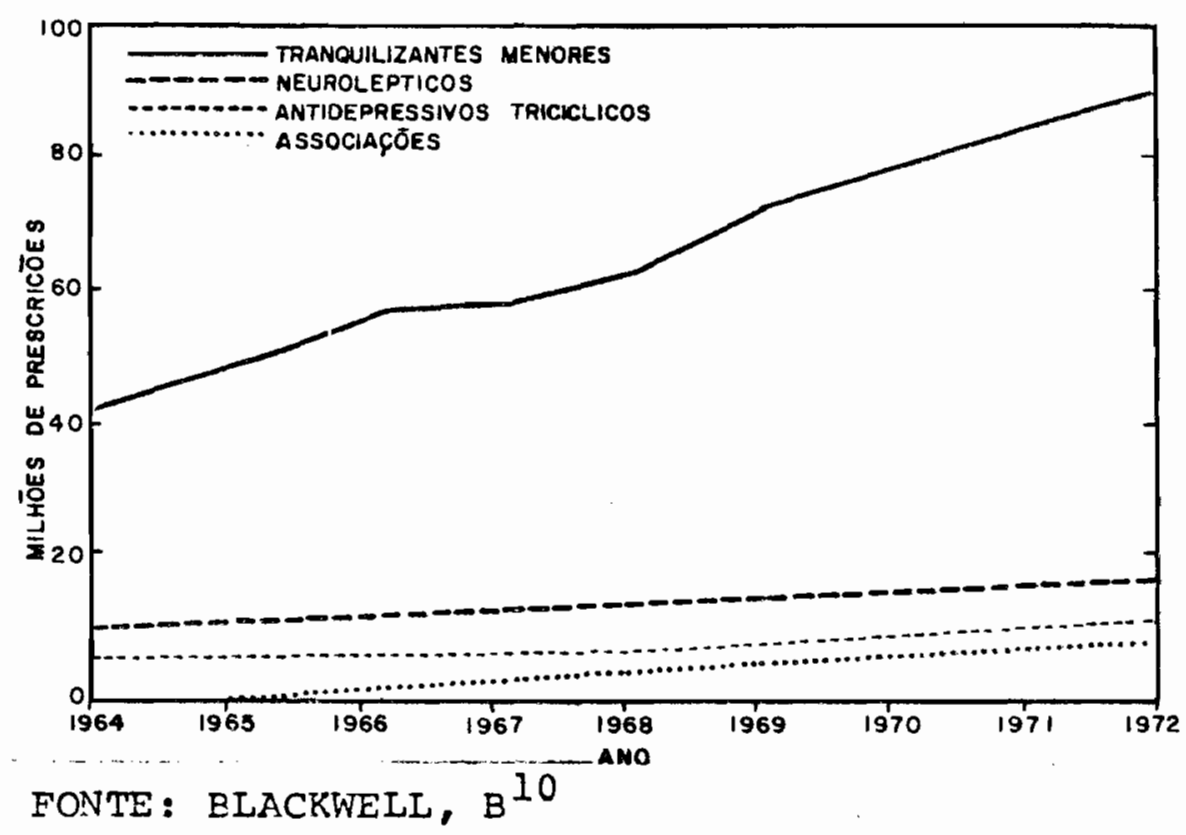

FIGURA 4 - TENDENCIAS DO CONSUMO DE MEDICAMENTOS ANSI LITICOS NOS ESTADOS UNIDOS, 1964 - 1972.

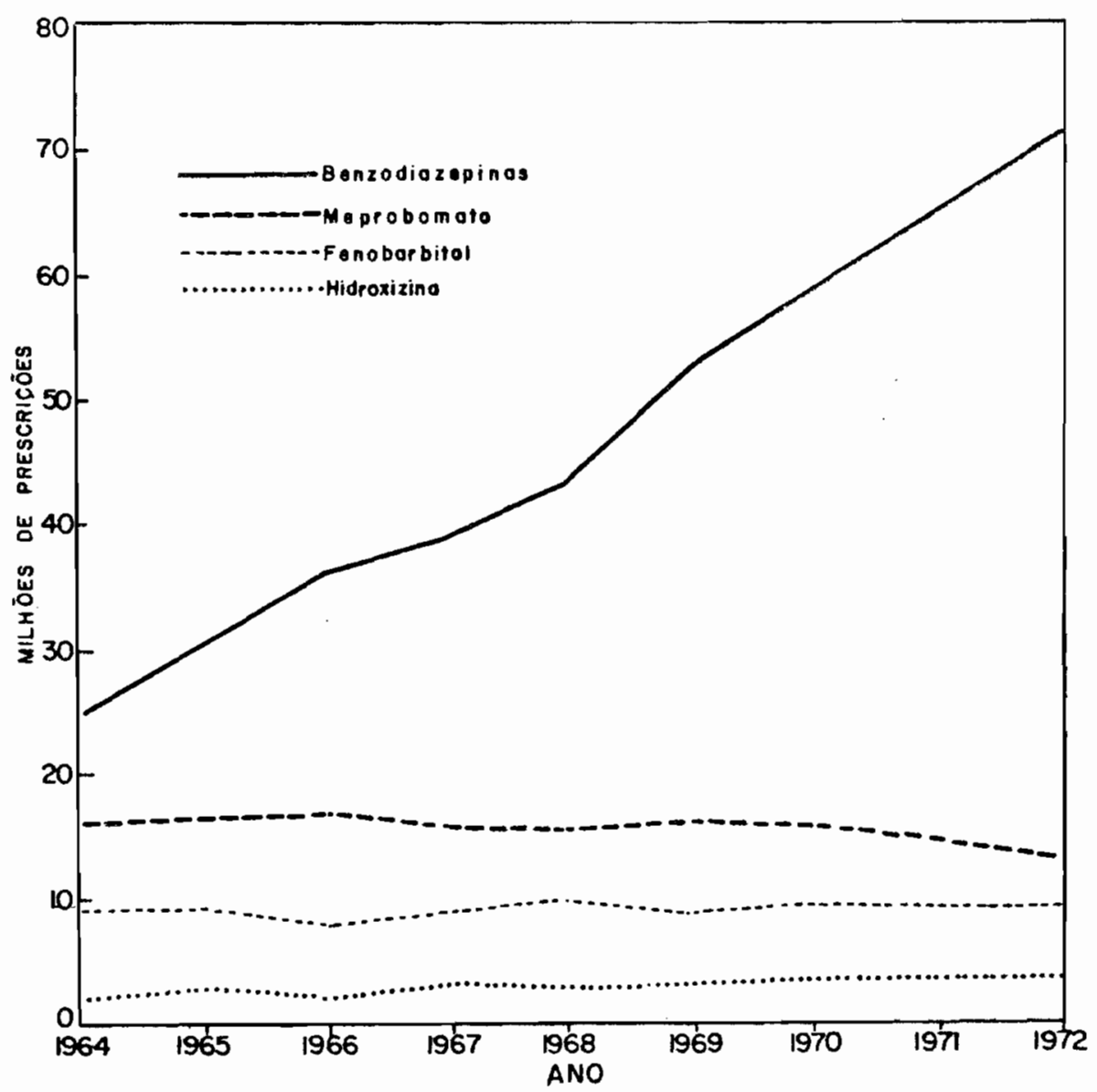

FONTE: BLACKWELL, B 10 . 
tre os dois sexos são, em grande parte, cievidas às diferenças no consumo de ansiolíticos e hipnóticos.

$\bar{E}$ compreensivel que os niveis de consumo de neurolēpticos sejam lenores e mais uniformes entre os dois sexos, posto que estes medicamentos tem seu campo de indicaçōes limitado aos estados psicóticos e alguns estados neuróticos graves. Já os ansioliticos, hipnčticos e sedativos indicados para alívio imediato da ansiedade encontram uma gama de indicações bem ampla. É provavelmente esta amplitude de indicações que leva grande parte dos clínicos a lançar mão dos ansiolíti cos, hipnóticos e sedativos para as mais diversas situações; contudo, dificilmente ele lança mão dos neurolépticos preferin do encaminhar o paciente a um especialista sempre que detecta um transtorno mental para cujo controle se exija o emprego destas drogas. o mesmo não se dá com os antidepressivos, os quais vem sendo cada vez mais empregados em clínica geral. BLACKWELL ${ }^{10}$ observa que nos Estados Unidos somente $30 \%$ das prescrições do diazepan são feitas para pacientes com transtor nos mentais; 17\% o são para transtornos ósteo-musculares, 168 para problemas circulatórios, 7응 no período pós-cirurgico e 38 para transtornos genito-urinārios.

En sintese, a observação da estrutura do consumo de medicamentos psicotrópicos leva a duas constataçōes. Em primeiro lugar, a de que hā um crescimento contínuo do seu consumo desde o surgimento das drogas mais modernas em 1952; em segundo lugar, que este crescimento se deveu principalmente ao emprego cada vez mais amplo dos ansioliticos, sedativos e hipnōticos com predileção pelos derivados de benzodiazepina.

Ora, estas ültimas foram introduzidas como auxiliares no tratamento dos transtornos mentais, como as neu roses, onde a ansiedade exerce papel importante. E difícil su 
por que o crescimento do consumo da benzodiazepina seja refle xo do puro crescimento da prevalência daqueles transtornos mentais. Se bem que se possa admitir um aumento da prevalência de estados neuróticos, inclusive pelo alargamento dos seus li mites conceituais, è de se admitir que o marcante crescimento do consumo de benzodiazepinas esteja, primordialmente, relacio nado ao seu emprego em situações que transcendem o conceito médico de ansiedade patológica, isto é, estas drogas ansiolítí cas/sedativas devem estar sendo empregadas, cada vez mais am plamente, en situaçōes onde a ansiedade deveria, a rigor, ser encarada em seu verdadeiro aspecto não médico.

Dentre os fatores que podem estar na raiz desta mudança de atitudes e comportamento, selecionamos para análise, aqueles mais diretamente relacionados à assistência médica. Se nosso foco de atenção recai sobre somente estes fa tores não è porque os consideremos necessariamente os mais im portantes, mas, simplesmente, porque num trabalho deste porte não podemos pretender abordar um conjunto por demais amplo e complexo de fatores sōcio-culturais cuja apreensão escapa à nossa capacidade de anālise.

A reorganização dos modelos de assistência médica com o desaparecimento do médico da familia em detrimen to da valorização do especialista, o crescente tecnicismo dos atos médicos decorrente do progresso da Biologia e, fato notó rio em nosso paîs, as distorções do sistema assistencial (com o paciente não raro sendo atendido por um médico diferente em cada consulta), levaram a uma profunda deteriorização da rela ção médico-paciente. como se a classe médica tivesse passa do a acreditar que $\circ$ aspecto mais importante da prática médica é a pesquisa detetivesca da natureza orgânica dos sintomas ${ }^{4}$, a formulação de um "diagnōstico" que satisfaça ao cliente e à 
sua prōpria omnipotência, e, por fim, a prescrição de uma dro ga que promova a "cura" da "doença".

E cada vez mais evidente que nestas cir cunstâncias o médico se olvida que a queixa somática trazida para dentro do consultório possa ser o "passaporte" de ingres so para uma situação de intimidade que permita ao paciente ex teriorizar suas dificuldades existenciais àquela figura que a cultura insiste em ver como "conselheiro" e buscar nele a ori entação ou palavra de alivio ${ }^{5}$.

Ao mesmo tempo em que deseja a manutenção do seu status social o médico procura eximir-se deste papel histórico que, na atualidade, parece inconveniente ao funcionamento de vários dos modelos assistenciais estabelecidos. Contudo, abdicar de sua projeção social não parece ser algo interessante para nenhuma classe profissional; para tanto, os recursos laboratoriais, os diagnósticos cada vez mais complexos e o emprego de drogas em larga escala (algumas vezes inū teis, outras vezes meros paliativos e cada vez mais dispendio sas) contribuem para manter a mistica da sua atuação.

o tempo que o médico dispensa a cada pací ente é importante determinante do exagero das prescrições. E fato observado que quanto maior a carga de trabalho, e menor - tempo dispensado a cada paciente, maior o volume de prescri çōes, incluindo os psicotrópicos ${ }^{30}$. o desejo de ascenção econô mico-social ou a remuneração inferior ao almejado leva o médi co a assumir um número grande de compromissos. Em nosso meio, a remuneração inadequada, agravada pelo aumento de oferta de mão-de-obra, tem levado o médico a assumir, na quase totalida de dos casos, de dois a três contratos de trabalho, redundando em uma pequena disponibilidade de tempo pará o efetivo atendi mento do paciente. Alēm disso, seja pelas condições de traba- 
lho, com excessivo número de atendimentos por jornada de tra balho, seja pela deterioração da relação médico-instituição, a disponibilidade emocional para a execução do trabalho é di minuida. o resultado regativo desta situação acaba recaindo com muito maior ênfase sobre o objetivo de toda esta estrutú ra: o próprio paciente. Ele que acaba por receber as prescri ções desnecessárias ou inapropriadas.

Neste contexto, torna-se mais dificil ao paciente expressar queixas psíquicas - exceto, é claro, nos serviços especializados - em busca de ajuda e compreensão; a reação do médico vai da indiferença ao medo e ao ceticismo. Sua intervenção limita-se à prescrição de um psicotrōpico (al gumas vezes, bastante inapropriado) ou ao encaminhamento a um serviço especializado; poucas vezes o médico dispõe-se a ouvir atentamente a queixa e utilizar o potencial de sua relação com - paciente a fim de orientá-lo na resolução daqueles problemas. Este comportamento cético, indiferente ou medroso diante das queixas psíquicas do paciente decorre, em grande parte, do desconhecimento observado entre a classe mé åica acerca da Psiquiatria e Psicologia Médica. Não poucos che gam mesmo a afirmar que "fazem questão de não conhecer estes problemas" e que "louco dever ser cuidado peio psiquiatra". Isto é, sem dūvida, um estigma absurdo e pode ajudar-nos a compreender porque o sintoma somático assume o papel de "passaporte" para entrada no consultório do generalista.

Seu desconhecimento também se estende ao campo da Psicofarmacologia. Levantamento realizado na cidade de são Paulo por uma indústria farmacêutica interessada em lançar no mercado um novo produto ansiolitico* constatou que a maioria dos médicos consultados - não especialistas - confun 
dia o efeito ansiolitico e efeito sedativo de uma droga psico trópica. As fontes de aquisição de conhecimentos sobre efeitos de medicamentos são, en geral, o propagandista do laboratório, os folhetos de propaganda médica, as bulas que acompanham a em balagem do medicamento e os guias de referência publicados sob patrocínio da indústria farmacêutica 58,61 ; com menor frequência - conhecimento é adquirido em publicações científicas e reuniões médicas. E, no entanto, o clínico geral é o maior responsável pelo grande volume de prescrições de ansioliticos, hipnōticos e sedativos ${ }^{6,47}$; no Brasil, os produtos mais vendidos são os derivados benzodiazepínicos contidos nos chamados "antidistōni cos" que receberam a preferēncia dos médicos e usuārios em fun ção da falsa crença de que são "calmantes fracos" e inócuos. Dentre as pressões a que o médico está submetido e que o induzem a prescrever com mais frequência do que o apropriado ${ }^{43}$, alēm destas apontadas até aqui, devemos considerar aquelas exercidas pelo próprio paciente em busca do alívio de sua ansiedade frente a uma doença somática ou psí quica, ou frente a uma situação existencial desconfortável. BALINT ${ }^{5}$ e BALINT et $a 1^{6}$ observando o fenômeno de pacientes fre quentadores assíduos dos consultórios de generalistas na Grã-Bretanha constatam que nestes casos estabelece-se um padrão de relacionamento médico-paciente em que o medicamento (frequentemente um psicotrópico) estabelece uma ponte entre os dois; ele é, simbolicamente, uma forma de contacto humano. Por outro lado, é preciso notar que este padrão também estabe lece uma barreira, na medida em que esconde aspectos mais pro fundos do relacionamento do paciente com o seu meio (incluindo aí o seu médico) os quais, desta forma, acabam por não vir à tona. Neste contexto surge a demanda pelo medicamento e, di ante da sua impossibilidade de trabalhar a situação, seja por 
que não a percebe ou porque não se dispõe a tal, o médico aca ba por ceder às pressões do paciente, recomendando-lhe o uso de ansiolíticos, hipnōticos e, não raro, antidepressivos.

Situações como desajustes $f$ miliares ou ro trabalho frequentemente são trazidas ao médico na forma de sintomas físicos mal caracterizados; problemas de origem eco nômica e social exteriorizam-se na forma de queixas psiquicas como a ansiedade, "nervosismo" ou insônia. Em tais circunstān cias, ou porque não tem tempo e condições de perceber as causas da queixa, ou porque não encontra alternativas, o médico apela para a prescrição de tranquilizantes. Como consequência, problemas econômicos e sociais são tratados no contexto do mo delo médico de alívio do desconforto individual ao invés de receber una abordagem dentro de um contexto político e social de esforços cooperativos visando a uma mudança social ${ }^{61 .}$ Dian te da constatação de que um quarto das mulheres norte-america nas de 30 a 60 anos de idade fazem uso de tranquilizantes, CA MILLERI ${ }^{14}$ se espanta e afirma que "... a tensão nervosa e a pressão psíquica resultantes do estado patológico da socieda de, que ameaçam paralisar a máquina social, tèm, pois, torna do necessária a manipulação psíquica do stress e a redefinição da normalidade. As drogas e o hospital psiquiátrico tornaramse o óleo lubrificante e a oficina de reparos indispensáveis para prevenir a parada completa do motor humano..."

Porém, não só a compreensão da dinâmica desta díade médico-paciente permite o entendimento do jogo de forças que determina o grande consumo de psicotrópicos. Neces sārio levar em consideração o papel desempenhado pelas indūs trias farmacêuticas e pelo farmacêutico ${ }^{45}$.

o papel do farmacêutico - en nosso pais, como em diversos outros, este papel è exercido por um atenden 
te balconista sem qualquer preparo acadêmico - naturalmente restringido com o desenvolvimento da indústria de medicamentos e consequente desuso das fórmulas magistrais, deveria se ater a orientações gerais quanto ao uso da medicação, efeitos adver sos ou incompatibilidades. Contudo, em áreas com deficiência ou má qualidade de serviços médicos sua atuação extende-se ao diagnóstico e à prescrição de medicamentos. Se este papel com plementar tem sido tolerado pelo Estado é porque ele tem sido necessārio para suprir as deficiēncias de serviços médicos, mas não se pode omitir que, alēm da sua impropriedade de prin cípios, ele é gerador de distorções no consumo.

Estas distorções devem decorrer, em parte, da crença do farmacêutico no poder dos medicamentos e, en par te, da possibilidade de aumentar seus lucros. Este desejo de lucro é compartilhado pela indústria farmacêutica que utiliza - farmacêutico como forma de incrementar as vendas de produtos de maior lucratividade para os dois. No Brasil é prática comur das indūstrias oferecer grandes margens de descontos para que certos produtos sejam colocados nas farmācias; com isso ganha - proprietārio da farmácia que, vendendo o produto pelo preço de tabela, chega a auferir mais de $100 \%$ de lucros e ganha a indūstria farmacêutica que atinge o objetivo de divulgação do seu produto. Só não ganha o usuārio que é induzido a comprar produtos de eficiência duvidável em São Paulo. Estes produtos de alta lucratividade recebem, entre representantes de vendas e proprietários de farmácias, o apelido de "B.O."; alguns ale gam que é uma corruptela de "bonificação" porque são repassados como tal; os mais francos afirmam que se trata de uma cor ruptela de "bomba", gíria empregada para descrever produtos de alto custo e de efeito terapêtico discutível. 
contendo substâncias psicotrópicas é totalmente sujeita a con trole, resta ao farmacètico a possibilidade de influir no consumo de produtos não-ēticos, como os "sleeping aids" e "stimulants" do mercado norte-americano, os quais contēm esç polamina ou cafeína e que representam importante segmento do mercado 42,47 . Entretanto, quando existe a possibilidade - co mo acontece em nosso pais - de se encontrar mesmo entre os produtos éticos alguns psicotrópicos que podem ser vendidos sem a apresentação de receita médica, vemo-nos diante de uma situação que não só leva ao super-consumo, mas, também, a um risco concreto à população. Ignorante ou indiferente ao fato, - farmacêutico (ou, mais propriamente, o balconista de farmá cia) recomenda e vende tranquilizantes "antidistônicos" con tendo benzodiazepínicos ou neurolépticos e sedativos contendo barbitúricos.

Quem certamente não deve ignorar os riscos do super-consumo de medicamentos psicotrópicos é, talvez, o a tor com maior poder de influência neste cenário:a indústria farmacêutica. Ela ter sido acusada de interessar-se primordial mente pelo lucro e não, pelo bem estar da população ${ }^{34}$; na ân sia de maximizar seus lucros impõe novos padrões de consumo 45,61 . GODDARD ${ }^{27}$ aponta que no mercado norte-americano, os laborató rios farmacêuticos são as indūstrias que auferem os maiores e mais estāveis lucros $(13,5 \%$ ao ano) e que, para atingir este objetivo, eles despendem $25 \%$ do seu faturamento em promoção de vendas; as despesas em pesquisa e obtenção de matérias-prí mas correspondem a $6 \%$ e $35 \%$ do faturamento respectivamente. "Os porta-vozes das indūstrias farmacêuticas frequentemente comparam o risco da pesquisa de novas drogas às prospecções da indūstria petrolifera, mas o fato é que nos ūltimos 25 anos nenhum grande laboratōrio farmacêutico encerrou seus negócios" 27. 
Em extenso trabalho WALDRON ${ }^{61}$ aponta que - Laboratório Roche aproveitou-se da lei de proteção de paten tes para manter altos os preços do Valium e Librium nos merca dos britânico e norte-c lericano. Os ingredientes ativos eram vendidos por preços 40 a 50 vezes mais altos do que na Itália, país que não segue efetivamente as leis de patentes; a comissão Britânica de Monopólios acusou a Roche de obter margens de lucro de 40 a $60 \%$ nas vendas de Valium e Librium e ordenou que reduzisse os seus preços en $75 \%$ e $60 \%$ respectivamente e ressarcisse ao Tesouro 30 milhões de dólares por lucros ilící tos. Nos Estados Unidos, esta mesma indústria lutou durante dez anos para retardar a entrada em vigor de uma nova regula mentação nas vendas de psicotrópicos (limitando a validade da receita médica a seis meses e obrigando o registro de receitas) e, finalmente, em 1975 cessou a luta; "talvez não seja coincí dência que as patentes do Valium e Librium expirarão brevemen te (em 1980 e 1976) de forma que se espera uma competição de preços por parte de outros fabricantes no futuro próximo"61.

Uma forma de conservar a lucratividade é - lançamento de "novos" produtos periodicamente. A pletora de derivados benzodiazepínicos è, possivelmente, reflexo desta estratēgia. O estoque de benzodiazepínicos testados e patentea dos, prontas a serem lançadas no mercado, chega a atingir 300 produtos $^{44}$. No mercado brasileiro já foram introduzicos e per manecem à disposição 12 derivados benzodiazepinicos (9 ansio liticos e 3 hipno-indutores) desde 1961, dando uma média de um lançamento a cada ano e meio. Enquanto isso, o mercado nor te-americano tinha em 1976 apenas 6 derivados $^{61}$ e o mercado escandinavo, controlado por empresa estatal, em 1979 conta com 7 deles $^{*}$. Isto corrobora a afirmação de SILVERMAN ${ }^{58}$ de que os

* Comunicação pessoal. 
mercados de países menos desenvolvidos são bastante propicios ao lançamento e permanência de drogas de duvidável superiorí dade sobre os produtos já existentes, na medida em que a legis lação controladora é mais permissiva do que em países desenvol vidos.

- Iançamento de um novo produto contendo um sucedâneo de uma droga já existente nem sempre segue ditạ mes científicos de exigência de melhores resultados terapêuti cos com menores efeitos colaterais. Pelo contrário, parece que o motivo é, não raro, eminentemente comercial. Em verdade, todos os derivados da benzodiazepina tem efeitos terapêticos bastante semelhantes, variando principalmente, a intensidade e qualidade dos efeitos colaterais 44,61 . Contudo, o apelo co mercial é suficientemente grande até para induzir a indústria a lançar derivados com efeitos colaterais mais adversos; exem plo disso é o lançamento no mercado brasileiro em 1970 e 1971 do temazepan e do lorazepan, dois derivados benzodiazepínicos com efeitos colaterais mais intensos e desagradáveis do que o clorodiazepóxido e o diazepan (utilizados desde 1961 e 1963 respectivamente). O temazepan teve história efêmera,mas o 10 razepan, ao que tudo indica, è hoje um dos benzodiazepínicos mais consumidos entre nós, só perdendo para o diazepan. Aliás, este derivado até hoje não é comercializado no mercado escan dinavo*.

Se para a indústria farmacêutica o lançą mento de novos produtos traduz um apelo a lucros maiores e mais estáveis, para o médico e farmacêutico existe o apelo da novidade. Os médicos que mais se deixam influenciar pelas no vidades do mercado são aqueles com curta experiência profissional ou com menores conhecimentos clinicos 36,41 . Diante da

* Comunicaçäo pessoal. 
precariedade de informações disponiveis sobre os efeitos e van tagens de novas drogas (e quando estas informações existem e chegam às mãos do médico, já foram "triadas" pela indústria farmacêutica) é difícil crer que ele tenha condi ões de avaliar suas vantagens e desvantagens; desta forma, "a adoção de uma nova droga se dá como um ato de fé" 41 .

Seja para o lançamento de novos produtos, para reativar as vendas de algum produto ameaçado por concor rente ou para conservar a faixa de mercado de um produto con sagrado, a indústria farmacêutica lança mão de diversas formas de propaganda sobre o médico e o farmacêutico. Se uma parcela da propaganda não se dirige tambëm ao consumidor final é por que a legislação não o permite para os produtos éticos e não porque este alvo seja desprezível; não faltaram tentativas de produtores de psicotrópicos de influir sobre os meios de comu nicação de massa ${ }^{61}$, prātica possivel atravēs da tëcnica de "mercharıdising" (veiculação indireta da mensagem).

o volume de propaganda dirigida ao médico é massivo e seu efeito sobre os hábitos de prescrição é consi derável $30,55,58,63$. Com maior frequència o médico se deixa in fluenciar pela publicidade dos laboratórios do que pelos artí gos científicos de revistas especializadas ${ }^{61}$; esta publicidade é voltada para a formação de hábitos de prescrição e aten de estritamente aos interesses das indústrias. Chega ao médico através do representante de vendas, das revistas médicas e da mala direta. O representante de vendas, supostamente um disse minador de informações objetivas é, em realidade treinado por psicológos e especialistas em mercadologia para induzir o médi co a adotar novos padrões de prescrição ${ }^{55}$; durante o treinamen to é instruido a não mencionar novas evidencias de reações ad versas dos medicamentos durante sua entrevista com o médico 61 . 
Seu discurso - quase sempre esteriotipado e repetitivo - não visa a informar o médico, mas, sim, a promover o produto.

O material promocional veiculado por mala direta ou em revistas médicas (que, эn nosso meio, frequente mente dependem deste material para sua subsistência financeira) é farto e luxuoso. Através de bem elaborados recursos de publicidade procura ampliar a gama de situaçōes em que o pro duto seria indicado. WALDRON ${ }^{61}$ cita que o valium e o Librium são mencionados neste material como úteis para "a dona-de-ca sa com muito pouco tempo para realizar a vocação para a qual ela se treinou por muitos anos"; ou "quando a ansiedade e ten são criam grandes discōrdias nas relações pais-íilhos"; ou ainda para o alívio da ansiedade do estudante cuja "recém estí mulada curiosidade intelectual tornou-o o mais sensível e a preensivo em relação às condições instáveis do mundo e da na ção". No Brasil, um importante laboratório utiliza na promoção de um novo ansiolítico um encarte retratando seis situações caracteristicamente existenciais - segundo o próprio texto que acompanha a foto - , para as quais ele recomenda o uso do pro duto (Anexo 1); outro laboratório brasileiro, na promoção do seu produto ansiolítico, g̣ualifica a ansiedade de "a emoçăo oficial de nosso tempo, o símbolo de nossa época".

Outra prātica utilizada - bastante corren te em nosso meio quando se trata de lançamento de novos nomes comerciais de drogas jā conhecidas - è a "encomenca" de ensaios clínicos cuja metodologia científica è de qualidade duvidosa (queremos ressalvar que não se deve confundi-los com ensaios clinicos criteriosamente conduzidos e amplamente encontrados entre nōs); estes ensaios, realizados sobre pequena amostra de pacientes, mas numerosos, "produzem" uma bibliografia ex tensa sobre o produto; esta é apresentada ao médico como "re 
sultado da experiência acumulada por inümeros colegas" e dian te de tal "evidência" - mas nem sempre tomando cuidado de con sultar os trabalhos citados - o médico adota uma atitude mais simpātica e permissiva em relação ao produto.

Outras técnicas, como o envio de presentes de aniversārio, brindes, amostras grātis e, inclusive, viagens para participação em congressos médicos complementam o elenco de medidas que criam um relacionamento amistoso entre a classe médica e a indústria farmacêutica ${ }^{61}$ trazendo para a primeira as benesses do tratamento preferencial e, para a segunda, o retorno seguro do investimento.

Assim, cada grupo, segundo seus próprios objetivos e interesses, contribui para compor, no conjunto, um quadro de facilitação do uso de psicotrōpicos. MULLER 45 pondera que "ao invés de condenar ou deplorar o comportanento de auto-satisfação de algumas pessoas e o conhecimento e julgamento deficientes de outras, pode se tomar como ponto de partida o fato de que a situação existente é, paradoxalmente, compreensivel no sentido que ela pode ser explicada por fato res objetivos. Isto $\bar{e}$, o super-consumo de drogas mantém-se porque certas características do mercado de atenção médica le vam várias diferentes partes a contribuir para elevar o nível de medicação a uma certa altura. Cada ator - indústria farma cêutica, médico, paciente, farmacêutico - é impelido a fazer isto porque está fazendo uma troca entre as drogas e alguma outra alternativa menos vantajosa para si. A cada ator é per mitido fazer isto porque a responsabilidade pela atenção médi ca é fragmentada e porque a contribuição da decisão individual de cada um para o incremento do uso de medicamentos é tão pe quena que os efeitos cumulativos são ignorados". 
mentos psicotrópicos para as mais variadas finalidades não-mé dicas já se estabeleceu como norma cultural. o uso dos tranqui lizantes é aceito como aspecto natural e necessārio da vida moderna; $m$ is aceitos pelas mulheres e pelos consumidores em geral ${ }^{40}$, eles vão, paulatinamente, minando as resistēncias ofe recidas por outros segmentos da sociedade. O esquema da Figura 5 facilita a visualização das relações entre as vãrias partes evoluidas no processo.

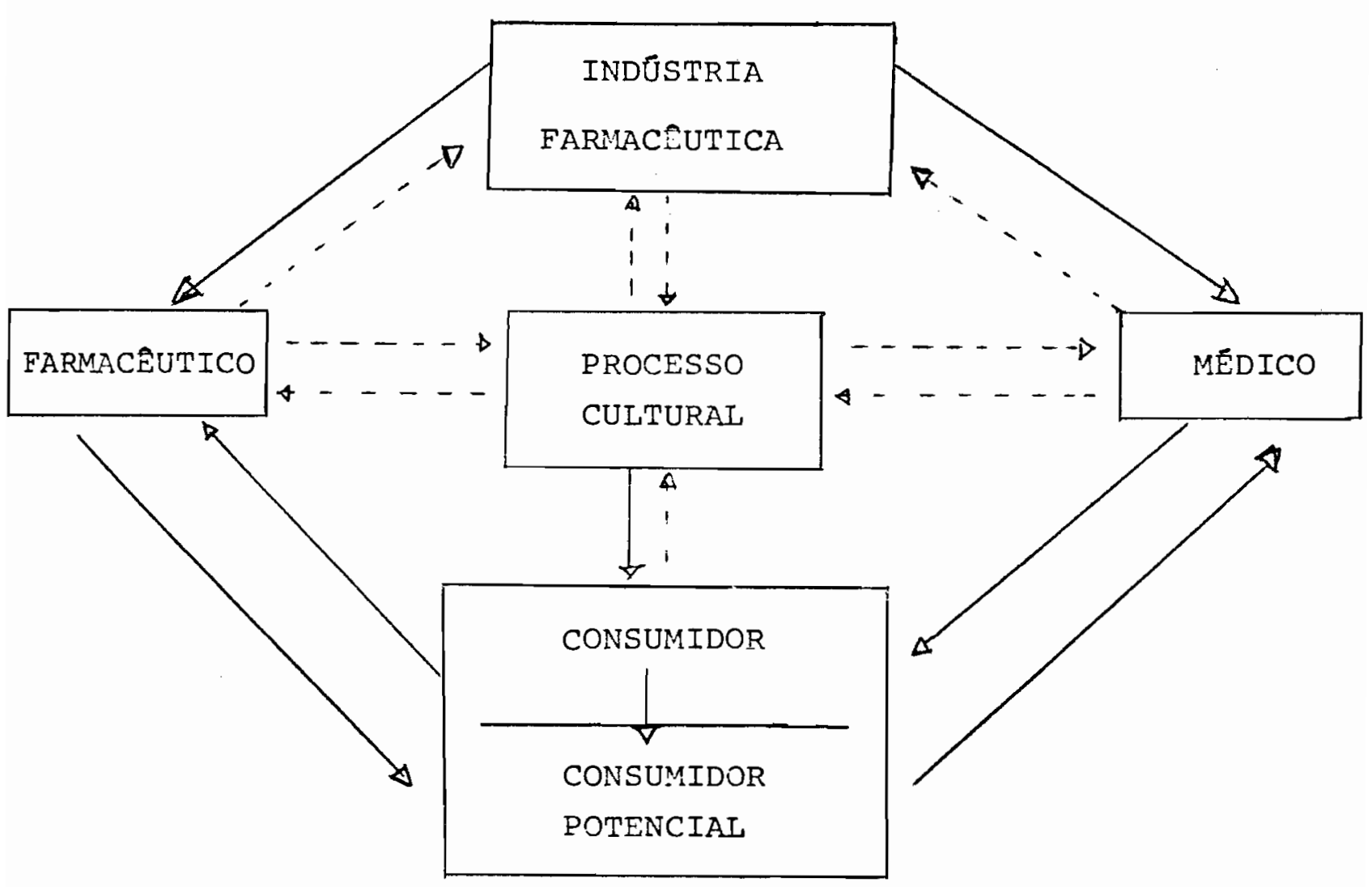

FIGURA 5 - REPRESENTAÇন̃̄O ESQUEMĀTICA DAS RELAÇŌES ENTRE OS VÂ RIOS SEGMENTOS ENVOLVIDOS NO PROCESSO DE SUPER-CON SUMO DE PSICOTRÓPICOS. AS LINHAS CHEIAS INDICAM UMA RELAÇÃO DE INFLUENCIA DIRETA; AS LINHAS PONTILHADAS INDICAM UMA RELAÇ̃̃̃ DE INFLUÊNCIA INDIRETA.

Nesta representação esquemātica o grupo consumidor è apontado como recebendo influência direta do pro cesso cultural. Acreditamos que esta seja a principal influēn 
cia a ser considerada nos casos de alta medicação com psicotró ficos. Outrossim, o grupo de pacientes è subdividido em "consumidor" e "consumidor potencial" podendo-se observar uma influência direta do primeiro sub-gruoo sobre o virtual apareci mento do hábito no segundo sub-grupo.

A auto-medicação, fenômeno frequente em nosso meio, tem suas origens calcadas em dois fatores principais: a repressão da demanda por serviços médicos (decorrente da falta de regionalização destes serviços, cia influência de recursos e das dificuldades econônicas de ponderável parcela da população) e a persistência de padrões herdados da Medicí na popular. Assim sendo, parcela ponderável do consumo de an tibiōticos e vitaminas decorre da auto-medicação; dos 20 medi camentos mais vendidos no Brasil, 9 são antibiōticos, 2 são vitaminas e 1 é psicotrōpico ${ }^{52}$.

Em relação aos medicamentos psicotrópicos é preciso acrescentar que a auto-medicação sofre a influência de normas culturais de formação bem mais recente. De fato, é principalmente após a descoberta das benzodiazepinas que se verifica o surgimento do conceito de que toda a ansiedade é prejudicial ao indivíduo e que ela pode ser eliminada de for ma segura e eficaz sem exigir a mobilização de elementos in ternos e sem sofrimento; surge a idéia de que o stress emocio nal é um produto natural e inevitável das sociedades modernas e que cada um deve encontrar meios individuais de evitar suas consequèncias.

Seja pela auto-medicaçāo ou por indicação do médico ou farmacêutico é fato que número crescente de pes soas assume atitudes de antipatia pela ansiedade e simpatia pelos psicotrópicos. Cada vez menos pessoas se dispõe a atra vessar um período de sofrimento pelo luto, para citar um só 
exemplo, sem recorrer aos tranquilizantes. Argunentar que eles são uma conquista tecnológica e, portanto, devem estar ao al cance de todos é um raciocínio, no mínimo, simplista.

Eles servem a todos, como aponta MULLER ${ }^{45}$, mas, certamente, alguns obtēm maiores vantagens do que outros e do que o todo. E cabe perguntar até que ponto a própria es trutura do Estado se beneficia com o esvanecimento da ansieda de. Aparentemente os seus benefícios imediatos são ponderāveis porque, assim, se ajuda a aplanar as tensões sociais. Contudo, não hã evidências de que o Estado tenha realmente se preocupa do com os resultados a longo prazo de tal situação. Sua atitú de passiva e, atē certo ponto permissiva parece mais ligada a interesses econômicos imediatos, seja facilitando o lucro da indústria farmacêutica, seja acobertando as pröprias falhas do seu papel de prover proteção e bem-estar coletivos.

1.4. ALGUMAS PARTICULARIDADES DO MERCADO BRASILEIRO DE MEDICAMENTOS PSICOTRŌPICOS.

A indústria farmacêutica brasileira é for mada por cerca de 400 empresas; 71 são de capital estrangeiro ${ }^{2}$ e detēm $88 \%$ do mercado total 22 . Is restantes são empresas "de capital genuinamente nacional" 2 e retém a parcela dos $12 \%$ res $\operatorname{tantes}^{22}$.

Em 1975 o consumo "per capita" de medica mentos no Brasil foi de $\operatorname{Cr} \$ 85,07$ anuais $(\operatorname{US} \$ 10,71)^{1}$; apesar desse valor baixo ${ }^{1}$, o pais situava-se entre os dez maiores mercados farmacêuticos dos países de econômia capitalista, ten cio apresentado, curante a década de 60, uma taxa de crescimen to superior à registrada nos Estados Unidos, França, Itália e Canadā 22 . 
Existem pouco mais de cinco mil produtos éticos no mercado brasileiro ${ }^{2}$, isto $\bar{e}$, que devem ser consumilos sob prescrição médica. Contudo, em que pese esta obrigato riedade, eles são desce há longo tempo adquiridos com certa liberalidade. A Lei de Vigilância Sanitāria 19,38 , aprovada em 1976, estabeleceu que a partir de então esta obrigatoriedade seria cumprida com rigor. Entretanto, já decorridos 3 anos, a situação persiste quase sem alteraçōes.

Se, como argumentam alguns, o retardo na implantação definitiva do controle de vendas de produtos étí cos vem beneficiar larga parcela da população residente em ā reas desprovidas de recursos médicos, ele vem, também, benefí ciar largamente a indústria farmacêutica que, assim, promove suas vendas não só através da classe médica como através dos proprietārios de farmácias e, indiretamente, atravēs do próprio consumidor.

Em nosso meio, a classe médica é virtual mente desprovida de uma fonte segura de informaçöes sobre os efeitos terapêuticos e reaçōes adversas dos medicamentos à sua disposição. SILVERMAN ${ }^{58}$ registra que aqui, como em diversos países sul-americanos, os laboratórios farmacêuticos anunciam indicaçōes terapêuticas que a lei norte-americana lhes proíbe de fazer naquele mercado e, por outro lado, omitem a informação d̃e efeitos colaterais que, lá elas são legalmente obrigadas a destacar. Em verdade, as fontes de informação são, en grande parte, manipuladas pela indústria. As bulas constantes na em balagem e o representante de vendas referem uma gama de indi cações que as revistas médicas independentes não referem.

Por outro lado, dos guias de referência disporiveis, um é financiado pela indústria farmacêutica e ou tro, se bem que aparentemente independente, limita-se a trazer 
a transcrição das bulas redigidas pela própria indústria.

A alternativa de buscar informação junto a revistas médicas fica limitada por vārias razões; de um la do a situação de pauperismo de vārias destas ediç j̃es que tem vida efêmera; de outro lado, as publicações realniente indepen dentes (editadas por grupos universitários ou associaçōes mé dicas) tem penetração pequena. Restaria ao médico a consulta de revistas independentes estrangeiras, o que, também, è difí cil dado o seu alto custo e a sua localização restrita.

Sem outra alternativa, o médico baseia-se largamente na informação trazida pelo representante do labora tório ou pelo material promocional ou, ainda, na simples leitura da bula de medicamentos.

Os psicotrōpicos sempre estiveram submetí dos a controles mais rígidos de comercialização. A legislação - frequentemente alterada e atualizada - estabelece que a ven da de medicamentos psicotrópicos só pode se dar mediante a a presentação de uma receita médica para cada produto em que conste o nome e endereço completos do usuário, o nome legível do medicamento e a quantidade que deve ser vendida; por mui tos anos esta quantidade esteve limitada a trēs embalagens co merciais. o comprador deve apresentar um documento de identidade que é anotado no verso da receita, a qual permanece reti da na farmácia à disposição dos órgãos de fiscalização. Flēm disso, em livro registrado próprio, o farmacêutico è obrigado a anotar todos os dados da venda (nome, endereço, produto, forma de apresentação e quantidade vendida) 50,51 . De posse des ses registros e das notas fiscais de compra da farmácia, os órgãos fiscalizadores tem condições de detectar eventuais ven das ilícitas.

Este ritual certamente desestimula médicos, 
pacientes, farmacêuticos e indústria farmacêutica. Médicos e pacientes porque se aborrecem com as consultas e receitas fre quentes. O farmacēutico porque tem ampliado seu trabalho admi nistrativo. E indústria farmacêutica porque vê estrangulado um filão rendoso que poderia superar em larga escala às vendas de antibióticos e vitaminas.

Assim, a convergência dos interesses des tes quatro grupos, buscou no mercado brasileiro, solução que pudesse satisfazer a todos. E esta solução veio na forma de sedativos (contendo barbitúricos) e dos "antidistônicos" (con tenđo benzodiazepinas ou neurolépticos), cuja venda é, à seme lhança de antibiōticos e diversos outros produtos, legalmente sujeita à apresentação de receita médica, mas, na prātica, li vre.

Esta saida ardilosa e inteligente foi pos sivel graças a aspectos obscuros da legislação pertinente. Em consulta que fizemos a très laboratórios produtores de "antidistōnicos" sobre as bases legais que permitiam a liberalidade para a produção e venda destes benzodiazepinicos em associa ção, dois deles responderam-ros, por telefone, que "a legisla ção não proibe"; o terceiro não enviou qualquer resposta. As origens dos sedativos e "antidistọnicos" é remota e distinta. Os sedativos - aqui definidos como aqueles produtos éticos compostos de extratos de vegetais, brometos, etc, associados ou não a barbitūricos e cuja venda não está sujeita aos rigores da legislação sobre medicamentos psi cotrópicos, têm existência longa. lluitos deles, antes da déca da de 60, eram associações de brometos e extratos vegetais; paulatinamente foram sendo introduzidos no mercado alguns pro dutos que associavam, tambēm, pequenas doses de fenobarbital (de 10 a 30mg/comprimido, quando a dose ütil diāria é da ordem 
de $100 \mathrm{mg})^{3,21}$. Gozaram de grande prestjgio antes da introdução dos "antidistōnicos", mas até hoje detêm a preferēncia de pon derável parcela de médicos e consumidores ainda afeitos à pas siflorina, maracujina e eretrina ou ao Vagostesyl e sedandrômaco (associações de extratos vegetais com fenobarbital). É nebulosa a razão pela qual estes sedativos contendo barbitúri cos não têm sua venda controlada enquanto todos os outros bar bitúricos são severamente controlados.

Os "antidistônicos" são de origem mais re cente e descendentes de um grupo de medicamentos primariamente utilizados como antiespasmódicos. Aliās, até hoje, suas vendas são classificadas entre os produtos para uso gastroentestinal ajudando a acobertar a verdadeira dimensão do mercado de psico trópicos. O início da produção de "antidistônicos" se deu com - advento do meprobamato en meados da década de 50 e decorre, provavelmente, da observação de que a tensão psíquica tem im portante papel no circuito da dor visceral; assim, a associação de pequenas doses do meprobamato (de 50 a 200mg/comprimido, cuando a dose útil diāria é da ordem de $1.200 \mathrm{mg})^{3}$ permitia di minuir a dose necessāria de antiespasmōdicos com melhor eficiēn cia. Até aî hã um raciocínio farmacológico claro, se bem que, a rigor, se contra-indiquem os medicamentos contendo associações porque não permitem os ajustes individuais das doses de cada componente.

Entre 1961 e 1965 surgiram no mercado qua tro "antidistônicos", três contendo clorodiazepóxido e um con tendo haloperidol, ainda em doses discretas de psicotrópicos. A esta altura (1965) o mercado dispunha de 13 antidistônicos. E a partir de 1968 que passam a surgir no mercado produtos contendo associações do diazepan (quase todos na dose de $5 \mathrm{mg} /$ comprimido quando a dose útil diária é de $10 \mathrm{mg})^{3,11}$. 
A competitividade pela conquista de segmentos do mercado para estes produtos levou a um rápido crescimento do número deles a ponto de, em 1972 estarem registrados quarenta e nove e em 1977, setenta e cinco "antidistônicos" ${ }^{35}$. No mes 10 período, os neurolépticos passaram de 26 para 29 produtos, os tranquili zantes menores sob controle passaram de 67 para 74 e os anti depressivos passaram de 17 para 18 produtos.

Os "antidistōnicos" conquistaram grande popularidade entre médicos, farmacēuticos e consumidores. o próprio fato de não serem submetidos a controle de venda pode ter contribuido para a crença de que são "calmantes fracos" e inócuos, apesar de, Erequentemente, conterem a mesma quantida de de psicotrópicos por comprimido que os produtos controlados. São vários os exemplos de laboratórios farmacêuticos que comercializam por exemplo, o mesmo produto A com o nome de "Produto A" e "Produto A-Antidistônico"; o pri meiro, contendo $5 \mathrm{mg}$ de diazepan é sujeito a controle de recei tuário e o segundo contendo os mesmos $5 \mathrm{mg}$ de diazepan associa do a pequenas doses de ergotamina e hometropina, ou ergotamina e propantelina é de venda livre. o mesmo tipo de procedimento é observado com medicamentos contendo lorazepan ou oxazepan. Não faltou, inclusive, uma indūstria farmacêutica que, em 1976 , lançou um "hipnōtico antidistōnico" à base de nitrazepan; do ponto de vista médico é muito difícil encontrar lógica nesta associação e somente o interesse comercial de dispor o mercado de um hipnótico de venda livre pode fazer-nos compreender o raciocinio daquela indústria.

A participação dos diversos grupos de medi camentos psicotrópicos no mercado brasileiro pode ser observa da na Tabela 4 .

Verifica-se um substancial crescimento de 
TABELA 4 - VALOR DAS VENDAS EM FARMACIAS COMERCIAIS DE DIVERSOS GRUPOS DE MEDICAMENTOS PSICOTROPICOS NO MERCADO BRASILEIRO, 1972 - 1977 (Valores expressos em milhares de dólares).

A-3C: Antiespasmódicos Gastrointestinais

e Anticolinérgicos em associação com Tranquilizantes ("Antidistônicos")

$$
\begin{array}{llllll}
7.800^{100} & 10.058^{129} & 15.491^{199} & 19.735^{253} & 20.536^{263} & 22.132^{284} \\
33,8 & 36,8 & 38,8 & 40,5^{28} & 42,6 & 40,8
\end{array}
$$

N-5A2: Tranquilizantes menores (Ansiolitt $\cos )$

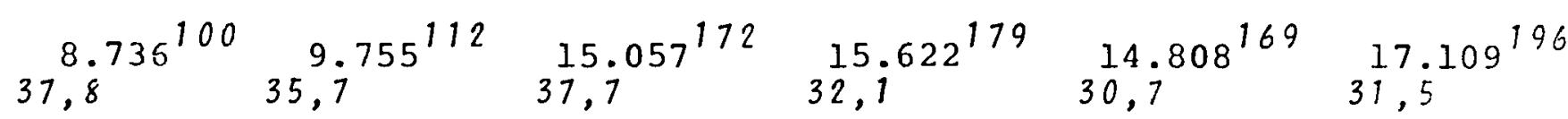

N-5Bl: Hipnóticos/Sedativos não barbitūri cos puros

$$
\begin{array}{llllll}
1.461 & 1.521^{104} & 2.239^{153} & 3.368^{230} & 3.119^{213} & 4.046^{277} \\
6,3 & 5,6 & 5,6 & 6,9^{2} & 6,5 & 7,4
\end{array}
$$

N-5B2: Associações Hipnóticos/Sedativos não barbitūricos

$$
\begin{aligned}
& \begin{array}{llllll}
1.686^{100} & 2.013^{119} & 2.256^{134} & 2.282^{135} & 1.851^{110} & 1.419^{84}
\end{array}
\end{aligned}
$$

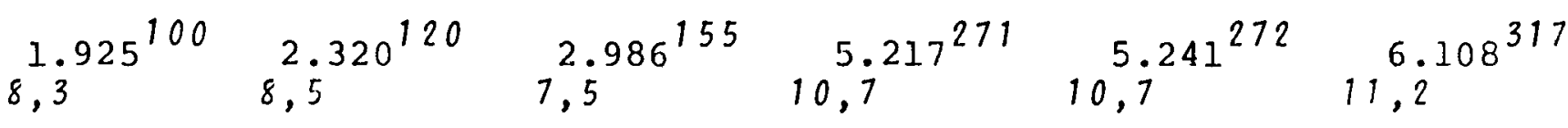

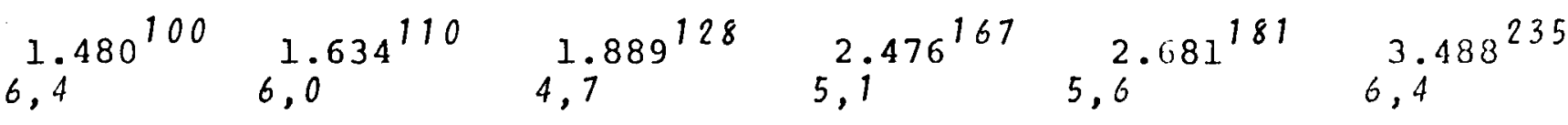

N-5Al: Neurolépticos

$\mathrm{N}-6 \mathrm{~A}: \quad$ Antidepressivos

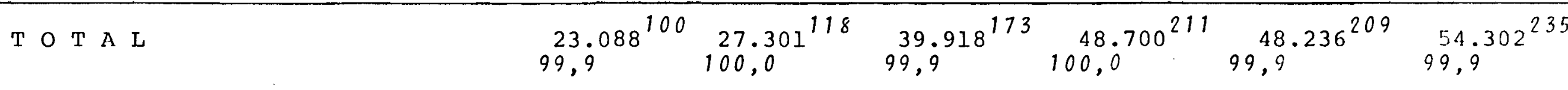

FONTE: Mercado Farmacêutico - Lrasil ${ }^{35}$.

OBS. - Os números apresentados no canto inferior esquerdo de cada valor corresponde ao percentual do grupo nas vendas totais de cada ano; os números apresentados no canto superior direito correpondem ao crescimento das vendas do grupo ano a ano, tomando como base o valor 100 para o ano de 1972. 
vendas de medicamentos psicotrópicos neste período, bem maior do que o crescimento vegetativo da população.

O grupo de neurolépticos $(N-5$ A 1$)$ foi 0

que apresentou maior crescimento no período, devido, principal mente, a um grande crescimento do ano de 1975 para 1976, tendo aumentado significativamente sua participação no mercado.

o crescimentos dos "antidistōnicos" (A-3

só é superado pelo dos neurolépticos, mas observa-se que os primeiros tiveram uma tendēncia mais uniforme de crescimento. Em contrapartida, os tranquilizantes menores (N-5 A 2), sujei tos a controle de receituário, apresentou crescimento bem me nor. A partir de 1974 observa-se que passa a haver um predomí nio do consumo de ansiolíticos de venda livre sobre aqueles de venda controlada; os primeiros, que respondiam por $47 \%$ das vendas de ansioliticos em 1972, passaram a responder por 56\%, em 1977.

o grupo de medicamentos ansioliticos è res ponsável por mais de $70 \%$ das vendas ao longo de todo o período. E, tambēm, digna de nota a queda da parti cipação percentual e o crescimento negativo do grupo das asso ciações de hipnōticos/sedativos não barbitūricos (N-5 B 2); a queda nas vendas observada a partir de 1976 é, provavelmente, decorrente da proibição da comercialização de produtos que continham metaqualona.

Finalizando, cabe a observação de que a grande peculiaridade do mercado brasileiro de medicamentos psicotrópicos é o fato de que os"antidistōnicos", igualmente existentes em outros países, podem ser adquiridos livremente sem a obrigatoriedade de apresentação de receita médica e sem se submeter aos rigores de nossa legislação sobre comercializâ ção de medicamentos psicotrópicos. Ao que tudo indica, esta 
particularidade traduz a convergência de interesses de médicos, pacientes, farmacêuticos e indústria farmacêutica como aponta MULLER ${ }^{45}$. E possível que o maior beneficiário deste estado de coisas seja a indústria farmacêutica e que o prejuízo, a cu. to prazo, recaia sobre o consumidor e a longo prazo, sobre a sociedade. 
2. OBJETIVOS 
Os objetivos deste trabalho são:

a) determinar a prevalència minima do consumo de me dicamentos psicotrópicos no período de um ano pela população de 16 ou mais anos de idade residente no Distrito de são Paulo;

b) determinar a incidência e prevalência nos 30 dias que antecederam a entrevista do consumo de medicamentos psico trópicos pela população de 16 ou mais anos de idade residente no Distrito de São Paulo;

c) analisar os padrões de consumo de medicamentos psicotrópicos bem como os motivos para seu uso, as fontes de indicação e os principais tipos de medicamentos consumidos;

d) descrever algumas características sócio-demográfí cas dos indivíduos consumidores de psicotrópicos (idade, sexo, estado civil, grau de instrução e condições de habitação) e compará-las às dos indivíduos que não consomem estes medicamen tos.

O trabalho tem um caräter eminentemente descritivo buscando una primeira abordagem do problema do con sumo de medicamentos psicotrópicos. A pesquisa de variáveis re lacionadas a ele viu-se, de alguma forma, limitada pelas carac terísticas de um inquérito epidemiológico domiciliar onde se contou com informantes-chave em cada unidade familiar; portan to, admitimos que o trabalho não esgota a observação dos di versos fatores intervenientes.

A anālise que é feita sobre a associação entre consumo de psicotrópicos e algumas variāveis tem caráter de formulação de hipóteses explicativas que poderão ser subme 
.64.

tidas a comprovação posteriormente. 
3. MATERIAL E METODO 
Os dados para a elaboração deste trabalho foram, em parte, obtidos daqueles resultantes do "Estudo do: Transtornos Mentais e suas Caracteristicas no Distrito de Sãc Paulo" (daqui para diante referido como "Estudo"). Assim, di versos aspectos da amostragem e do levantamento de dados são comuns àquela pesquisa e jā haviam sido estabelecidos de ante mão. Desta forma, torna-se compulsörio descrever a maior par te da metodologia empregada no "Estudo"*para compreensão e de senvolvimento deste trabalho.

\subsection{AMOSTRA}

O universo amostral do "Estudo" foi consti tuido pela população de dois ou mais anos de idade residente nos 48 sub-distritos que compõem o Distrito de São Paulo (Anexo 2).

A amostra foi determinada por um processo de amostragem estratificada por partilha proporcional segundo o nümero de domicílios de cada sub-distrito**. Com o objetivo de atingir 3.000 domicilios foram sorteados 3.381 endereços, esti mando-se, a priori, que cerca de $10 \%$ deles corresponderiam a casas não incluiveis na amostra (endereços não localizados, ende reços não residenciais e domicilios vazios).

Todo o processo de amostragem foi realiza do em duas etapas sucessivas, cada uma delas cobrindo integral

* Este estudo ainda se encontra em fase de anälise de resulta dos e não tem nerihuma de suas partes publicada.

* O trabalho de amostragem foi realizado pelo Departamento de Epidemiologia da Faculdade de Saúde Püblica da Universidade de Säo Paulo, sob orientação da Dra. Eunice Pinho de Castro Silva. 
mente o Distrito de São Paulo. Na primeira etapa foram sortea cos 1.617 endereços e na segunda etapa, 1.764 endereços. Esta característica do processo de amostragem foi, certamente, um fator que oossibilitou a realização deste trabalho, na medida em que, mesmo após o início do inquérito tornou viável a utili zação de una amostra que abrangesse todo o Distrito de são Pau 10 .

Neste trabalho a unidade amostral referiu-se a todo indivíduo de 16 ou mais anos de idade residente no domicillio visitado, exceto na análise das condições de habita Ção, onde a unidade amostral considerada foi a familia. Os em pregados domésticos e os membros da família temporariamente ausentes foram considerados residentes.

Dos 1.764 endereços utilizados, $90(5,18)$ correspondiam a endereços comerciais, $67(3,8 \%)$ a domicilios vagos e $52(2,9 \%)$ não foram localizados. Restaram, portanto, 1.521 domicilios incluiveis na amostra.

\subsection{LeVAntamento DE Dados}

\section{o "Estudo" foi realizado em quatro etapas,}

a saber:

a) "fase de rastreamento" - inquérito domiciliar ví sando à obtenção de dados sobre a composição familiar, estado geral de saúde dos membros da unidade familiar e o estado da saúde mental;

b) "avaliação da entrevista de rastreamento" - visou à formulação de um "diagnōstico presuntivo" da presença de transtorno mental em cada individuo da amostra;

c) "fase de confirmação" - inquêrito domiciliar 
(re-visitação domiciliar) com o objetivo de colher dados médi cos que permitissem a confirmação e caracterização do transtor no mental presumido, e realizada sobre uma amostra de 480 indi víduos considerados "doentes" e 120 indivíduos considerados "não-doentes" na fase b);

d) "anālise e avaliação da entrevista de confirmação" - visou à confirmação da suspeita anteriormente formulada e, quando fosse o caso, à classificação diagnóstica do transtorno mental.

Este trabalho utilizou parte das informa çōes obtidas nas fases (a) e (b). portanto, daqui para diante, omitimos o detalhamento das fases (c) e (d).

As informações pertinentes ao consumo de medicamentos psicotrópicos foram obtidas durante a "fase de rastreamento" atravēs de un conjunto de questões introduzidas a partir de julho de 1976 até abril de 1978 .

\subsubsection{FASE DE RASTREAMENTO}

A fase de rastreamento foi realizada atra vés de inquéito domiciliar empregando-se um roteiro de entrevista aberta (Anexo 3) aplicado por assistentes sociais e psi cológos que receberam treinamento especifico sobre os objetivos do levantamento, naneira de apresentação dos objetivos ao en trevistado e noções de psicopatologia:

o roteiro da entrevista foi pré-testado em abril de 1975. As informações solicitadas referiam-se ao perío cio de 12 meses que antecedeu a data da realização da entrevís ta. Se bem se tratasse de uma entrevista aberta ela continha perguntas obrigatórias sobre diversos aspectos que foram consi 
derados como prováveis indicacores da presença de transtornos mentais.

Os entrevistados deviam ser todos os mem bros da familia maiores de 18 anos encontrados no domicílio no momento da entrevista. Eles deviam prestar informações so bre si mesmos a sobre os membros momentaneamente ausentes. Os empregados domésticos podiam ser o informante-chave caso esti vessem residindo com a familia hä, pelo menos, 1 ano. A entre vista devia se desenrolar em clima ameno e livre; os entrevis tadores foram orientados a anotar todas as informações trazidas sobre o relacionamento inter-pessoal dos membros da familia, mesmo que não tivessem sido solicitadas em alguma das questões. Desta forma, a entrevista se enriquecia com citações textuais e opiniões do entrevistado. O entrevistador era livre para fa zer observações pessoais sobre o comportamento do entrevista do, Cesde que, expressasse claramente que se tratava de sua 으 pinião.

Para o levantamento sobre o consumo de me dicamentos psicotrópicos, os entrevistadores foram treinados para aplicar, em aditamento ao roteiro de entrevista domiciliar, um questionário específico sobre o consumo de psicotrópicos (Anexo 4) sempre que o entrevistado referisse o uso de "medica mentos para nervos" nos ültimos doze meses. Dado que o entrevistado e o entrevistador não possuiam condições de distinguir sempre quais medicamentos efetivamente continham substāncias psicotrópicas, os entrevistadores foram orientados a preencher o questionário sempre que se referisse que um dado medicamento fora utilizado "para os nervos", "para dormir", "para acalmar" ou expressão semelhante.

Alēm desta informação, o entrevistador ob teve dados sobre os motivos, a frequência e as doses em que $\underline{e}$ 
ram utilizados os medicamentos, as fontes de indicação e obten ção e a opinião do entrevistado sobre a necessidade da posse de uma receita médica para a aquisição dos mesmos em farmācias.

\subsubsection{AVALIAÇÃO DA ENTREVISTA DE RASTREAMENTO}

A seguir, esta entrevista de rastreamento foi analisada separadamente por dois médicos psiquiatras, os quais, com base nas informações ali contidas fizeram um "diag nōstico presuntivo" da presença de transtorno mental sobre ca da membro da unidade familiar. Para este "diagnóstico" o médi co podia lançar mão de quatro valores de score assim definidos:

score 0 - com base no conjunto das informações colhi das não hã quaisquer elementos que levem à suspeita da presen ça de um transtorno mental;

score 1 - com base no conjunto das informações colhị das não hã suspeita da presença de transtorno mental, embora algum elemento isoladamente se refira a um desequilibrio no desempenho do aparelho psíquico;

score 2 - com base no conjunto das informações colhi das hã elementos para suspeitar da presença de um transtorno mental, embora não se possa afirmar com certeza que este trans torno exista;

score 3 - com base no conjunto das informações colhi das há elementos para afirmar que se está diante de um caso de transtorno mental.

E importante observar que este critério de valoração referiu-se, exclusivamente, ao grau de certeza que o médico tinha ao afirmar seu "diagnóstico" e não levou em con 
sideração a gravidade do transtorno mental em pauta. fssim, for exemplo, tanto um caso de psicose de tipo esquizofrênico em fase aguda como um moderado estado depressivo-ansioso situa cional e transitório poderiam receber o score $\underline{3}$ se o médico tivesse um adequado grau de certeza em seu diagnóstico. Da mes ma forma - e obedecendo o critério de prevalência em um ano um individuo que referisse ter recebido diagnóstico de alcoolis mo há dois ou três anos e que se encontrasse bem adaptado e livre do hábito no último ano, recebeu o score $\underline{0}$.

Os individuos que receberam score $\underline{0}$ ou $\underline{1}$ foram considerados "não doentes" e aqueles que receberam score $\underline{2}$ ou $\underline{3}$ foram considerados "doentes". Sempre que houvesse dis cordâncla entre os dois médicos (isto é, quando os scores não fossem $0-0,0-1,2-2$ ou 2-3) as entrevistas eram remetidas a um terceiro médico-psiquiatra, o qual, separadamente e desonhe cendo as opiniōes dos médicos que o precederam, procedia a no va anālise e dava sua valoração obedecendo aos mesmos critérios e fornecendo, desta maneira, o "voto de Minerva".

As informações sobre o consumo de medicamentos psicotrópicos foram analisadas separadamente pelo autor. Atravēs dos dados coletados foi possivel, na maioria dos ca sos, caracterizar o tipo de medicamento utilizado e o tipo de controle de venda a que estava submetido, a frequēncia e as do ses em que fora utilizado, os motivos para o uso e as fontes de medicação.

\subsection{ANÁLISE DOS RESULTADOS}

Para o cálculo dos indices de prevalência e incidèncla foram utilizados coeficientes por 1.000 habitantes. Na análise das variáveis sōcio-demográficas utilizamos o modelo dos estudos de tipo caso-controle onde a 
população de consumidores de medicamentos psicotrópicos foi considerada o grupo-caso e a população de não consumidores foi considerada o grupo-controle.

\subsubsection{ANÅLISE DO TIPO DE MEDICAMENTOS UTILIZADOS}

Na anālise do tipo de medicamentos psico trópicos consumidos foram considerados aqueles medicamentos que contivessem substâncias predominantemente psicotrópicas os quais foram enquadrados em uma das seguintes categorias consa gradas:

A- Neurolépticos

A.1 - neurolēptico puro

A.2 - neuroléptico em associação em dosagem ansio İtica ("antidistônico")

B- Antidepressivos

B.1 - antidepressivos puros

B.2 - antidepressivos em associação

C- Barbitüricos Anticomiciais

C.1 - barbitúrico puro

C.2 - barbitúrico em associação

D- Tranquilizantes menores (ansioliticos) derivados da benzodiazepina

D.1 - benzodiazepínico puro

D.2 - Senzodiazepínico em associação ("antidistô nico") 
D.9 - benzodiazepínico - sem outra indicação

E- Tranquilizantes menores (ansiolíticos) não deriva dos da benzodiazepina

E.1 - não benzodiazepínico puro

E.2 - não benzodiazepínico em associação ("antí distonicos")

E.9 - não benzodiazepínico - sem outra indicação

F- Hipnóticos benzodiazepínicos

F.1 - hipnótico benzodiazepínico puro

F.2 - hipnótico benzodiazepínico em associação ("hipnótico antidistônico")

G- Sedativos (venda livre)

G.1 - sedativos à base de barbitúricos

G.2 - sedativos $̇$ base de extratos vegetais

G.3 - sedativos à base de associações de barbitū ricos com extratos de vegetais

Observa-se que esta classificação não in clui medicamentos contendo derivados anfetamínicos e que são comumente utilizados para inibição do apetite. Tampouco, foram incluidos medicamentos anticomiciais que não contivessem bar bitúricos.

De outro lado, vimo-nos compelidos a abri gar nesta classificação, para efeito de apuração de resultados, as categorias de "nome ignorado" e "classificação inconclusiva" dado que um número significativo de entrevistados não soube declinar o nome correto do medicamento utilizado. 
Sendo, em grande número, medicamentos sin tomáticos é de se admitir que os ps. cotrōpicos não sejam sem pre utilizados de forma regular, isto $\bar{e}$, com intervalos e do ses constantes. Pode se encontrar três padrōes caracteristicos de consumo de psicotrópicos:

A - regular:- quando o medicamento é utilizado com intervalos e doses constantes. Em geral, os in tervalos variam de 1 a 3 tomadas diárias e as doses, muito variáveis de caso para caso, são prē-fixadas. O padrão regular de consumo é o mais frequentemente encontrado quando o tratamento é feito sob orientação mēdica, mas, tambēm, è lar gamente observado quando da auto-nedicação. Oụ trossim, está associado aos tratamentos com neu rolépticos, antidepressivos e anticomiciais, is to é, de forma geral, aqueles medicamentos que não visam ao alívio imediato da ansiedade;

B - esporádico:- caracteriza-se pela inconstância no intervalo das tomadas; a dose de cada tomada po de ser fixa ou variada. E o padrão de consumo mais caracteristicamente encontrado quando se ob jetiva exclusivamente o alívio sintomático da an siedade. Erequentemente associado à auto-medi cação e, mais raramente, aos tratamentos sob su pervisão médica. Os intervalos entre as tomadas são muito variados podendo ir de 2-3 dias até 1-2 meses; em geral, estes intervalos se situam na faixa de 7 dias. O motivo que leva o usuário 
esporādico a tomar o medicamento é, quase sempre, - alívio imediato da ansiedade para permitir maior bem-estar e/ou induzir o sono.

C - episódico:- a nosso ver, existe um padrão de $\mathrm{Co}_{\perp}$ sumo episódico que frequentemente tem sido con fundido com o esporādico e nele incluído. 0 pa drão episódico tem como característica a tomada em intervalos regulares por poucos dias associa da a episódios de conteúdo desagradável, como, por exemplo, o luto, uma separação, o período que antecede um exame ou una cirurgia ou o perío do de tensão pré-menstrual. Ele não pode ser con siderado regular porque o período de consumo é muito curto e não deve ser confundido com o espo rádico porque estas situações desencadeantes não tendem a ser repetitivas (exceto nos casos de tensão pré-menstrual).

Alguns autores consideram que se deve ob servar um período minimo de 30 dias de uso continuo para carac terizar o padrão regular de consumo ${ }^{7}$. Neste trabalho considera mos como critério básico para definir o padrão regular, a in tencionalidade do consumidor em usā-la regularmente; assim, mesmo que o uso tenha sido interrompido após alguns dias por motivos intervenientes, consideramos um padrão de uso regular sempre que o usuário tivesse, ao iniciar o consumo, demonstra do a intenção de fazê-lo em doses constantes e intervalos re gulares. 
As informaçōes obtidas no levantamento fo ram codificadas de acordo com os manuais apresentados nos An. xos 5 e 6; a seguir foram transcritas em cartōes perfuráveis tipo IBM e processadas eletronicamente*.

\subsection{TRATAMENTO ESTATISTICO}

Foi realizado o teste de hipóteses de di ferença das médias das idades das populações de usuários de psicotrópicos (grupo caso) e não usuārios (grupo controle) u tilizando-se o teste $t$ de student para duas populações com mé dias supostamente diferentes e desvio padrão supostamente $\underline{i}$ gual, com nível de significância de 5\% (alpha $=0,05)$.

No estudo da associação entre consumo de psicotrōpicos e diversas variáveis sócio-āemogrāficas (sexo, estado civil, grau de instrução) foi utilizado o teste do qui quadrado com nível de significância de 5 f $($ alpha $=0,05)$.

Foi ainda utilizado o produto cruzado que nos introduz ao conceito de risco relativo na análise das re lações entre consumo e grau de instrução. O intervalo de con fiança do produto cruzado foi estabelecido para um nivel de significância de 958 .

* O trabalho de processamento eletronico foi gentilmente reali zado pelo Centro de Informática de Bernardini S/A, Industria e Comércio. 
3.6. ESTIMATIVA DO INDICE DE CORREÇÃO PARA INEORMAÇÕES INCOMPLETAS

Dac, que o inquērito abrangeu um periodo

de 12 meses que antecedia a data da entrevista e que as infor mações não eram necessariamente prestadas pelo próprio usuārio do medicamento, era esperado que em certo número de casos o informante não tivesse condições de recordar o nome do medica mento utilizado. Este fato pode colocar uma dúvida sobre a va lidade desta informação, isto é, se o entrevistado não dã o nome do medicamento utilizado, como julgar se se tratava de um medicamento psicotrópico ou não?

Simplesmente desprezar-se as informações todas as vezes em que o entrevistado não soubesse o nome do medicamento poderia levar-nos a uma sub-estimativa dos índices de prevaléncia do consumo; e este erro poderia ser muito gran de, a ponto de invalidar os resultados, na medida em que o in quérito abrangeu um periodo relativamente longo. Por outro la do, admitir que todas as informações "não sabe o nome" se re ferissem a medicamentos que efetivamente fossem psicotrópicos, poderia levar a uma super-estimativa dos indices de prevalência.

Por estas razões optamos pelo aproveitamen to das informações em que o entrevistado não sabia o nome do medicamento, mas calculamos um indice de correção que permitis se estimar a magnitude do erro dos indices de prevalência. Es te indice de correção foi calculado da seguinte maneira: 
sabe o nome do medicamento mas o mesmo não é psicotrō pico

número total de informações em que o entrevistado sabe o nome do medicamento não sabe o nome do medica mento e o mesmo supostamen te nāo é psicotrōpico

nümero total de informações em que o entrevistado não sabe o nome do medicamento

Este cálculo é possível porque sempre que è dado o nome do medicamento o pesquisador tem condições de julgar se ele se enquadra em algum dos grupos descritos no $\underline{i}$ tem $3.3 .1 .$.

o nümero total de medicamentos de nome co nhecido encontrado foi 480 (hā individuos que referiram ter tomado mais de um medicamento); deste total, 73 , isto é, 15,2\% correspondiam a medicamentos que não se enquadravam entre os psicotrópicos. Portanto, estimamos que $19(15,2 \%)$ das 123 infor mações incompletas ("não sabe o nome do medicamento") correspondem a medicamentos não psicotrópjicos.

De outro lado, 109 dos 452 indivíduos que referiam ter consumido psicotrōpicos não souberam declinar o nome do medicamento. Se aplicarmos aquele indice de correção, concluimos que hā nos resultados uma super-estimativa de 17 consumidores $(15,28$ de 109$)$ no total de 452 , isto é, um erro de 3,8\% para mais na estimativa da prevalência.

Outra possivel fonte de erro da estimativa da verdadeira prevalência, e, desta vez, levando a una sub-estị mativa deste valor, é a omissão voluntāria ou involuntária da informação. A omissão involuntária é bastante passível de acon tecer devido à larga abrangência do período de observação (12 meses) e ao fato de as informações terem sido obtidas, indistintamente, do próprio consumidor ou de algum outro membro da familia lo qual poderia ignorar o fato ou não rememorā-lo na 
ocasião da entrevista); dadas as dificuldades metodológicas, este tipo de erro nāo foi medido. De outro lado, a omissão vo luntāria da informação, passível de controle prēvio mas extre mamente di íicil de ser medida a posteriori, pode ocorrer sem pre que o entrevistado tiver algum tipo de reserva frente ao entrevistador.

Acreditamos que os erros que levam à sub-ẹ timativa do indice de prevalência possam ser ainda maiores do que o erro de 3,88 de super-estimativa. Por isso, admitimos que os resultados encontrados possam ser aceitos como a preva lência minima do consumo de medicamentos psicotrópicos. 
4. RESULTADOS E DISCUSSĀO 
Dos 1.521 domicilios visitados e pertencen tes à amo: tra a entrevista foi realizada em 1.345. Em 104 $(6,8 \%)$ a pessoa que atendeu o entrevistador recusou-se a pres tar informações; em $6(0,48)$ alegaram "falta de tempo" o que pôde ser equiparado a uma recusa; e em $57(3,78)$ não foi encon trado qualquer pessoa em casa em três tentativas realizadas em dias diferentes apesar de a casa dar mostras de ser habitada. Ainda, 21 entrevistas realizadas foram inadvertidamente extra viadas.

Nas 1.345 familias computadas foram obtidas informações a respeito de 3.690 indivíduos de 16 ou mais anos de idade, sendo 1.729 homens e 1.961 mulheres. A Tabela 5 mostra a distribuição desta população por idade e sexo.

Em 369 familias $(27,48$ do total) foram en contrados 451 indivíduos $(12,2 \%$ do total) que consumiram medi camentos psicotrópicos no período de 12 meses que antecedeu a data da entrevista, sendo 131 do sexo masculino $(29,08)$ e 320 do sexo feminino $(71,08)$ (Tabela 6).

4.1. PREVALENCIA EM UM ANO DO CONSUMO DE MEDICAMENTOS PSICOTROPICOS

Com base na distribuição por idade e sexo da população amostral e dos usuários de psicotrópicos podemos elaborar coeficientes de prevalência em un ano do consumo de medicamentos psicotrópicos pela população de 16 ou mais anos de idade residente no Distrito de são Paulo para o períndo de julho de 1976 a abril de 1978 (Tabela 7 e Figura 6). 
TABELA 5 - DISTRIBUIÇÃO DA POPULAÇÃO AMOSTRAL POR IDADE E SEXO NO DISTRITO DE SÃO PAULO, 1976 - 1978 .

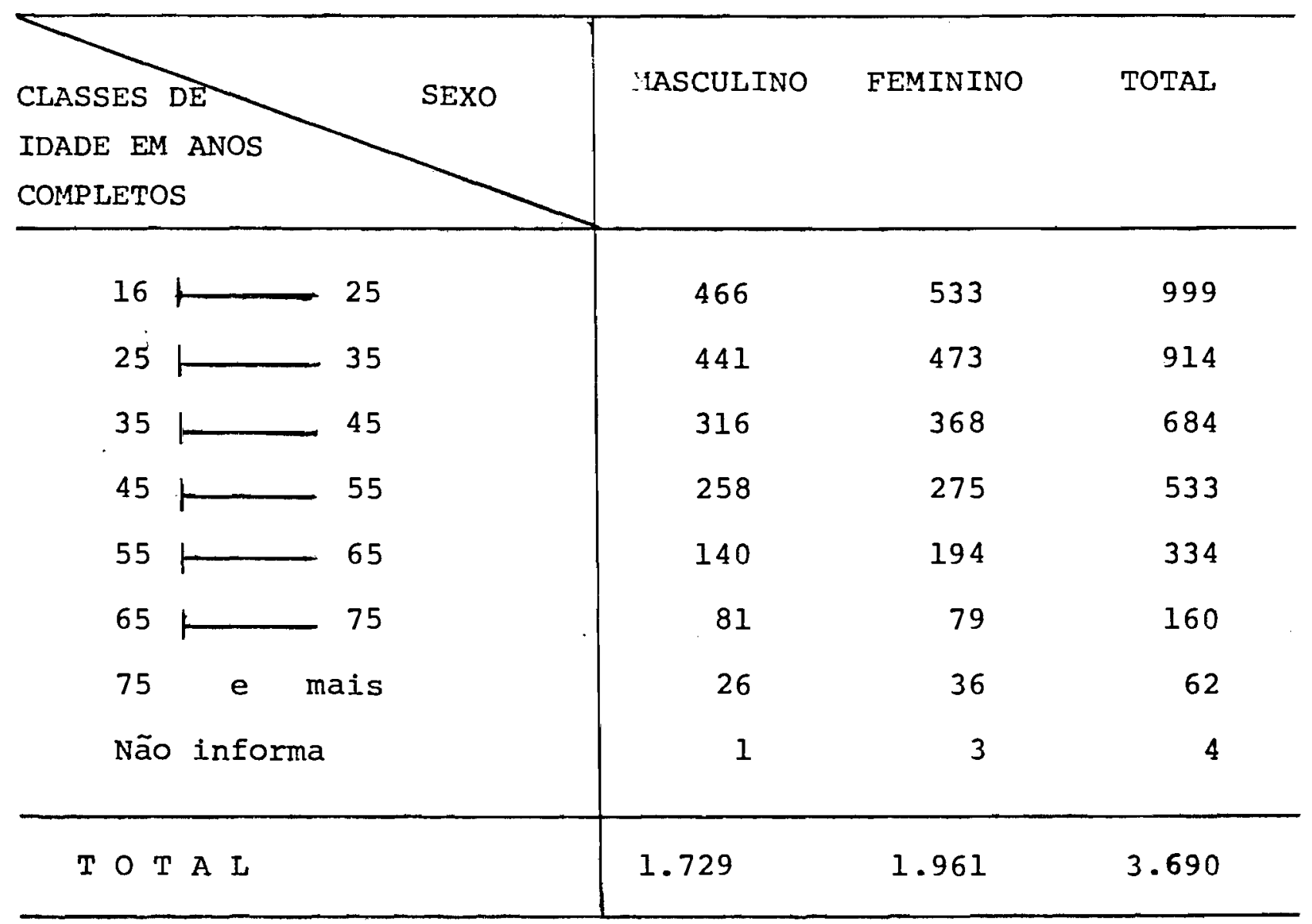

FONTE: Levantamento de dados.

NOTA: Todas as Tabelas que seguem referem-se a população do Dis trito de são Paulo nos anos de 1976 a 1978 . 
TABELA 6 - DISTRIBUIÇÃO DA POPULAÇÃ̄) DE USUĂRIOS DE PSICOTRÓPICOS POR SEXO E IDADE.

\begin{tabular}{|c|c|c|c|}
\hline $\begin{array}{l}\text { CLASSES } \\
\text { DE IDADE EM } \\
\text { ANOS }\end{array}$ & MASCULINO & FEMININO & TOTAL \\
\hline $16 \longmapsto 25$ & 24 & 52 & 76 \\
\hline $25 \vdash 35$ & 28 & 61 & 89 \\
\hline $35 \longmapsto 45$ & 25 & 81 & 106 \\
\hline $45 \longmapsto 55$ & 27 & 56 & 83 \\
\hline $55 \longmapsto 65$ & 14 & 46 & 60 \\
\hline $65 \longmapsto 75$ & 8 & 18 & 26 \\
\hline 75 e mais & 5 & 6 & 11 \\
\hline Não informa & - & - & - \\
\hline$T \circ \mathbf{T} L$ & 131 & 320 & 451 \\
\hline
\end{tabular}

FONTE: Levantamento de dados. 
TABELA 7 - COEFICIENTE DE CONSUMO DE PSICOTROPICOS POR 1.000 HABITANTES POR SEXO E IDADE.

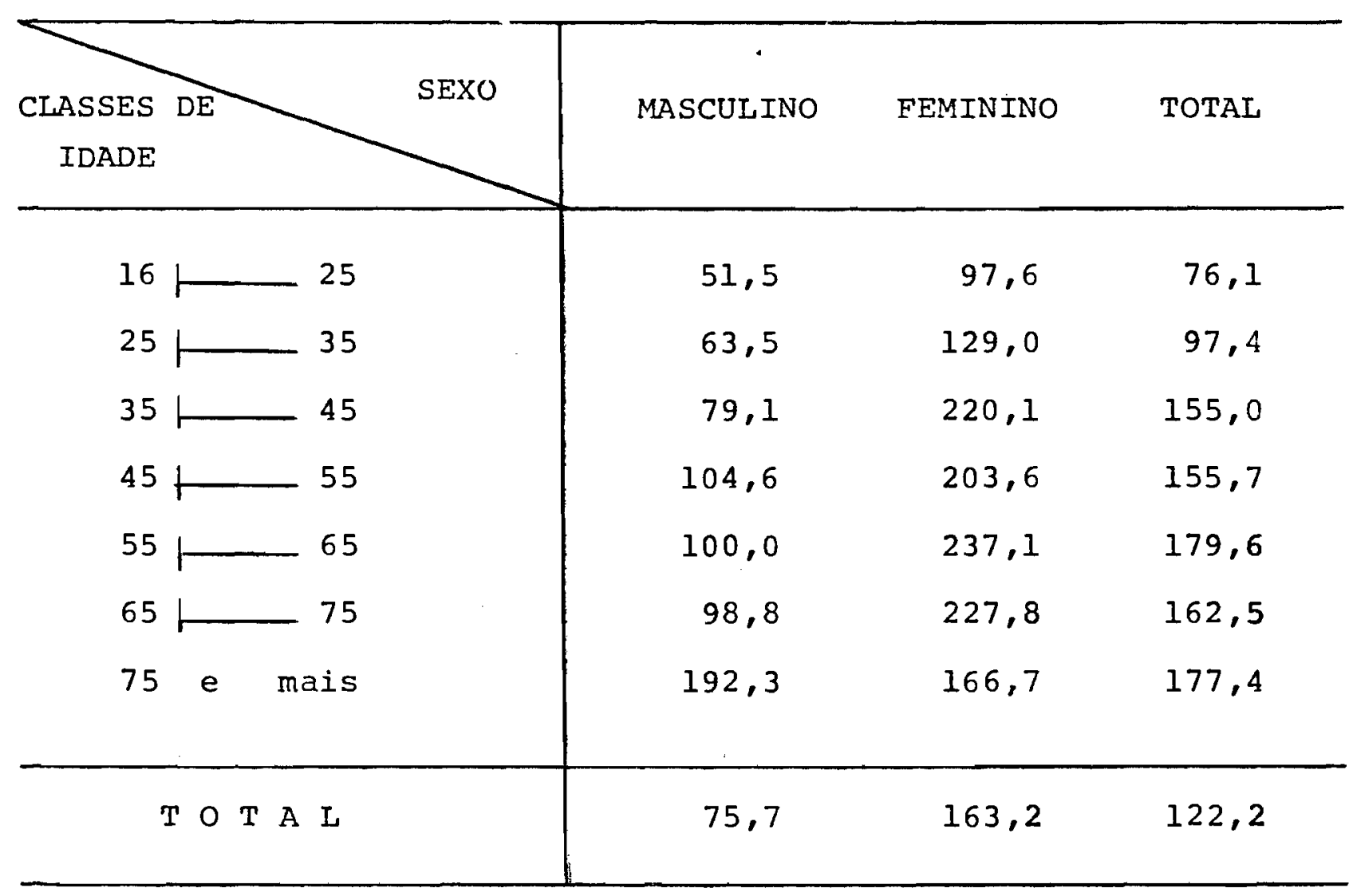

FONTE: Levantamento de dados. 
FIGURA 6 - VARIAÇÃo dOS COEFICIENTES DE CONSUMO DE PSICOTROPICOS SECUNDO IDADE E SEXO PELA POPULÃÇÃO DO DISTRI TO DE SÃo PAULO, 1976 - 1978.

COEF. DE CONSUMO

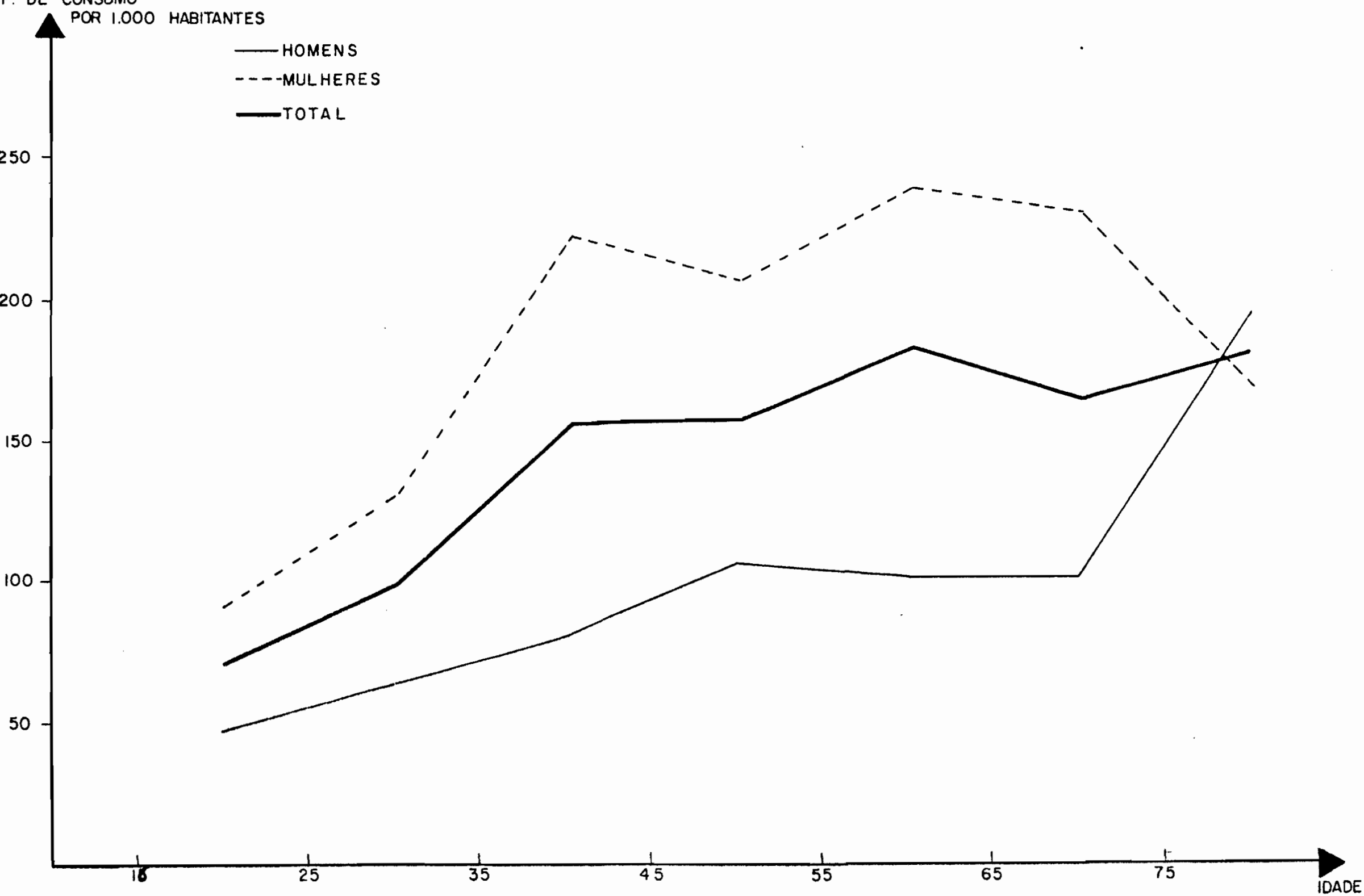

FONTE: Levantamento de dados. 
Os resultados obtidos concordam em grande parte com aqueles encontrados por BALTER et al ${ }^{22}$ em 1971 para nove países europeus. O coeficiente de prevalència de consumo de $122,2 /: .000$ habitantes $(75,7 / 1.000$ para homens e $163,2 / 1.000$ mulheres) é, sem dūvida, elevado e deve situar-se entre os mais altos para os diversos grupos de medicamentos comercializados em nosso meio.

Chama a atenção o fato de o consumo entre as mulheres ser sempre maior do que entre os homens, exceto para a faixa etāria de 75 ou mais anos, quando, praticamente, se equiparam. Entre as mulheres de 35 a 75 anos ele mantém-se sempre acima dos 200/1.000 habitantes enquanto que, para os ho mens, atinge valores próximos a 100/1.000 habitantes somente a partir dos 45 anos de idade. No total, há uma relação de 2,44 mulheres para cada homem que consome este tipo de medicamentos. A súbita queda observada na prevalência do consumo entre mulheres de 75 ou mais anos de idade é, possi velmente, casual e devida à pequena dimensão da amostra para esta faixa etāria.

Esta marcante e constante diferença nos niveis de consumo entre os dois sexos concorda com o que tem sido observado seguidamente em diversos países $22,24,26,27,33$. A atitude das mulheres frente aos medicamentos psicotrópicos é mais permissiva ${ }^{29}$; de outro lado, a crença de que o apelo ao psicotrópico é um sinal de fraqueza ${ }^{30}$ e a maior possibilida de que tem de recorrer a outras formas de alivio da ansiedade, como o àlcool, por exemplo, podem responder pelo menor consumo pelo sexo masculino.

Cabe interrogar se a suposta atitude nega tiva do sexo masculino frente ao uso de medicamentos psicotró picos não seria responsável por uma sonegação de informações 
ao entrevistador. Contudo, a metodologia empregada neste trabalho - o informante foi o membro da familia localizado en ca sa no momento da entrevista e não, necessariamente, o indiví duo objeto das informações - ver, casualmente, contribuir pa ra reduzir a influência deste possível fator de erro, pois em pelo menos $921(68,5 \%)$ das familias entrevistadas o informan te era do sexo feminino e podemos raciocinar que elas teriam menor tendência a sonegar a informação do uso destes medica mentos pelos membros masculinos da família.

\subsection{INCIDENCIA E PREVALENCIA DO CONSUMO DE MEDICAMENTOS} PSICOTROPICOS EM 30 DIAS

o tipo de entrevista empregada permitiu-nos detectar os novos usuārios de medicamentos psicotrópicos no período de 30 dias que antecedeu a data da entrevista. A Tabe la 8 mostra a distribuição destes indivíduos por sexo e idade; com base na distribuição da população amostral obtivemos o coe ficiente de incidência do consuno de medicamentos psicotrópicos em 30 dias de $7,6 / 1.000$ habitantes. Ainda aqui se repete a pre dominância do sexo feminino $(9,2 / 1.000$ habitantes) sobre o se xo masculino $(5,8 / 1.000$ habitantes). A pequena magnitude dos números não recomenda o cālculo deste coeficiente nas diversas faixas etārias.

Foi, tambēm, possível detectar 313 indiví duos que nos 30 dias que antecederam a entrevista, fizeram uso de algum medicamento psicotrópico o que nos dá um coeficiente de prevalência no mês de $84,8 / 1.000$ habitantes (não foi feita a distribuição por idade e sexo).

Estes dados padecem de impossibilidade de comparação no momento, posto que em todos os trabalhos consul 
.86.

TABELA 8 - DISTRIBUIÇÃO DOS NOVOS USUĂRIOS DE PSICOTRÓPICOS (ŨLTIMOS 30 DIAS) POR IDADE E SEXO.

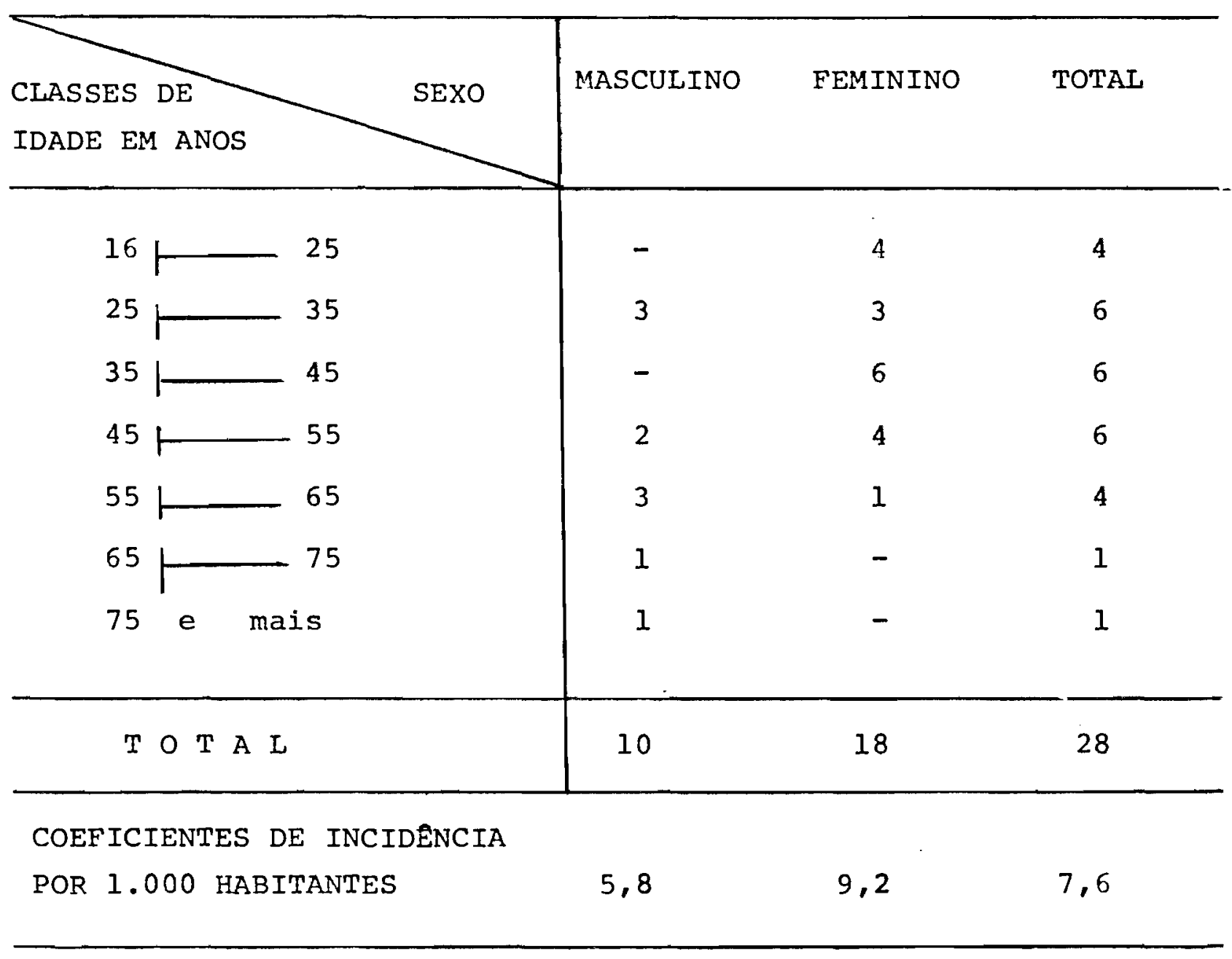

FONTE: Levantamento de dados. 
tados os autores não se preocuparam en meäir a incidéncia e prevalência no mês, restringindo-se à medida da prevalência em um ano. De qualquer forma, nota-se que a prevalência ainda conserva valores elevados quando medida no espaço de 30 dias, a relação entre a prevalència no último ano e a prevalência no último mês é 0,69 . Por outro lado, a relação entre a incidência e a prevalência no último mès é igual a 0,08 . Isto vem in dicar que o consumo destes medicamentos deve se dar por espaço de tempo relativamente longo.

\subsection{DISTRIBUIÇÃO GEOGRÁFICA DA PREVALENCIA DO CONSUMO DE MEDICAMENTOS PSICOTRÓPICOS}

Utilizando-se do agrupamento dos sub-dis tritos de São Paulo em 6 áreas homogêneas, conforme o propos to pela Secretaria de Economia e Planejamento ${ }^{56}$, calculamos os coeficientes de prevalência de consumo de medicamentos psicotró picos para estas 6 áreas separadamente. A Tabela 9 apresenta os valores encontrados em cada uma das áreas.

\section{Cumpre salientar que o critērio utilizado} para o agrupamento $\in m$ áreas homogêneas leva em consideração as seguintes variáveis ${ }^{56}$ : renda familiar, saneamento básico, den sidade demográfica, crescimento populacional, uso residencial do solo urbano e mortalidade proporcional. A numeração das á reas se dā em ordem decrescente de qualidade de vida.

Observa-se uma tendência decrescente dos coeficientes de prevalência de consumo da área l para a área 6. Reagrupando-se as 6 áreas, verifica-se que a prevalência de consumo nas Áreas 1,2 e 3 é $62 \%$ superior à prevalência das Areas 4, 5 e 6 . 
TABELA 9 - PREVALENCIA EM UM ANO DO CONSUMO DE MEDICAMENTOS PSICOTROPICOS NO DISTRITO DE SÃO PAULO, SEGUNDO A DISTRIBUIÇÃO DOS SUB-DISTRITOS EM గREAS HOMOGENEAS, 1976 - 1978.

$\begin{array}{cccc} & & \text { NGMERO DE USUR̈TOS DE } & \text { POPULAÇÃO COEFICIENTE DE PREVA- } \\ \text { AREAS HOMOGENEAS } & \text { PSICOTROPICOS } & \text { AMOSTRAL LENCIA DE CONSUMO POR } \\ & & \text { L.000 HABITANTES }\end{array}$

AREA 1 - Jardim Amērica, Jardim Paulista, Indianópolis, Perdizes, Pinheiros, Vila Madalena, Cambuci.

ÁREA 2 - Cerqueira Cezar, Santa Cecília, Aclimação, Be la Vista, Liberdade, Alto da Móoca.

ÁREA 3 - Consolação, Vila Mariana, Bom Retiro, Belenzí nho, Barra Funda, Santa Efigênia, Móoca, Pari, sē, Brās.

ÅREA 4 - Ibirapuera, Lapa, Saủde, Santana, Tatuapé, Ipiranga.

ÁREA 5 - Butantã, Casa Verde, Penha de França, Tucurü vi, Vila Maria, Limão, Vila Formosa, Vila Ma tilde, Jabaquara, Vila Prudente, Vila Jaguara, Nossa Senhora do $\delta$, Cangaiba, Vila Guilherme

AREA 6 - Santo Amaro, Pirituba, Capela do Socorro, Vi la Nova Cachoeirinha, Brasilândia 
Estas diferenças possivelmente se devem a um maior acesso aos recursos médicos por parte da população residente nas āreas de melhor qualidade de vida, mas não se pode, através destes dados, fazer qualquer infe-ēncia a respei to do nível de stress nas populaçōes das diversas āreas geogrā ficas.

\subsection{PADRÕES DE CONSUMO DE MEDICAMENTOS PSICOTRÖPICOS}

As Tabelas 10 e 11 mostram a distribuição dos 451 usuārios de psicotrōpicos detectados no levantamento segundo o padrão de consumo observado nos ültimos 12 meses e nos últimos 30 dias, respectivamente.

Os resultados se assemelham e mostram uma larga predominância do padrão regular de consumo que responde por mais da metade dos casos. o padrão esporádico de consumo com $38,1 \%$ e $42,5 \%$ tem magnitude expressiva e, como veremos a diante na anālise das fontes de indicação, é provāvel que este ja largamente associado a tratamentos sob orientação médica. Os baixos valores encontrados para o padrão episódico $(4,48$ e 1,0\%) estão de acordo com a sua característica principal, isto è, eventos episōdicos e não repetitivos.

No estudo multi-nacional coordenado por BALTER, LEVINE e MANHEIMER 22 em nove paises europeus, os valo res encontrados para o padrão regular de consumo variaram de 30,08 a 64,08 não tendo se observado diferenças significativas entre os sexos. Como sugerem aqueles autores, o padrão regular è bem mais significativo como critērio de estimativa da exten são da prevalēncia do consumo de medicamentos psicotrópicos pela população do que "a mera tomada de uma droga por uns pou 


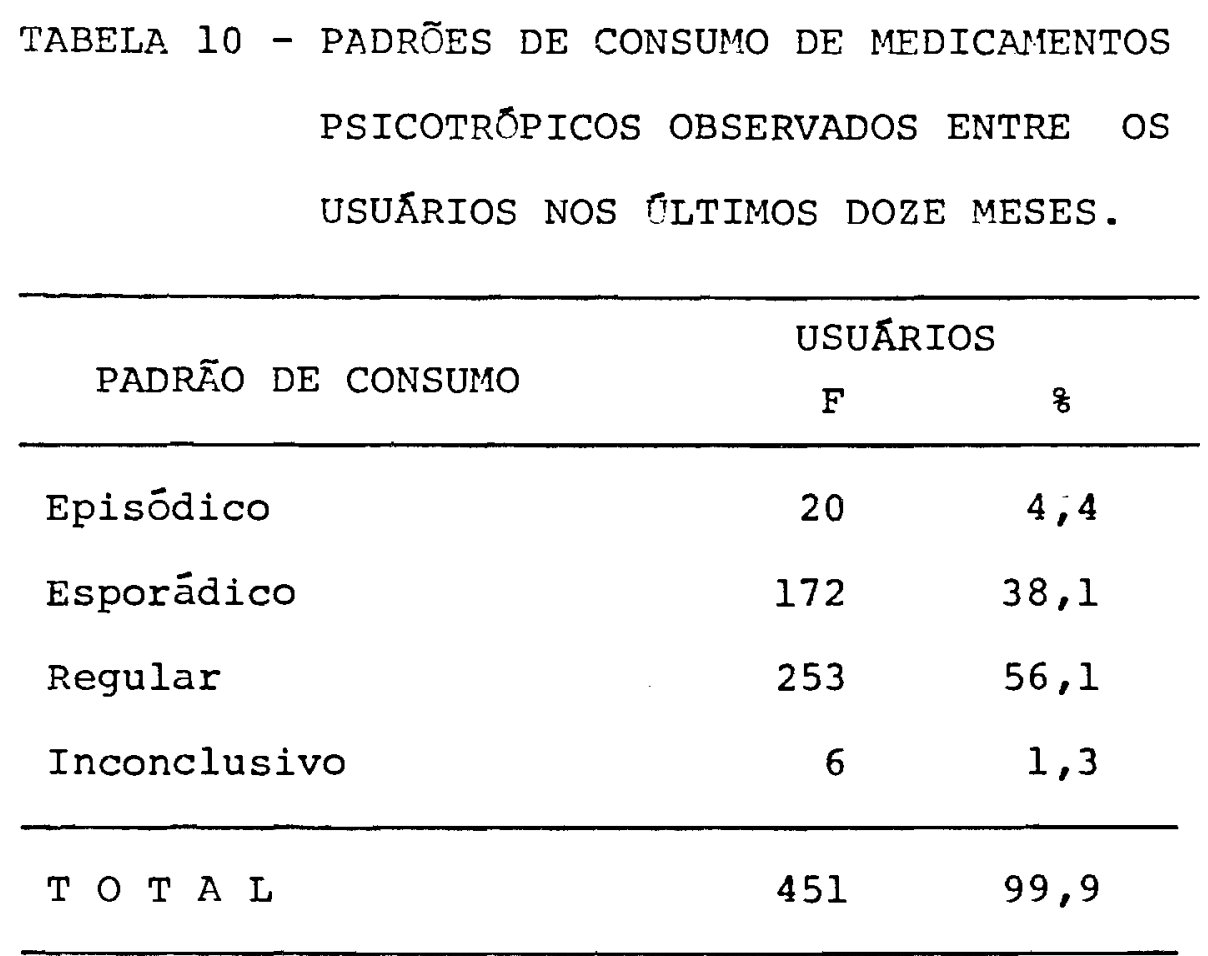

FONTE: Levantamento de dados.

TABELA 11 - PADRÕES DE CONSUMO DE MEDICAMENTOS PSICOTRÓPICOS OBSERVADOS ENTRE OS USUÃRIOS NOS ULTIMOS 30 DIAS.

\begin{tabular}{lcc}
\hline & \multicolumn{2}{c}{ USUÃRIOS } \\
PADRÃO DE CONSUMO & F & $\%$ \\
\hline Episódico & 3 & 1,0 \\
Esporádico & 133 & 42,5 \\
Regular & 171 & 54,6 \\
Inconclusivo & 6 & 1,9 \\
\hline T O T A L & 313 & 100,0 \\
\hline
\end{tabular}

FONTE: Levantamento de dados. 
cos dias em alguma época do ano". Acreditamos que a distinção feita entre os padrões episódico e esporádico ajuda a compreen der melhor o significado do padrão esporádico no compto geral da prevalêcia, pois exclui "a mera tomada de uma droga por uns poucos dias em alguma época do ano" (padrão episódico"), deixando restar o contingente daqueles que usam psicotrópicos com maior frequência e em maior quantidade durante $o$ ano e que representam importante parcela de usuārios. O usuārio esporāii co, apesar de menos "assỉduo" do que o usuário regular parece ser bastante "fiel" ao medicamento, passando largos periodos de tempo em sua situação de consumidor enquanto um usuārio re gular pode cessar o consumo tão logo termine um tratamento médi co. Assim sendo, um usuário esporädico que tome, por exemplo, um comprimido hipnótico a cada cinco dias em média terá tomado, ao cabo de um ano, tantas doses quantas tomou um indivíduo que fez uso regular durante dois meses e meio. Em termos gerais de consumo, estes dois indivíduos tem o mesmo peso.

\section{A Tabela 12 ilustra as mudanças de situa-} ção do padrão de consumo dos 451 usuários observados. Verifi ca-se que de 231 individuos que referiram padrão regular de consumo nos ültimos 11 meses continuavam a consumir regularmen te nos últimos 30 dias, $2(0,9 \%)$ mudaram para o padrão esporā dico e 81 (35,18) jā haviam abandonado a medicação. Outrossim, dos 166 que referiram padrão esporádico de consumo, $125(75,38)$ ainda se utilizaram esporadicamente do medicamento nos ültimos 30 dias e $40(24,18)$ não se utilizaram dele. Note-se que, den tre estes ültimos, uns efetivamente devem ter deixado de ser usuārios e outros simplesmente não tomaram porque seu interva lo entre tomadas deve ter sido maior do que 30 dias. 
TABELA 12 - VARIAÇÕES OBSERVADAS NOS PADRÕES DE CONSUMO DE MEDICAMENTOS PSICOTROPICOS NO PERIODO DE UM ANO.

\begin{tabular}{|c|c|c|c|c|c|c|}
\hline $\begin{array}{lr}\text { CONSUMO } \\
\text { NOS GLTIMOS } \\
30 \text { DIAS }\end{array} \quad \begin{array}{r}\text { CONSUMO NOS } \\
\text { ULTIMOS II }\end{array}$ & $\begin{array}{c}\text { NÃO USOU ANTES } \\
\text { DOS ULTIMOS } 30 \\
\text { DIAS }\end{array}$ & EPISODDICO & ESPORÃDICO & REGULAR & INCCON LUSIVO & TOTAL \\
\hline Não usou & - & 1.7 & 40 & 81 & - & 138 \\
\hline Episōdico & - & 3 & - & - & - & 3 \\
\hline Esporädico & 6 & - & 125 & 2 & - & 133 \\
\hline Regular & 22 & - & 1 & 148 & - & 171 \\
\hline Inconclusivo & - & - & - & - & 6 & 6 \\
\hline $\mathrm{T} O \mathrm{~T} A \mathrm{~L}$ & 28 & 20 & 166 & 231 & 6 & 451 \\
\hline
\end{tabular}

FONTE: Levantamento de dados. 
4.5. TIPOS DE MEDICAMENTOS CONSUMIDOS

$\bar{A}$ entrevista pediu-se ao entrevistado que declinasse o nome de todos os medicarentos psicotrópicos uti lizados quer simultaneamente, quer sucessivamente durante $0 \underline{a}$ no precedente. Dos 451 individuos, $388(86,0 \%)$ referiram ter $\underline{u}$ tilizado um só medicamento, $48(10,6 \%)$ referiram dois medicamen tos e $15(3,3 \%)$ referiram très medicamentos usados simultanea ou sucessivamente. Desta forma, foram referidos 530 produtos, dos quais 123 de nome ignorado; como argumentado no item 3.6., admitimos que 19 deles não sejam psicotrópicos; para os 104 restantes vamos admitir que sua distribuição seja igual àquela dos 407 produtos de nome conhecido.

o Quadro 2 mostra a distribuição dos prodū tos de nome conhecido, de acordo com as categorias descritas no item 3.3 .1$.

Observa-se uma predominância evidente dos derivados da benzodiazepina que sozinhos respondem por $72,8 \%$ do consumo. Os neurolépticos puros (Al), os antidepressivos (B) e os barbitúricos anticomiciais (C), em geral associados a tratamentos sob estrita orientação médica, e sem o objetivo de alivio imediato da arsiedade, respondem por, somente, 12,48 do total de produtos consumidos. Por outro lado, os neurolépti cos em associaçăo (antidistōnicos), os ansiolíticos (D,E), se dativos (G) e hipnōticos (F) indicados, em geral, para alivio sintomātico são responsāveis por $86,55 \%$ do total do consumo.

Estes ültimos são, frequentemente utiliza dos sob a forma de produtos livres de controle de receituário (antidistōnicos, sedativos) cuja aquisição é bastante facilita da. A Tabela 13 mostra que, pelo menos, $62,6 \%$ deles são desti tuidos de qualquer tipo de controle para sua aquisição. São os sedativos à base de barbitúricos e/ou extratos de vegetais e 
QUADRO 2 - TIPOS DE MEDICAMENTOS CONSUMIDOS PELA POPULAÇÃO DO DISTRITO DE SÃo PAULO, 1976 - 1978.

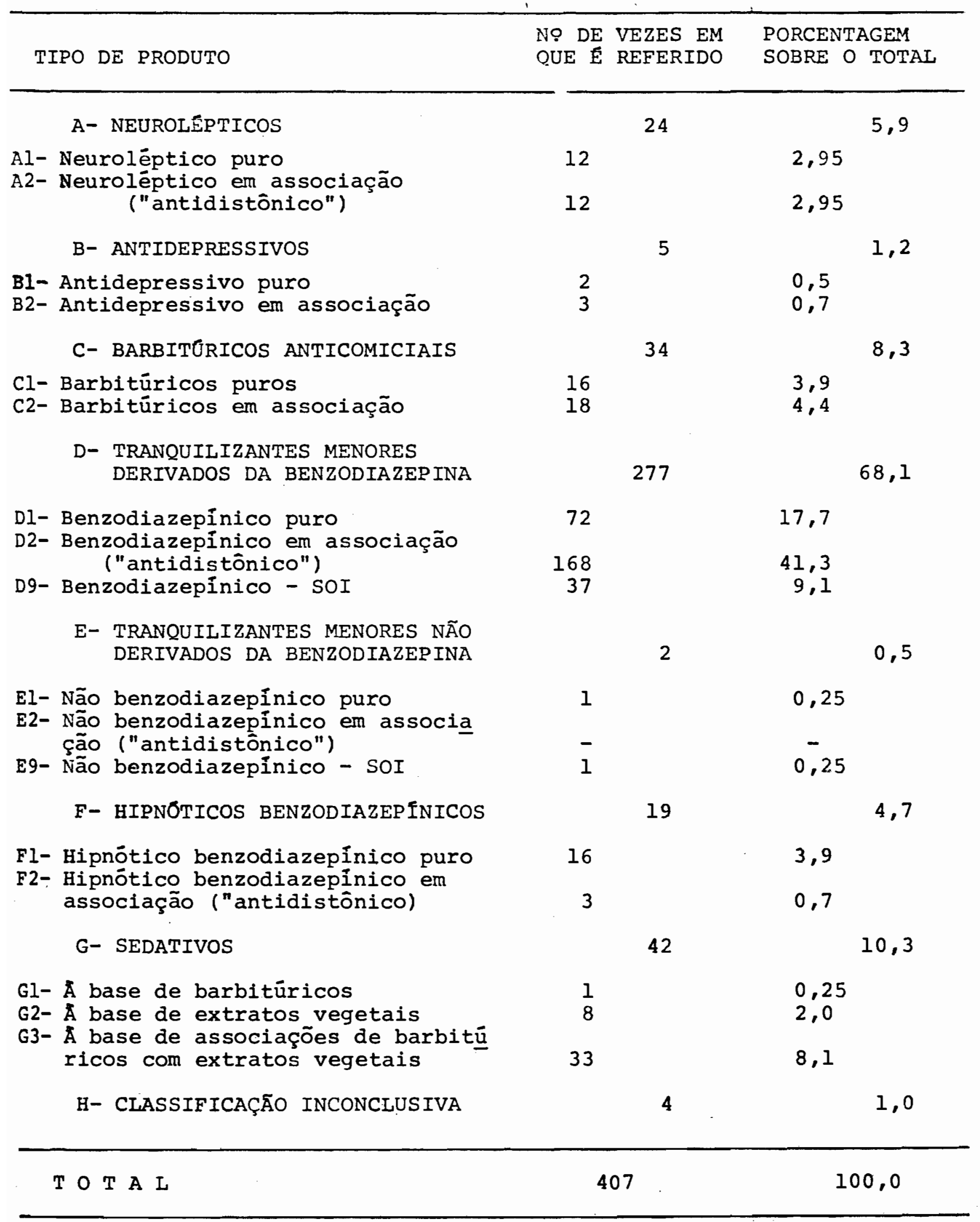

FONTE: Levantamento de dados. 
os "antidistônicos" à base de haloperidol em baixa dosagem ou benzodiazepinicos em dosagens convencionais.

TABELA 13 - FORMA DE AQUISIÇÃO DE ANSIOLITICOS, SEDATIVOS E খIㅌ NÓTICOS NÃO BARBITÚRICOS UTILIZADOS PELA POPULAÇÃO DO DISTRITO DE SÃO PAULO, 1976 - 1978.

\begin{tabular}{lcc}
\hline FORMA DE AQUISIÇÃo & $\begin{array}{c}\text { NUMERO DE PRODUTOS } \\
\text { REFERIDOS }\end{array}$ & $\begin{array}{c}\text { PORCENTAGEM SOBRE } \\
\text { O TOTAL }\end{array}$ \\
\hline $\begin{array}{l}\text { Com controle de recei } \\
\text { tuário (DI, El, F1) }\end{array}$ & 89 & 26,2 \\
Sem controle de recei & & 62,6 \\
tuário (D2, E2, F2, G) & 213 & 11,2 \\
Inconclusivo & 38 & 100,0 \\
\hline
\end{tabular}

FONTE: Levantamento de dados.

A preferência pelos produtos livres de con trole de receituārio existe - como veremos adiante - não só por parte dos que se auto-medicam mas, também, por parte dos médicos clínicos gerais.

BLACKWELL ${ }^{23}$ em 1973 constatava que $51 \%$ dos medicamentos psicotrópicos vendidos nos EUA eram ansiolíticos derivados da benzodiazepina, essencialmente o clorodiazepóxi do e o diazepan; $12,8 \%$ eram neurolépticos e $14 \%$ antidepressivos.

$$
\text { PARRY et al }{ }^{33} \text { apontam que os tranquilizan }
$$
tes menores correspondem à grande maioria dos medicamentos con sumidos pelos adultos nos EUA e que, o seu consumo entre as mulheres, bastante elevado, pode ser apontado como o responsā vel pelas maiores taxas de prevalència de consumo de todos os 
psicotrópicos entre mulheres do que entre homens. MELLINGER et al 24 tambēm apontam a predominância dos tranquilizantes menores e seu maior uso entre as mulheres mostrando que elas os consomem 1,5 mais vezes do que os homens.

Cabe uma referência particular ao volume de consumo dos produtos comercialmente conhecidos como "anti distônicos"; trata-se, como vimos, de uma forma disfarçada de colocação no mercado de derivados benzodiazepinicos que, ori ginalmente, deveriarn estar sujeitos a controle de venda. Pois bem, vemos que eles correspondem a, pelo menos, 42,08 (catego rias D2 e F2) de todos os produtos consumidos ou, ainda, a 57,8\% do total do consumo de benzodiazepínicos; estes valores concor dam de maneira marcante com aqueles apresentados na Tabela 4 (pāg. 60).

De outro lado, è de se supor que em diferen tes grupos etários se encontrem diferenças com relação ao tipo de medicamento consumido. A Tabela 14 mostra que os neurolépti $\cos e$ anticomiciais são usados com maior frequência pelos in divíduos mais jovens enquanto os hipnóticos e sedativos são mais usados pelos indivíduos mais velhos. Observa-se,tambëm, nos três grupos etários un consumo crescente dos ansiolíticos, hipnóticos e sedativos $(78,8 \%, 89,8 \%$ e $90,6 \%)$, não havendo di ferença significativa entre os dois grupos mais velhos.

Pela Tabela 15 podemos verificar que, den tre os medicamentos de aquisição livre, o grupo de 55 e mais anos de idade consome com maior frequência os sedativos à ba se de barbitúricos e extratos vegetais, enquanto os dois gru pos mais jovens dão preferência aos psicofármacos modernos. Estes valores parecem refletir diferentes atitudes entre os grupos etários. Recorde-se que os benzodiazepínicos foram in troduzidos no mercado brasileiro a partir de 1965 e que, até 
TABELA 14 - TIPOS DE MEDICAMENTOS USADOS SEGUNDO O GRUPO ETÁRIO DOS CONSUMIDORES

\begin{tabular}{|c|c|c|c|c|c|c|}
\hline $\begin{array}{lc}\text { TIPO DE } & \text { GRUPO DE } \\
\text { MEDICAMENTO } & \text { IDADE }\end{array}$ & 16 & $\begin{array}{c}-35 a n o s \\
8\end{array}$ & $\begin{array}{c}35 \\
F\end{array}$ & $\begin{array}{c}55 \approx \text { nos } \\
8\end{array}$ & 5 & $\begin{array}{r}\text { mais } \\
z\end{array}$ \\
\hline Neurolēpticos & 6 & 4,5 & 5 & 3,4 & 1 & 1,2 \\
\hline Antidepressivos & 3 & 2,3 & 1 & 0,7 & 1 & 1,2 \\
\hline Anticomiciais & 19 & 14,4 & 9 & 6,1 & 6 & 7,0 \\
\hline Ansioliticos (com controle) & 24 & 18,2 & 27 & 18,4 & 22 & 25,6 \\
\hline Hipnóticos & 4 & 3,0 & 6 & 4,1 & 6 & 7,0 \\
\hline "Antidistônicos" & 64 & 48,5 & 84 & 57,1 & 35 & 40,7 \\
\hline Sedativos & 12 & 9,1 & 15 & 10,2 & 15 & 17,4 \\
\hline $\mathrm{T} \circ \mathrm{TAI}$ & 132 & 100,0 & 147 & 100,0 & 86 & 100,0 \\
\hline
\end{tabular}

FONTE: Levantamento de dados.

OBS: Não estão incluidos os grupos D9, E9 e H. 
então, os barbitúricos e extratos vegetais gozavam de boa acei tação por parte de médicos e pacientes.

TABELA 15 - CONSUmo DE "ANTIdistônicos" E SEDATIVOS SEgundo A IDADE DOS CONSUMIDORES.

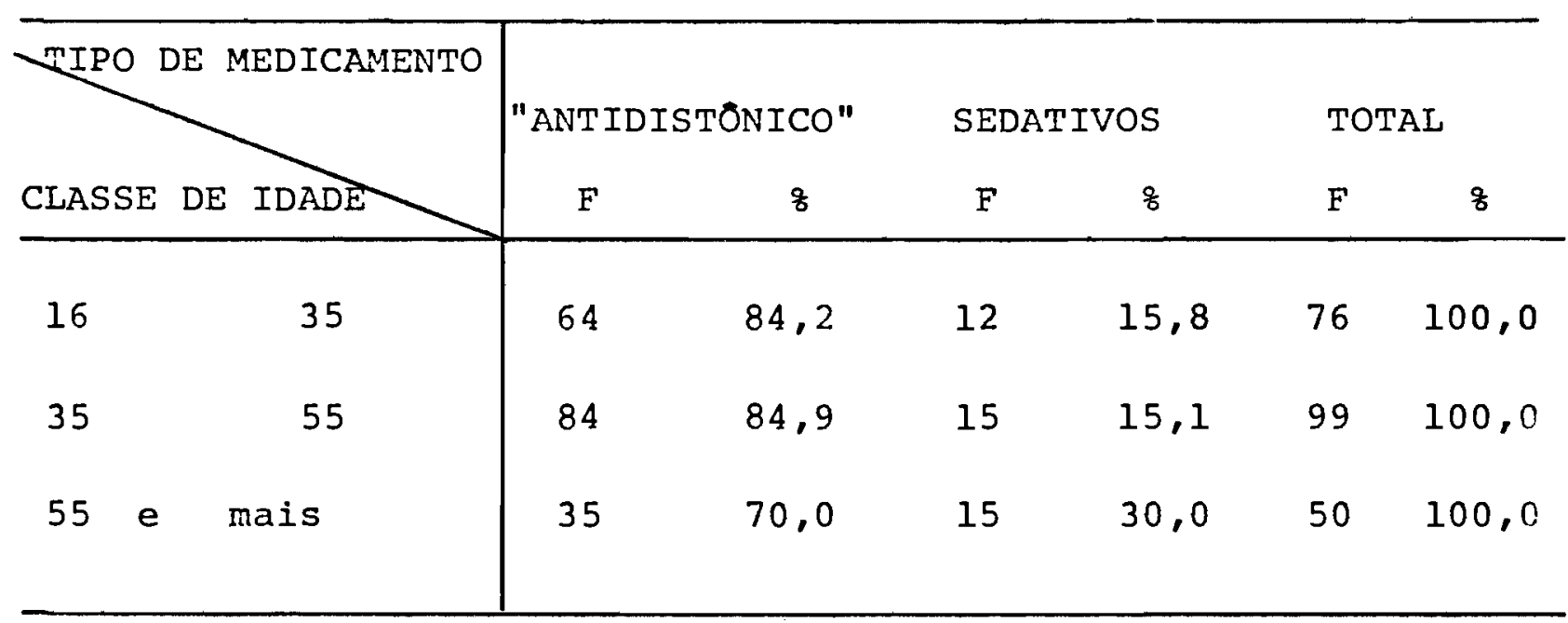

FONTE: Levantamento de dados.

4.6. MOTIVOS PARA O USO DE MEDICAMENTOS PSICOTRŌPICOS

A Tabela 16 mostra a distribuição dos 451 usuários de psicotrópicos segundo o motivo alegado para o uso do medicamento. Verifica-se que 382 pessoas $(84,7 \%)$ consumiram os psicotrōpicos por apresentarem queixas psíquicas ou queixas somäticas de presumível etiologia psíquica. Por ordem de frequência seguem-se os quadros neurológicos $(4,2 \xi)$, cardiocircu latörios $(3,5 \%)$, endocrinolögicos $(2,9 \%)$ e gastroenterolögicos $(1,38)$. Cumpre salientar que o emprego associado a tratamentos endocrinolögicos, se deu, na maior parte das vezes, aos trata mentos da menopausa.

Outrossim, a entrevista direta provavelmen te explica a grande diferença entre os valores encontrados por nös e aqueles apresentados por BLACKWELL ${ }^{10}$; este autor refere 
TABELA 16 - DISTRIBUIÇÃO DOS USUARIOS SEGUNDO O MOTIVO ALEGADO PARA O USO DO MEDICAMENTO.

\begin{tabular}{|c|c|c|}
\hline $\mathrm{M} O \mathrm{~T} I \mathrm{~V} O$ & NÚMERO DE USUÁRIOS & $\begin{array}{c}\text { PORCENTAGEM SOBRE O } \\
\text { TOTAL }\end{array}$ \\
\hline 0 - Não informa & 5 & 1,1 \\
\hline 1 - Queixas psíquicas & 371 & 82,3 \\
\hline 2 - Queixas somāticas de presumivel etiologia psíquica & 11 & 2,4 \\
\hline 3 - Associado a tratamento neurológ1co & 19 & 42 \\
\hline 4 - Associado a tratamento cardiológico & 16 & 3,5 \\
\hline 5 - Associado a tratamento endocrinológico & 13 & 2,9 \\
\hline 6 - Associado a tratamento gastroenterológico & 6 & 1,3 \\
\hline 7 - Associado a outros tratamentos médicos & 9 & 2,0 \\
\hline 8 - Inconclusivo & 1 & 0,2 \\
\hline $\begin{array}{llllll} & \mathbf{O} & \mathbf{T} & \mathbf{A} & \mathrm{L}\end{array}$ & 451 & 99,9 \\
\hline
\end{tabular}

FONTE: Levantamento de dados. 
que, nos Estados Unidos somente $30 \frac{\circ}{5}$ das prescrições do diazepan são feitas para pacientes com transtornos mentais. Contudo, Blackwell se baseou exclusivamente na origem da receita médica para a sua estimativa ‘ é possível que seus valores reflitam aquelas prescrições feitas somente por mēdicos psiquiatras.

4.7. FONTES DE INDICAÇÃO DO USO DOS MEDICAMENTOS PSICOTRŌPICOS

Diante da possibilidade de livre aquisição de medicamentos psicotrópicos e da suposição de que a classe médica lança mão deles para o manejo das mais variadas situa ções de desconforto psicológico é de se supor que seu uso não esteja restrito ao médico especialista; em nosso meio onde a prática da auto-medicação é corrente acredita-se que uma parce la ponderável do consumo de medicamentos psicotrópicos se dē por iniciativa própria.

Na Tabela 17 observa-se que em $81,6 \%$ dos casos o uso da medicação se deveu a uma indicação médica; oḅ serve-se que os médicos psiquiatra e neurologista são responsā veis por uma proporção relativamente pequena das indicações $(12,28$ e 2,98 respectivamente) e que o clínico geral è o respon sāvel por $57,4 \%$ de todas as indicações. Estes valores se apro ximam, de alguma forma, àqueles apresentados por BLACKWELL 10 que referiu somente $30 \%$ das prescriçōes de psicotrōpicos pro venientes de psiquiatras. Chama a atenção o valor relativamen te alto - se considerarmos que estamos diante de um grupo de medicamentos que deveria ser sujeito a estrito controle - de consumidores que usaram a medicação por auto-indicação $(10,2 \%)$, por indicação de parentes ou conhecidos $(4,48)$ ou por indicação 
TABELA 17 - FONTES DE INDICAÇÃO PARA O USO DE MEDICAMENTOS PSI COTRÓPICOS .

\begin{tabular}{|c|c|c|c|}
\hline $\begin{array}{lc}\text { FONTE DE } \\
\text { INDICAÇÃO }\end{array} \begin{array}{l}\text { NUMERO DE CON- } \\
\text { SUMIDORES }\end{array}$ & F & 8 & \\
\hline Não informa & 5 & 1,1 & \\
\hline Conta prōpria & 46 & 10,2 & \\
\hline Parente ou conhecido & 20 & 4,4 & \\
\hline "Farmacêutico" & 12 & 2,7 & \\
\hline Médicos & 368 & & 81,6 \\
\hline Psiquiatra & 55 & 12,2 & \\
\hline Neurologista & 13 & 2,9 & \\
\hline Cardiologista & 15 & 3,3 & \\
\hline Ortopedista & 2 & 0,4 & \\
\hline Clinico Gëral & 259 & 57,4 & \\
\hline Outras especialidades & 24 & 5,3 & \\
\hline$T \circ T A L$ & 451 & 99,9 & \\
\hline
\end{tabular}

FONTE: Levantamento de dados. 
do "farmacêutico" $(2,7 \%)$, totalizando 17,3 dos casos.

A Tabela 18 revela que os medicamentos não puramente sintomáticos (neurolépticos, antidepressivos e anti comiciais) são de domí:io quase exclusivo do receituário do psiquiatra, do neurologista e do clinico geral. E provável que a participação do clínico geral na prescrição de neurolépticos se deva à escassez de recursos de assistência psiquiátrica, da mesma forma como a predominância de prescrições de anticomiciais pelo clínico geral se deva a dificuldades de acesso ao neurolo gista e/ou psiquiatra.

Observe-se que $62 \%$ das indicaçōes de medi camentos não sintomāticos são de responsabilidade do psiquia tra e do neurologista ao passo que eles respondem somente por $11 \%$ das indicações de ansiolíticos, hipnóticos e sedativos. Dentre estes últimos, $22 \%$ das indicações são de fonte não mê dica.

o "farmacêutico", a quem se costuma atribuir ponderāvel importância nos hābitos de consumo de medicamentos, contribuiu com somente $2,7 \%$ das indicaçōes (Tabela 17), as quais restringem-se somente aos"antidistônicos" e sedativos (Tabela 18) provavelmente por reflexo do estrito controle a que são submetidos os outros grupos de psicotröpicos.

Dentre a classe mëdica, verifica-se pela Tabela 19 que os psiquiatras e neurologistas prescrevem prefe rentemente produtos sujeitos a controle de receituário $(69,28$ e 55,6\% respectivamente) enquanto os clinicos gerais e médicos de "outras especialidades" indicam com maior frequência os pro dutos livres de controle de receituário $(65,5 \%$ e $87,5 \%$ respec tivamente). Estas diferenças são explicáveis, em parte, pelo fato de psiquiatras e neurologistas atenderem, com maior fre quência, pacientes portadores de estados mentais de maior gra 
TABELA 18 - DISTRIBUIÇÃO DOS MEDICAMENTOS CONSUMIDOS SEGUNDO TIPO DE MEDICAMENTO E A FONTE DE INDICAÇÃO (SOMENTE MEDICAMENTOS DE NOME CONHECIDO).

\begin{tabular}{|c|c|c|c|c|c|c|c|c|c|c|c|c|c|c|c|c|}
\hline \multirow[t]{2}{*}{ FONTE DE INDICAÇÃO } & \multicolumn{2}{|c|}{$\begin{array}{l}\text { NEUROLEPTI } \\
\text { COS }\end{array}$} & \multicolumn{2}{|c|}{$\begin{array}{l}\text { ANTIDEPRES- } \\
\text { SIVOS }\end{array}$} & \multicolumn{2}{|c|}{$\begin{array}{l}\text { ANTICOMI- } \\
\text { CIAIS } \\
\end{array}$} & \multicolumn{2}{|c|}{$\begin{array}{l}\text { ANSIOLITI- } \\
\text { COS (com } \\
\text { controle) }\end{array}$} & \multicolumn{2}{|c|}{ HIPNÓTICOS } & \multicolumn{2}{|c|}{$\begin{array}{l}\text { "ANTIDISTO- } \\
\text { NICOS" }\end{array}$} & \multicolumn{2}{|c|}{ SEDATIVOS } & \multicolumn{2}{|c|}{ TOTAL } \\
\hline & F & 8 & $F$ & 8 & $F$ & 8 & F & 8 & $F$ & 8 & $F$ & 8 & $F$ & 8 & F & 8 \\
\hline $\begin{array}{l}\text { Por conta própria/ } \\
\text { parente ou conheci } \\
\text { do }\end{array}$ & - & & - & & 2 & 3,2 & 2 & 3,2 & 2 & 3,2 & 45 & 72,6 & i1 & 17,7 & 62 & 99,9 \\
\hline "Farmacêutico" & - & & - & & - & & - & & - & & 6 & 85,7 & 1 & 14,3 & 7 & 100,0 \\
\hline Psiquiatra & 8 & 15,1 & 3 & 5,7 & 11 & 20,7 & 13 & 24,5 & 6 & 11,3 & 10 & 18,9 & 2 & 3,8 & 53 & 100,0 \\
\hline Neurologista & - & & 1 & 8,3 & 8 & 66,7 & 1 & 8,3 & - & & 2 & 16,7 & - & & 12 & 100,0 \\
\hline Cardiologista & - & & - & & - & & 6 & 42,9 & - & & 7 & 50,0 & 1 & 7,1 & 14 & 100,0 \\
\hline clinico Geral & 4 & 2,0 & - & & 12 & 6,1 & 50 & 25,6 & 8 & 4,1 & 97 & 49,7 & 24 & 12,3 & 195 & 99,8 \\
\hline $\begin{array}{l}\text { Outras especialida } \\
\text { des }\end{array}$ & - & & 1 & 5,9 & - & & 1 & 5,9 & - & & 13 & 76,5 & 2 & 11,8 & 17 & 100,1 \\
\hline $\mathrm{T} O \mathrm{~T} A \mathrm{~L}$ & 12 & 3,3 & 5 & 1,4 & 33 & 9,2 & 73 & 20,3 & 16 & 4,4 & 180 & 50,0 & 41 & 11,4 & 360 & 100,0 \\
\hline
\end{tabular}

FONTE: Levantamento de dados.

OBS: 1) Não estão incluidos os grupos D9, E9 e H.

2) Não estão incluidos os medicamentos de fonte de indicação desconhecida. 
TABELA 19 - CONSUMO DE MEDICAMENTOS INDICADOS POR MÉDICOS SEGUN DO O CONTRC $-E$ DE VENDA.

\begin{tabular}{|c|c|c|c|c|c|c|}
\hline \multirow{2}{*}{ MËDICO } & \multicolumn{2}{|c|}{$\begin{array}{l}\text { COM CONTROLE } \\
\text { DE RECEITUARRIO }\end{array}$} & \multicolumn{2}{|c|}{$\begin{array}{l}\text { SEM CONTROLE } \\
\text { DE RECEITUĀRIO }\end{array}$} & \multicolumn{2}{|c|}{ TOTAL } \\
\hline & $\mathbf{F}$ & 8 & $\mathbf{F}$ & 8 & F & 8 \\
\hline Psiquiatra & 27 & 69,2 & 12 & 30,8 & 39 & 100,0 \\
\hline Neurologista & 5 & 55,6 & 4 & 44,4 & 9 & 100,0 \\
\hline Cardiologista & 6 & 50,0 & 6 & 50,0 & 12 & 100,0 \\
\hline Clínico Geral & 61 & 34,5 & 116 & 65,5 & 177 & 100,0 \\
\hline $\begin{array}{l}\text { Outras especiali } \\
\text { dades }\end{array}$ & 2 & 12,5 & 14 & 87,5 & 16 & 100,0 \\
\hline $\mathrm{T} O \mathrm{~T} A \mathrm{~L}$ & 101 & 39,9 & 152 & 60,1 & 253 & 100,0 \\
\hline
\end{tabular}

FONTE: Levantamento de dados.

OBS: o critério de "controle de receituário" é estabelecido pelo pesquisador. Estão excluidos os produtos onde não foi possí vel chegar à conclusão sobre a exigência de receita médica para aquisição do medicamento. 
vidade e, portanto, sujeitos ao uso de medicamentos neurolép ticos ou antidepressivos, os quais, em qualquer circunstância são submetidos a rigoroso controle de vendas. Contudo, pela Tabela 18 verifica-se qu ? também em relação aos ansiolíticos, hipnóticos e sedativos os psiquiatras dão preferência aos pro dutos controlados.

\subsection{ESTUDO DAS CARACTERISTICAS DE IDADE E SEXO DOS CONSU-} MIDORES DE MEDICAMENTOS PSICOTRÓPICOS

A apresentação e análise dos resultados deste item e dos seguintes seguirá o modelo dos estudos de ca so-controle definindo-se como "grupo caso" o conjunto de indi víduos da população que referiram ter consumido medicamentos psicotrópicos no ano que antecedeu a entrevista e "grupo con trole" o conjunto de indivíduos que referiram não ter consumi do psicotrópicos.

A Tabela 6 (pág.8I) e a Tabela 20 mostram a distribuição dos grupos caso e controle, respectivamente, por sexo e grupos etários. Os valores encontrados para a mediana, média e desvios padrão das idades são apresentados no Quadro 3; observa-se tanto para a mediana como para a média das ida des em ambos os sexos uma marcante diferença entre o grupo cá so e o grupo controle. A idade média dos indivíduos consumido res de psicotrópicos é 5,13 anos maior do que a dos não consumidô res $(42,01$ e 36,88 anos respectivamente). A mediana das idades nos dois grupos mostra uma diferença de 7,27 anos a favor dos consumidores. O teste $t$ de student revela que essas diferenças são significativas para o nível de significância de 5\% tanto para os homens como para as mulheres. 
TABELA 20 - DISTRIBUIÇÃO DA POPULAÇÃO DE NÃO CONSUMIDORES DE PSI COTROPICOS (GRUPO CONTROLE) POR IDADE E SEXO.

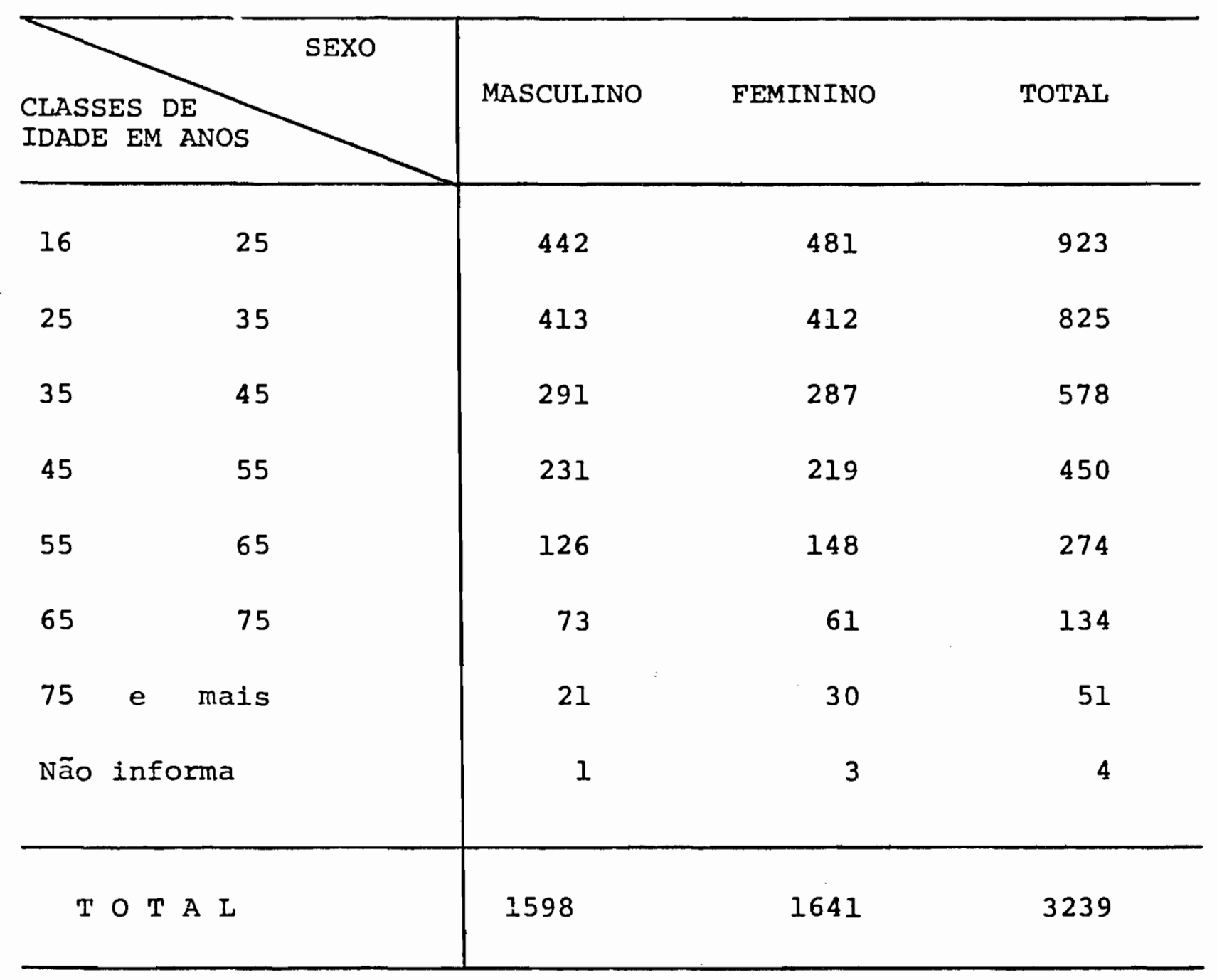

\footnotetext{
FONTE: Levantamento de dados.
} 
QUADRO 3 - VALORES OBSERVADOS PARA A MEDIANA, MÉdIA E DESVIO PADRÃO DAS IDADES DOS GRUPOS DE CONSUMIDORES E NÃO CON SUMIDORES DE PSICOTRÓPICOS SEGUNDO O SEXO.

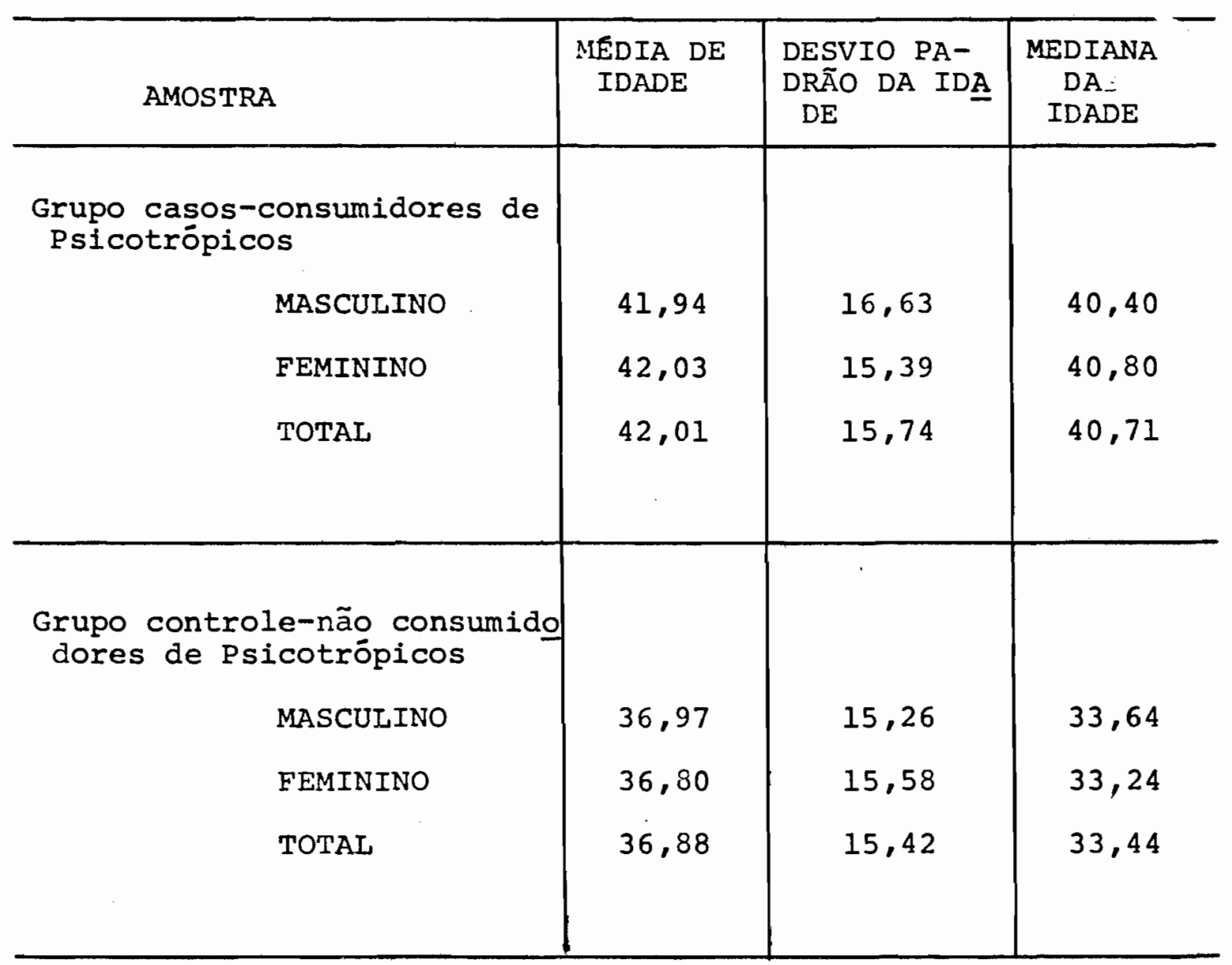

Valor de $t$ para o grupo de homens $=3,57$

Valor de $t$ para o grupo de mulheres $=5,51$

Valor de $t$ para ambos os sexos $=6,60$ 
Já na análise dos coeficientes de prevalên cia de consumo (Figura 6) podia se notar uma tendência ao cres cimento do consumo de psicotrópicos dos grupos mais jovens pa ra os mais velhos, faztndo supor que a população de indivíduos que tomam estes medicamentos é mais velha do que a população em geral. Os valores aqui observados confirmam esta hipótese e concordam com as observaçōes de diversos autores.

Podemos admitir que a maior idade média do grupo de consumidores deve-se essencialmente ao grupo que uti liza ansiolíticos, hipnóticos e sedativos, jā que o uso de neurolēpticos e anticomiciais é mais frequente nos grupos mais jovens (Tabela 14).

Na Tabela 21 observamos que 0 consumo de psicotrópicos no sexo feminino é bem mais elevado do que no se xo masculino. O teste do qui quadrado (para 1.g.1. e alpha $\underline{i}$ gual a 0,01 ) indica que esta diferença é significativa. O pro duto cruzado é igual a 2,38 (com intervalo de confiança a 958 variando de 1,34 a 4,18) indicando maior risco de consumo de psicotrópicos entre as mulheres. Ainda uma vez, os valores ob servados concordam com aqueles encontrados em diversos estudos realizados em outros países. O maior consumo observado entre mulheres não deve, a priori, ser considerado um indicador de maiores niveis de ansiedade e stress no sexo feminino, mas, como aponta COOPERSTOCK ${ }^{18}$, é, provavelmente, devido à fatores como maior aceitação social para a expressão dos sentimentos e procura mais frequentemente do médico para a solução de pro blemas existenciais. 
TABELA 21 - DISTRIBUIÇÃO DOS CONSUMIDORES E NT̃O CONSUMIDORES DE PSICOTROPICOS SEGUNDO O SEXO.

\begin{tabular}{|c|c|c|c|c|c|c|}
\hline \multirow[t]{2}{*}{ GRUPO } & \multicolumn{2}{|c|}{ CONSUMIDORES } & \multicolumn{2}{|c|}{$\begin{array}{l}\text { NĀO CONSUMIDO- } \\
\text { RES }\end{array}$} & \multicolumn{2}{|c|}{ TOTAL } \\
\hline & $\mathrm{F}$ & 8 & $\mathbf{F}$ & 8 & $\mathbf{F}$ & 8 \\
\hline Masculino & 131 & 7,6 & 1598 & 92,4 & 1729 & 100,0 \\
\hline Feminino & 320 & 16,3 & 1641 & 83,7 & 1961 & 100,0 \\
\hline$T \circ T A L$ & 451 & 12,2 & 3239 & 87,8 & 3690 & 100,0 \\
\hline
\end{tabular}

FONTE: Levantamento de dados.

$$
\begin{array}{ll}
x^{2}=65,39 \quad & \text { Produto cruzado }=2,38 \\
& \text { Intervalo de confiança do produto } \\
& \text { cruzado }=1,34-4,18
\end{array}
$$


o estado civil - ou, mais propriamente, o tipo de vinculo matrimonial - pode estar associadu a maiores ou menores niveis de ansiedade e, portanto, ao consumo de me dicamentos tranquilizantes. Observa-se na prática clínica que, aparentemente, o consumo de ansiolíticos, hipnóticos e sedatị vos é mais elevado entre as pessoas com vinculo matrimonial rompido, seja por viuvez ou separação. De outro lado, tem sido arglido que as mulheres na faixa etăria de 30 a 50 anos despon tam como os maiores consumidores de psicotrópicos em decorrên cia, talvez, de um elevado nível de conflito psicológico dian te das modificaçōes de seu papel social.

De qualquer forma, pode se supor que, em uma determinada cultura, haja uma "expectativa" em relação ao estado civil dos indivíduos em determinados grupos etārios, expectativa esta decorrente da observação de que a maior proporção dos indivíduos naquela faixa de idade se encontre em determinado estado civil. Assim, por exemplo, é mais frequen te observar individuos solteiros ou casados nas idades de 18 a 30 anos e menos frequente encontrar viúvos; ou, por outro la do, encontrar com maior frequência pessoas casadas, viúvas ou desquitadas nas idades de 50 a 70 anos do que pessoas solteiras. Ora, o desvio da normalidade - aqui enten dido unicamente no seu aspecto estatístico de frequência rela tiva de ocorréncia do evento - pode ser fator predisponente ao aparecimento de estados ansiosos, seja pelas dificuldades de desempenho do papel social, seja pela dificuldade individual de escapar à norma cultural. Assim, pessoas casadas antes da maioridade, pessoas separadas ou viúvas na idade dos 20 aos 30 anos ou pessoas solteiras na idade dos 50 aos 70 anos teriam 
maiores dificuldades de relacionamento social.

Ainda dentro desta suposição de um gradien te de vinculos matrimoniais de acordo com a idade, pode se su por que seja social e individualmente mais fáci.' a adaptação de um viúvo na faixa dos 50 aos 70 anos do que na faixa dos 30 aos 50 anos.

Se forem verdadeiras estas suposições, po demos admitir que, como reflexo das dificuldades de adaptação, se encontre diferentes proporções de consumo de medicamentos psicotrópicos en diferentes faixas etārias de acordo com o es tado civil.

E obvio que, se existirem, estas diferenças não podem ser entendidas como uma comprovação da hipótese aven tada na medida em que as variáveis intervenientes são inúmeras. Contudo, dentro de uma perspectiva de esforços corporativos de observação da realidade com o objetivo de uma apreensão global da mesma a partir da somatória das diversas observaçōes seto riais, julgamos conveniente analisar as relaçōes entre o esta do civil e os níveis de consumo de psicotrópicos.

Para esta anālise optamos por agrupar os estados civis (ou vínculos matrimoniais) em três categorias: a) onde o vínculo matrimonial não chegou a existir - os soltei ros; b) onde existe um vínculo matrimonial - os casados de fa to ou de direito, os separados que se casaram novamente ou viú vos que se casaram novamente; c) onde o vínculo matrimonial e xistiu e foi rompido - os separados, desquitados e viúvos.

As Tabelas 22, 23, 24, 25, 26 e 27 apreșen tam a distribuição da população amostral por faixas de idade, sexo e estado civil; o teste do qui quadrado aplicado sobre os resultados destas tabelas revelou que estas diferenças não são estatisticamente significativas para o nível de significância 
de 5응 (qui quadrado crítico igual a 5,99).

A Tabela 28, que consolida estas observa ções, mostra a distribuição porcentual destes indivíduos em ca da sexo, faixa etāria e estado civi'; verifica-se nos dois se xos as menores proporçōes de consumidores entre os solteiros e casados no grupo etário de 18 a 29 anos. As maiores proporçōes de consumidores são, entre os homens, a dos solteiros de 30 a 50 anos $(14,38)$ e entre as mulheres a das separadas de 30 a 50 anos $(28,3 \%)$ e das solteiras de 51 a 70 anos $(27,3 \%)$. $\mathrm{Na}$ anālise destes valores percentuais é mister considerar as diferenças de prevalência de consumo en tre os sexos masculino, feminimo e as diversas faixas etárias (item 4.1.). Os indices mostram-se sempre superiores entre as mulheres e seu crescimento tende a acompanhar a idade. Nas Ta belas 23,24 e 25 observa-se que os indices de consumo crescem de 11,88 para 19,08 e 23,98 entre as mulheres de 18 a 29,30 a 50 e 51 a 70 anos respectivamente. Chama a atenção o Indice de 28,38 encontrado entre as mulheres separadas do grupo de 30 a 50 anos cujo valor é 468 superior à média do consumo na quela idade (Tabela 25); esta é, sem dúvida, a única condição de vinculo matrimonial e idade onde podemos constatar uma di ferença marcante nos niveis de consumo de psicotrópicos. Este valor fornece-nos um indício de que possa haver neste grupo maiores niveis de ansiedade e dificuldades de adaptação; cabe ressalvar que em se tratando de pessoas desquitadas ou separa das somente atravēs de estudos clínicos é possível avaliar a causa ou a consequência do rompimento do vínculo matrimonial. 
TABELA 22 - DISTRIBUIÇÃO DOS HOMENS DE 18 a 29 ANOS SEGUNDO O CONSUMO DE MEDICAMENTOS PSICOTRÓPICOS E O ESTADO CIVIL.

\begin{tabular}{|c|c|c|c|c|c|c|}
\hline \multirow{2}{*}{$\begin{array}{l}\text { ESTADO } \\
\text { CIVIL }\end{array}$} & \multicolumn{2}{|c|}{ CONSUMIDORES } & \multicolumn{2}{|c|}{$\begin{array}{l}\text { NÃO CONSUMI } \\
\text { DORES }\end{array}$} & \multicolumn{2}{|c|}{ TOTAL } \\
\hline & $\mathrm{F}$ & 8 & $\mathbf{F}$ & 安 & $\mathbf{F}$ & 8 \\
\hline Solteiros & 21 & 5,1 & 394 & 94,9 & 415 & 100,0 \\
\hline Casados & 13 & 6,8 & 178 & 93,2 & 191 & 100,0 \\
\hline Separados & - & - & 3 & 100,0 & 3 & 100,0 \\
\hline$T \circ T A I$ & 34 & 5,6 & 575 & 94,4 & 609 & 100,0 \\
\hline
\end{tabular}

FONTE: Levantamento de dados.

$$
x^{2}=1,43
$$

TABELA 23 - DISTRIBUIÇÃO DAS MULHERES DE 18 a 29 ANOS SEGUNDO O CONSUMO DE MEDICAMENTOS PSICOTRÓPICOS E O ESTADO CIVIL.

\begin{tabular}{|c|c|c|c|c|c|c|}
\hline \multirow{2}{*}{$\begin{array}{l}\text { ESTADO } \\
\text { CIVIL }\end{array}$} & \multicolumn{2}{|c|}{ CONSUMIDORES } & \multicolumn{2}{|c|}{$\begin{array}{l}\text { NÃO CONSUMI } \\
\text { DORES }\end{array}$} & \multicolumn{2}{|c|}{ TOTAL } \\
\hline & $F$ & q & $\mathbf{F}$ & q & $F$ & 8 \\
\hline Solteiras & 43 & 11,7 & 325 & 88,3 & 368 & 100,0 \\
\hline Casadas & 35 & 11,8 & 261 & 88,2 & 296 & 100,0 \\
\hline Separadas & 2 & 16,7 & 10 & 83,3 & 12 & 100,0 \\
\hline $\mathrm{T} O \mathrm{TAL}$ & 80 & 11,8 & 596 & 88,2 & 676 & 100,0 \\
\hline
\end{tabular}

FONTE: Levantamento de dados.

$$
x^{2}=0,25
$$


TABELA 24 - DISTRIBUIÇÃO DOS HOMENS DE 30 a 50 ANOS SEGUNDO O CONSUMO DE MEDICAMENTOS PSICOTRÖPICOS E O ESTADO CIVIL.

\begin{tabular}{|c|c|c|c|c|c|c|}
\hline \multirow{2}{*}{$\begin{array}{l}\text { ESTADO } \\
\text { CIVIL }\end{array}$} & \multicolumn{2}{|c|}{ CONSUMIDORES } & \multicolumn{2}{|c|}{$\begin{array}{l}\text { NÃO CONSUMI } \\
\text { DORES }\end{array}$} & \multicolumn{2}{|c|}{ TOTAL } \\
\hline & $F$ & 8 & $\mathrm{~F}$ & $\frac{8}{8}$ & $\mathrm{~F}$ & 8 \\
\hline Solteiros & 6 & 14,3 & 42 & 85,7 & 48 & 100,0 \\
\hline Casados & 51 & 9,0 & 564 & 91,0 & 615 & 100,0 \\
\hline Separados & 2 & 10,0 & 18 & 90,0 & 20 & 100,0 \\
\hline$T O T A L$ & 59 & 8,6 & 624 & 91,4 & 683 & 100,0 \\
\hline
\end{tabular}

FONTE: Levantamento de dados.

$$
x^{2}=1,07
$$

TABELA 25 - DISTRIBUIÇÃO DAS MULHERES DE 30 a 50 ANOS SEGUNDO O CONSUMO DE MEDICAMENTOS PSICOTROPICOS E O ESTADO CI VIL.

\begin{tabular}{l|rrrrrr}
\hline & CONSUMO & \multicolumn{2}{c}{ CONSUMIDORES } & \multicolumn{2}{c}{ NÃO CONSUMI } \\
ESTADO \\
$\begin{array}{l}\text { CIVIL } \\
\text { Solteiras }\end{array}$ & F & 8 & $\mathrm{~F}$ & 8 & $\mathrm{~F}$ & TOTAL \\
\hline $\begin{array}{l}\text { Casadas } \\
\text { Separadas }\end{array}$ & 14 & 18,4 & 62 & 81,6 & 76 & 100,0 \\
& 105 & 17,6 & 491 & 82,4 & 596 & 100,0 \\
\hline T O T A L & 26 & 28,3 & 66 & 71,7 & 92 & 100,0 \\
\hline
\end{tabular}

FONTE: Levantamento de dados.

$$
x^{2}=5,83
$$


TABELA 26 - DISTRIBUIÇÃO DOS HOYENS DE 51 a 70 ANOS SEGUNDO O CONSUMO DE MEDICAMENTOS PSICOTRÓPICOS E O ESTADO CIVIL.

\begin{tabular}{|c|c|c|c|c|c|c|}
\hline \multirow{2}{*}{$\begin{array}{l}\text { ESTADO } \\
\text { CIVIL }\end{array}$} & \multicolumn{2}{|c|}{ CONSUMIDORES } & \multicolumn{2}{|c|}{$\begin{array}{l}\text { NÃO CONSUMI } \\
\text { DORES }\end{array}$} & \multicolumn{2}{|c|}{ TOTAL } \\
\hline & $\mathrm{F}$ & 8 & $\mathbf{F}$ & 8 & $\mathbf{F}$ & 8 \\
\hline Solteiros & - & - & 7 & 100,0 & 7 & 100,0 \\
\hline Casados & 27 & 10,3 & 236 & 89,7 & 263 & 100,0 \\
\hline Separados & 2 & 11,8 & 15 & 88,2 & 17 & 100,0 \\
\hline $\mathrm{T} O \mathrm{TA} \mathrm{L}$ & 29 & 10,1 & 258 & 89,9 & 287 & 100,0 \\
\hline
\end{tabular}

FONTE: Levantamento de dados.

$$
x^{2}=0,35
$$

TABELA 27 - DISTRIBUIÇÃO DAS MULHERES DE 51 a 70 ANOS SEGUNDO O CONSUMO DE MEDICAMENTOS PSICOTRÓPICOS E O ESTADO CIVIL.

\begin{tabular}{|c|c|c|c|c|c|c|}
\hline \multirow{2}{*}{$\begin{array}{l}\text { ESTADO } \\
\text { CIVIL }\end{array}$} & \multicolumn{2}{|c|}{ CONSUMIDORES } & \multicolumn{2}{|c|}{$\begin{array}{l}\text { NÃO CONSUMI } \\
\text { DORES }\end{array}$} & \multicolumn{2}{|c|}{ TOTAL } \\
\hline & $\mathrm{F}$ & 8 & $F$ & 8 & F & 8 \\
\hline Solteiras & 6 & 27,3 & 16 & 72,7 & 22 & 100,0 \\
\hline Casadas & 49 & 24,9 & 148 & 75,1 & 197 & 100,0 \\
\hline Separadas & 27 & 21,8 & 97 & 72,2 & 124 & 100,0 \\
\hline $\mathrm{T} O \mathrm{TA} \mathrm{L}$ & 82 & 23,9 & 261 & 76,1 & 343 & 100,0 \\
\hline
\end{tabular}

FONTE: Levantamento de dados

$$
x^{2}=0,52
$$


TABELA 28 - PORCENTAGEM DE CONSUMIDORES DE MEDICAMENTOS PSICOTRŌ PICOS NA AMOSTRA SEGUNDO IDADE, SEXO E ESTADO CIVII.

\begin{tabular}{|c|c|c|c|c|}
\hline $\begin{array}{l}\text { GEXO E ERUPO } \\
\text { ESTADO CI } \\
\text { VII }\end{array}$ & $18-29$ & -50 & 51 & TOTAL \\
\hline \multicolumn{5}{|l|}{ HOMENS } \\
\hline Solteiros & 5,1 & 14,3 & - & 5,7 \\
\hline Casados & 6,8 & 9,0 & 10,3 & 8,5 \\
\hline Separados & - & 10,0 & 11,8 & 10,0 \\
\hline \multicolumn{5}{|l|}{ MULHERES } \\
\hline Solteiras & 11,7 & 18,4 & 27,3 & 13,5 \\
\hline Casadas & 11,8 & 17,6 & 24,9 & 17,3 \\
\hline Separadas & 16,7 & 28,3 & 21,8 & 24,1 \\
\hline $\mathrm{T} \circ \mathrm{TA}$ & 8,9 & 14,1 & 17,6 & 12,8 \\
\hline
\end{tabular}

FONTE: Levantamento de dados. 
4.10. CONSUMO DE MEDICAMENTOS PSICOTRÓPICOS E CONDIÇÕES DE HA BITAÇÃO

A observação de que grande parte do consu mo de medicamentos psicotrópicos è devida ao uso de produtos que visam ao alívio sintomático da ansiedade, levou-nos à hi pótese de que pudesse haver uma associação entre os níveis de consumo e as condições de aglomeração domiciliar, isto é, que em domicílios onde houvesse escassez de pessoas (baixo indice de aglomeração) ou excesso de pessoas (alto indice de aglome ração) por espaço útil pudesse haver maior consumo de medica mentos psicotrópicos na medida em que nestas condições de exis tência haveria maior nível de ansiedade individual.

o Indice de aglomeração tem sido utilizado por diversos autores para mensurar a qualidade de vida; é ob tido pela relação entre o nümero de pessoas residentes no domi cỉlio e o espaço ütil existente. Para a definição do espaço ú til hã autores que consideram somente certas dependências da casa (quartos e salas); neste estudo consideramos espaço útil todas as dependências da casa. Assim, a relação

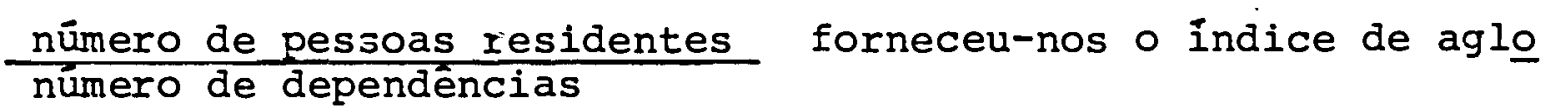
meração com o qual trabalharemos.

Para o estudo da associação entre consuno de psicotrōpicos e condiçōes de habitação classificamos as fa mîlias em dois grupos: no grupo caso foram incluídas as famí lias onde havia pelo menos uma pessoa que tivesse referido o uso de psicotrópicos no último ano e no grupo controle foram incluŕalas as famỉlias onde não havia nenhuma pessoa que tives se referido o uso destes medicamentos naquele período. 
TABELA 29 - DISTRIBUIÇño DAS FAMILIAS SEGUNDO O INDICE DE AGLOMERA ÇÃO E A EXISTÊNCIA DE ADULTOS QUE TOMARAM PSICOTRÓPICOS.

\begin{tabular}{|c|c|c|c|c|c|c|c|}
\hline \multirow{2}{*}{\multicolumn{2}{|c|}{ INDICE DE }} & \multicolumn{2}{|c|}{$\begin{array}{l}\text { COM ADULTOS QUE } \\
\text { TOMARAM PSICO- } \\
\text { TROPICOS }\end{array}$} & \multicolumn{2}{|c|}{$\begin{array}{l}\text { SEM ADULTOS QUE } \\
\text { TOMARAM PSICO } \\
\text { TROPICOS }\end{array}$} & \multicolumn{2}{|c|}{ TOTA } \\
\hline & & $\mathrm{F}$ & 8 & $F$ & 8 & $\mathrm{~F}$ & 8 \\
\hline 0,1 & $-0,3$ & 10 & 2,83 & 29 & 3,17 & 39 & 3,08 \\
\hline 0,4 & $-\quad 0,6$ & 98 & 27,76 & 191 & 20,90 & 289 & 22,81 \\
\hline 0,7 & $-\quad 0,9$ & 78 & 22,10 & 211 & 23,09 & 289 & 22,81 \\
\hline 1,0 & - $\quad 1,2$ & 42 & 11,90 & 126 & 13,79 & 168 & 13,26 \\
\hline 1,3 & $-\quad 1,5$ & 32 & 9,07 & 93 & 10,17 & 125 & 9,87 \\
\hline 1,6 & $-\quad 1,8$ & 25 & 7,08 & 62 & 6,78 & 87 & 6,87 \\
\hline 1,9 & $-\quad 2,1$ & 10 & 2,83 & 16 & 1,75 & 26 & 2,05 \\
\hline 2,2 & $-\quad 2,4$ & 16 & 4,53 & 31 & 3,39 & 47 & 3,71 \\
\hline 2,5 & $-\quad 2,7$ & 16 & 4,53 & 76 & 8,31 & 92 & 7,26 \\
\hline 2,8 & $-\quad 3,0$ & 11 & 3,12 & 52 & 5,69 & 63 & 4,97 \\
\hline 3,1 & $-3,3$ & 3 & 0,85 & 6 & 0,66 & 9 & 0,71 \\
\hline 3,4 & $-\quad 3,6$ & 3 & 0,85 & 8 & 0,88 & 11 & 0,87 \\
\hline 3,7 & 3,9 & - & & - & & - & \\
\hline 4,0 & $-\quad 4,2$ & - & & - & & - & \\
\hline 4,3 & $-\quad 4,5$ & 1 & 0,28 & - & & 1 & 0,08 \\
\hline 4,6 & $-\quad 4,8$ & 2 & 0,57 & - & & 2 & 0,16 \\
\hline 4,9 & $-\quad 5,1$ & - & & 1 & 0,11 & 1 & 0,08 \\
\hline 5,2 & $-\quad 5,4$ & 1 & 0,28 & - & & 1 & 0,08 \\
\hline 5,5 & $-\quad 5,7$ & 3 & 0,85 & 1 & 0,11 & 4 & 0,32 \\
\hline 5,8 & $-6,0$ & 1 & 0,28 & 10 & 1,09 & 11 & 0,87 \\
\hline 6,1 & $-\quad 6,3$ & - & & 1 & 0,11 & 1 & 0,08 \\
\hline 6,4 & $-6,6$ & 1 & 0,28 & - & & 1 & 0,08 \\
\hline \multicolumn{2}{|c|}{$T O T A L$} & 353 & 99,99 & 914 & 100,00 & 1267 & 100,02 \\
\hline
\end{tabular}

FONTE: Levantamento de dados.

$\begin{array}{llll}\text { MÉDIA } & 1,25 & 1,33 & 1,31 \\ \text { DESVIO PADRÃO } & 0,99 & 0,97 & 0,98\end{array}$


FIGURA 7 - DISTRIBUIÇÃO PORCENTUAL SEGUNDO O INDICE DE AGLOMERAÇÃO DAS FAMILIAS COM ADULTOS QUE TOMARAM PSICOTROPICOS E SEM ADULTOS QUE TOMARAM PSICOTROPICOS.

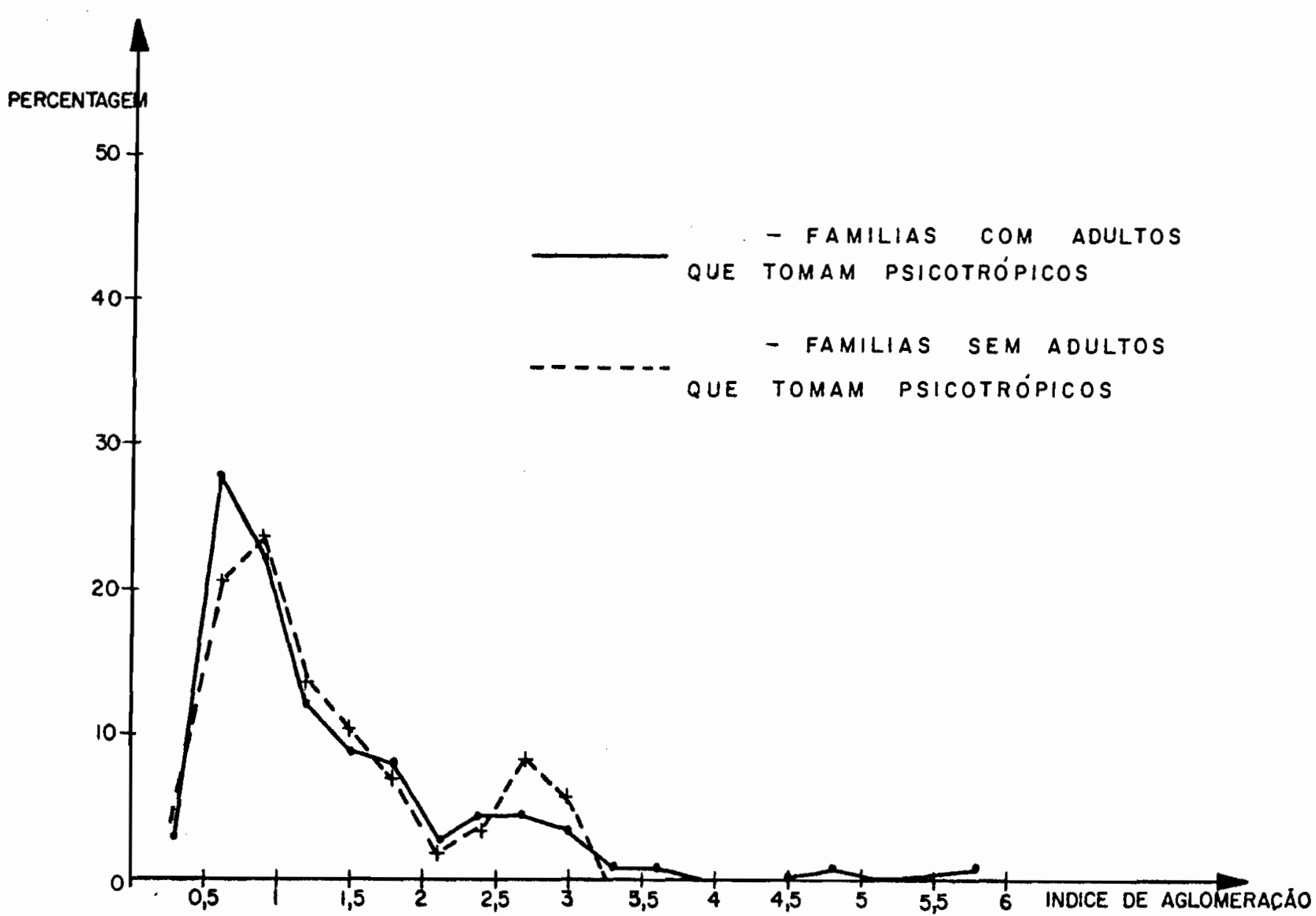

FONTE: Levantamento de dados. 
buição destas famỉlias segundo o indice de aglomeração. Não foi possivel definir este indice em 16 familias do grupo caso $(4,3 \%)$ e em 62 familias do grupo controle $(6,3 \%)$ por falta de informa ção conclusiva sobre o número de dependências da casa. Obs ' va-se que a distribuição porcentual dos dois grupos é pratica mente igual; a moda no grupo caso situa-se no intervalo 0,4 a 0,6 pessoas por dependência e no grupo controle situa-se no in tervalo 0,7 a 0,9 pessoas por dependência. As médias do Indice de aglomeração para o grupo caso e controle foram, respectiva mente, 1,25 e 1,33 pessoas por dependência; o teste $t$ de Student bicaudal indica que a diferença entre as médias observadas não è significativa. Concluimos, portanto, que não hã associação entre o consumo de psicotröpicos e as condições de aglomeração do domicilio.

E digno notar na Figura 7 carāter bimodal da distribuição nos dois grupos; esta particularidade leva-nos a admitir que a amostra é constituida de duas populações distin tas no que se refere à aglomeração domiciliar; a primeira delas, mais numerosa, apresenta a moda do Indice de aglomeração situa da em 0,6 habitantes por dependência e a segunda apresenta a moda situada em 2,6 habitantes por dependência. Assim, por $\underline{e}$ xemplo, supondo-se uma unidade bãsica de habitação (um quarto, uma sala, uma cozinha, um banheiro e uma ärea de serviço), na primeira hipótese residiriam cerca de três pessoas e na segun da hipōtese residiriam treze pessoas. E provável que esta se gunda população, com alto índice de aglomeração, seja constitui da por aquelas familias de baixo poder aquisitivo que residem em cortiços e favelas, onde, não raro, observa-se familias re sidindo em um único cômodo. 
4.11. CONSUMO DE MEDICAMENTOS PSICOTROPICOS E GRAU DE INSTRUÇÃo

O grau de instrução guarda uma relação dı̣ reta com o nível sócio-econômico. Nesta medida,é importante a anālise da associação entre os níveis de prevalência de consụ mo de psicotrópicos e o grau de instrução dos usuários.

Em nosso meio temos ouvido com frequência a afirmação de que "a Q Psiquiatria para as classes pobres é fei ta à base de medicamentos e a Psiquiatria dos abastados, à ba se de psicoterapia". Isto reflete uma critica dos profissionais que, engajados ou não neste tipo de comportamento, mostram-se insatisfeitos com o uso excessivo de psicofármacos em situações que, idealmente, deveriam receber um outro tipo de abordagem terapêutica.

PARRY et al ${ }^{47}$ observaram nos Estados Unidos em 1970 - 1971 que apesar de as cifras de prevalência de consu mo serem semelhantes em todas as classes sōcio-econōmicas, as classes de menor nivel educacional usavam os medicamentos de forma mais regular $\epsilon$ constante.

Na Tabela 30 é mostrada a distribuição dos grupos de consumidores e não consumidores segundo o grau de ins trução. Observa-se maior porcentagem de consumidores entre as pessoas de menor nivel educacional $(14,4 \%)$ e, contrariamente, a menor porcentagem de consumidores entre as pessoas de instru ção superior $(8,1 \%)$. O teste do qui quadrado indica que estas diferenças são significativas e o cālculo do produto cruzado indica que, em relạção às pessoas de nĩvel superior de instru ção , o risco relativo de indivíduos analfabetos ou de instru ção primāria que consumiram psicotrópicos é igual a 1,92 e para os inđivĩuos de instrução média é 1,34(intervalo de confiança 
TABELA 30 - DISTRIBUIÇÃO L 'S ADULTOS SEGUNDO O CONSUMO DE MEDICAMEN TOS PSICOTRÓPICOS E O GRAU DE INSTRUÇÃO.

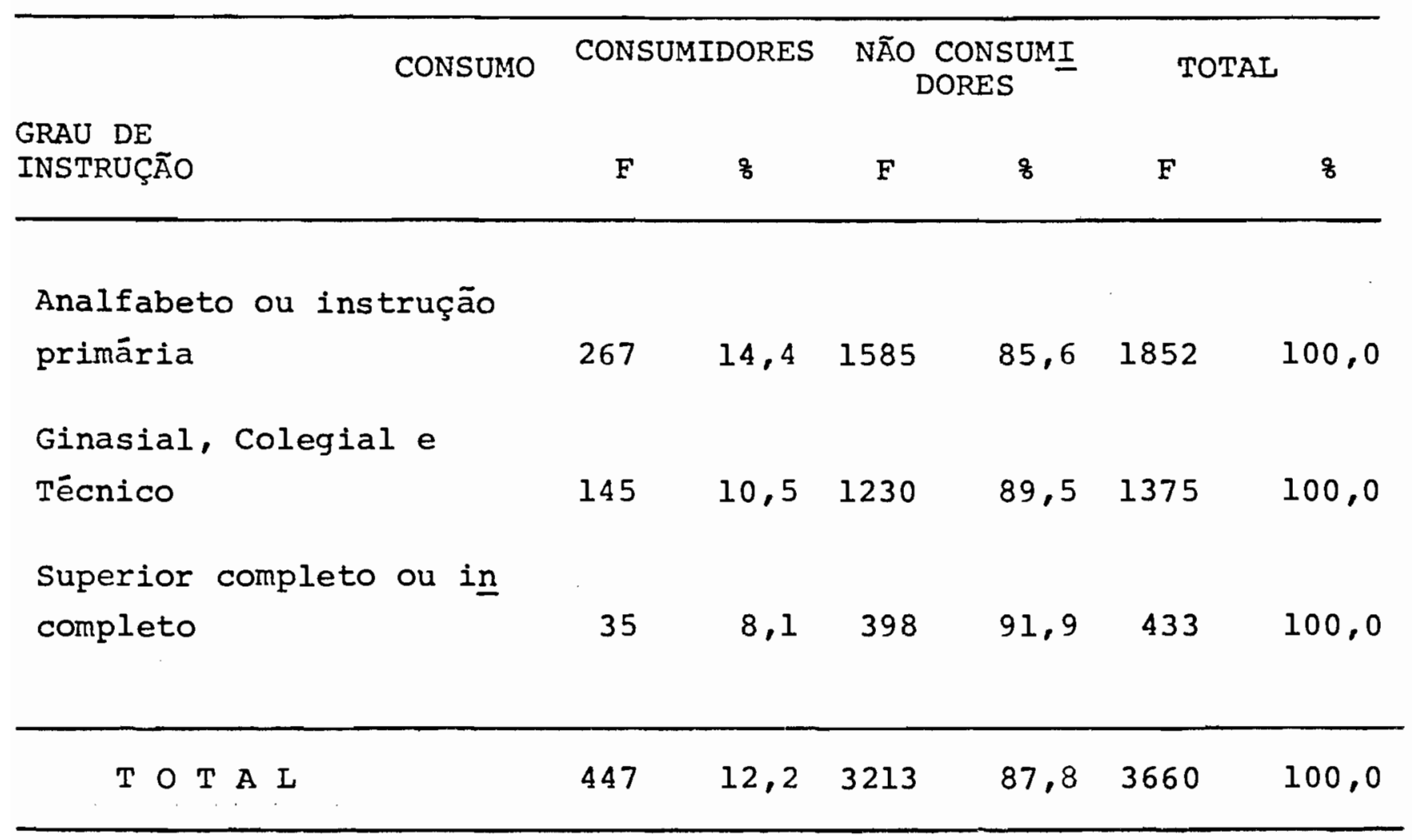

FONTE: Levantamento de dados.

$$
x^{2}=19,26
$$

OBS: Não foi obtida informação sobre o grau de instrução de 30 individuos. 
igual a 1,39 - 2,57 para indivíduos de instrução primāria e 2,97 - 5,65 para indivíduos de instrução média).

Podemos fazer diversas suposiçōes a partir dos valores observados. Em primeiro lugar, poden ss aventar a hipótese de que o nivel de ansiedade entre pessoas de menor instrução e, portanto, situadas em estratos sociais inferiores, seja maior en decorrência de condições de vida mais difíceis; os altos indices de prevalência do consumo de ansiolíticos, hipnōticos e sedativos, frequentemente utilizados para o alívio da ansiedade decorrente de situações não médicas, vem, de algu ma forma, reforçar esta hipótese.

Contudo, deve-se, por outro lado, conside rar que as condições de prestação de assistência médica à po pulação de menor renda são mais precārias e, habitualmente, baseiam-se muito mais na farmacoterapia do que nas psicotera pias. No Capítulo I apontávamos que, com frequência, o pacien te que procura o médico com queixas psiquicas não recebe o a tendimento mais indicado, seja por desconhecimento ou falta de condições do médico e este pode ser um dos fatores que expliquem a maior frequência de prescrições de psicotrópicos para as classes sociais mais baixas. Não devemos, inclusive, olvidar que, em nosso meio, mesmo os serviços de assistência psiquiā trica estão organizados de forma tal a não permitir uma aborda gem psicoterāpica dos estados ansiosos como seria tecnicamente recomendado; mesmo nestes centros especializados, a psicofarma coterapia tem papel de primeira linha nos tratamentos.

$$
\text { Por outro lado, os individuos com niveis }
$$
mais elevados de instrução e renda têm maiores possibilidades de acesso à assistência médica privada, onde o tempo disponível para o atendimento é maior e os encaminhamentos aos especialis tas são mais frequentes. Assim, hã maior chance de que as quei 
xas de ansiedade recebam um tratamento mais profundo com uma busca e tentativa de resolução de sua etiologia através de téc nicas não farmacolögicas.

Outra hipōtese a ser aventac: è a de que haveria, entre os indivíduos de menor grau de instrução, maior crença nos benefícios dos psicofärmacos, levando-os a assumir uma atitude mas complacente em relação ao seu uso. Observando uma população nos Estados Unidos, MANHEIMER et al ${ }^{40}$ chegam à conclusão exatamente oposta. Em nosso meio carecemos de levan tamentos deste tipo e seria necessārio a realização de estudos de atitudes populares acerca dos psicotrópicos para confirmar a veracidade desta hipōtese.

Na anālise dos coeficientes de prevalência de consumo segundo as āreas geogrāificas (itèm 4.3.) observāra mos que os menores valores encontrados nas āreas geogräficas de menor qualidade de vida eram, provavelmente, devidos a uma repressão da demanda por serviços médicos. Ora, a relação dire ta agora observada entre baixo nivel de instrução e consumo de psicotrópicos vem reforçar aquela hipótese. Isto é, se as pes soas de menor nível sócio-econômico consomem mais $e$, no entan to, nas āreas geográficas onde estão mais concentradas obser va-se menores valores globais de consumo,é provāvel que isto se deva a uma repressão da demanda de serviços de saũde. 
5. CONCLUSOES 


\section{CONCLUSŌES}

(1) $I$ descoberta dos modernos psicofámacos a partir do in cio da década de 1950 trouxe mudanças notáveis no tratą mento e prognóstico dos transtornos mentais, particular mente em relação aos distūrbios psicōticos, tendo-se ob servado maiores indices de recuperação de pacientes e utilização mais eficaz dos leitos hospitalares.

(2) A ansiedade è uma erroção necessāria à preservação do in divíduo. Ela pode, no Homer, assumir caracteristicas de uma ansiedade neurōtica que é claramente patológica e passivel de uma abordagem médica; contudo, aquela forma de ansiedade, dita objetiva, que decorre das relações do Homem com o seu reio ambiente é ütil e não tem conotação médica, não devendo ser confundida com a ansiedade neurótica. Tem sido observada uma tendência a enca rar a ansiedade objetiva como um "patos", como algo inc̉esejāvel e, em consequência, se observa uma tendência a buscar o seu alívio atravēs de recursos médicos.

(3) A descoberta dos derivados da benzodiazepina, os quais se mostram bastante eficientes no controle da ansiedade, representou, ao mesmo tempo, um beneficio na redida em que permitiu um método alternativo de tratamento da ansiedade neurótica e um risco, na medida em que pode ser empregada indiscriminadamente para o alivio da ansiedade objetiva. 
Observa-se um crescirento constante e acentuado do consumo de redicamentos psicotrōpicos, particularmen te daqueles que contēr derivacos da benzodiazepina. Es cudos realizados em diversos paises entre 1971 e 1975 indicam que os indices gerais ce prevalència de consumo destes medicamentos entre adultos variaram de 90 a 170 por 1000 habitantes; a maioria dos consu midores se utiliza de ansioliticos, hipnóticos e sedativos, ou seja, produtos que visam ao alivio ime diato da ansiedade.

(5)

A análise do consumo excessivo de medicamentos nsico trópicos leva-nos a admitir que se trata de um fenōmeno multicausal; o estudo das diversas variāveis in tervenientes è complexo e faz-se necessärio realizar diversos estudos méaico-sociais que busquem ura análise profunda de cada variável.

(6) Numa abordagem epidemiológica prelirinar concluímos haver quatro seqmentos diretamente envolvidos com o consumo de redicamentos psicotrópicos e que mantém, entre si, relações dinâmicas: a indústria farmacêutị ca, a classe médica, os pacientes e os proprietārios de farmäcias. A responsabilidade pelos excessos de consumo não deve ser irputada a algum destes secrentos separadamente, mas o poder de influência de cada um è diferentè e, aparenterente, è a indústria farma cêutica que detém a maior capacidade de influenciar - mercado, seja através de sua ação junto à classe médica, seja atravēs de sua ação junto às agências estatais fiscalizadoras de suas atividades. 
o mercado brasileiro de redicamentos psicotrōpicos possui duas caracteristicas facilitadoras do consumo excessivo ou indiscriminado destas drogas. De um lad. a precariedade de fontes independentes de informa ção científica, levando o médico, não raramente, a basear-se somente na informação fornecida pela incūs tria farmacêutica para avaliar as indicações e con tra-indicações de um medicamento. De outro lado, o grande número de produtos que, sob o rótulo de "anti distônicos" e sedativos, podem ser adquiridos livremente nas farmácias, se bem que a leọislação sanitária só permita seu uso sob prescrição médica; assin, escapando ao rigor a que são submetidos os produtos psicotrōpicos em geral, estes "antidistônicos" e sedativos permitem a médicos, pacientes e farmacêuti cos uma certa liberalidade no consumo de psicotröpicos, e à indústria farmacêutica a exploração de um. segmento importante do rercado de medicamentos.

(8) D prevalência em um ano do consumo de medicamentos psicotrópicos entre pessoas de 16 ou rais anos de idade residentes no Distrito de são Paulo foi, em 1976-1978, de 122,2 por 1000 habitantes $(75,7$ por 1000 habitantes no sexo masculino e 163,2 por 1000 habitantes no sexo feminino). A prevalência de consumo nos últimos trinta dias foi de 84,8 por 1000 habitantes para ambos os sexos e a incidência de no vos usuários nesse mesmo período foi de 7,6 por 1000 habitantes $(5,8$ por 1000 habitantes para o sexo masculino e 9,2 for 1000 habitantes para o sexo feminino). 
Existem diferenças significativas nos incices gerais de prevalência de consuro entre as diversas áreas ho mogêneas do Distrito de são Paulo. Foi observado que nas três āreas horrogēneas de melhor qualidade de vi. da 03 níveis de prevalência de consuro são 628 superiores aos níveis das três āreas com fior qualidade de vida. Provavelmente, estas diferenças se devem à maior satisfação da demanda de serviços rédicos nas três primeiras āreas.

(10) Existem três padrões bāsicos de consuro de recicaren tos psicotrópicos. o padrão de consumo recular è o rais frequente $(56,1 \%$ dos casos), seçuido co padrão de consumo esporádico $(38,1 \%)$ e do padrão de consumo episódico $(4,4 \%)$. Os usuários que adotam o padrão es porádico tendem a ser mals constantes, consurindo os medicamentos for mais longo tempo do que os restantes.

(11) 86,58 dos medicamentos consumidos foram ansioliticcs, hipnóticos e sedativos. Os restantes 13,58 pertenciam aos grupos dos neurolépticos, antidepressivos e antico miciais. Dentre os primeiros, 62,68 podem ser adcuiridos em farmācias sem a exiợncia da apresentação de recelta médica. Do total de medicarentos consumidos, 72,88 continham, basicamente, derivados de benzodiazepina. Assim, concluimos aue c consumo de psicotróplcos em nosso relo é essencialmente voltado na ra o alívio da ansiedade e suas manifestaçōes e que as preferências recaer sobre os produtos livres do controle da legislação sobre venda de ssicotrópicos. 
Dentre os produtos de aquisicão livre, os consuricior res de 55 ou mais anos de idade tender a preferir os produtos à base de barbitüricos e extratos vecetais enquanto os grupos rais jovens preferem os derivados da benzodiazepina. Isto reflete, possivelmente, as mudanças de padrões culturais frente às drogas osico trópicas, levando-se er conta que as benzodiazepinas são de aquisição relativamente recente.

Em 81,68 dos casos o uso destes medicamentos foi indicado por médicos. Seguer-se as auto-indicaçōes $(10,2 \%)$, as indicações de parentes ou conhecidos $(4,4 \%)$ e as indicações de "farmacêuticos" $(2,7 \%)$. O clinico geral é responsāvel por 57,4 de todas as indicaçōes e o médico psiquiatra responsável por 12,28. Observou -se una clara preferência pelos produtos livres de controle de receituārio por parte dos clínicos gerais.

(14) A idade média dos consumidores é 5,13 anos maior do que a idade média dos não consumidores de psicotrōpí cos. Entre os consumicores observa-se un nitico au mento dos indices de prevalência de consumo a partir da faixa etāria de 35 a 45 anos, atingindo os maiores valores entre 55 e 65 anos de idade $(179,6$ por 1000 ha bitantes).

(15) Em todos os grupos etários as mulheres sempre apresen taram coeficientes de consumo mais elevados do tue os homens. 70,98 dos consumidores são do sexo ferint no e a relação entre os coeficientes ce prevalência de consumo do sexo feminino e rasculino é içual a 2,16. 
(16) Não se observaram diferencas estatisticamente sicnificativas nos níveis de consumo entre as pesscas de diferentes estados civis e diferentes orupos de idade. Contudo, hä indicios is que os maiores coeficien tes de prevalência de consuro se encontrer entre as mulheres viúvas, descuitadas e separadas com idade compreenaida entre 30 e 50 (coeficientes de prevalên cia estimado em 282,6 por 1000 habitantes).

(17) Não foi observado associação entre consumo de medica mentos psicotrónicos e o indice de aglomeração domiciliar.

(18) Observou-se uma associação estatisticarente siọnificativa entre os níveis de consumo de medicamentos psicotrōpicos e o grau ce instrução. As pessoas cor menor grau de instrução são as que mais consorem, seçuindo-se as pessoas de instrução mëdia e, com os menores níveis de consumo, as pessoas de instruçāo superior. 
6. REFERENCIAS BIBLIOGRAFICAS 
1. ASSOCIAÇÃO BRASILEIRA DA INDOSTRIA FARMACEUTICA - E O brasileiro um hipocondriaco? Rev. pauli. Med., 91: VIII, mar/ abr., 1978.

2. ASSOCIAÇÃO BRASILEIRA DA INDOSTRIA FARMACEUTICA - Carta semanal da Ablfarma, n: 694 J. bras. Med., 37:80, 1979.

3. BAKSAAS-AASEN, I. et al. - Drug dose statistics: list of defined doses for drugs registered in Norway. Norsk Medisinaldepot, Oslo, 1975.

4. BALINT, E. \& NORELL, J. S. - Sels minutos para o seu paciente. São Paulo, Editora Manole, 1976.

5. BALINT, M. - O médico, seu paciente e a doença. 2a. ed., Rio de Janeiro, Livraria Atheneu, 1975.

6. BALINT, M. et al. - Treatment or diagnosis: a study of repeat prescriptions in general practice. London, Tavistock Publ., 1970.

7. BALTER, M. B. et al. - Cross-national study of the extent of anti-anxiety/sedative drug use. New Engl. J. Med., 290: 769-774, 1974 .

8. BENEDETTI, G. - La angustia desde el punto de vista psiquiatriCo. In: HEDIGER, H. et al. - La anoustia. Madrid, Tribuna de la Revista de Ocldente, 1960. p.201-238.

9. BETTS, T. A., et al. - Effects of four commonly-used tranguilizers on low-speed driving performance tests. Brit. Med. J. , 4:580, 1972 .

10. BLACKWELL, B. - Psychotropic drugs in use today. J.Amer. med. Ass., 225:1637-1641, 1973

11. BOETHIUS, G. \& WESTERHOLM, B. - Purchases of hypnotics, sedatives and minor tranquilizers among 2.556 individuals in the county of Jumtland, Sweden. pcta psychiat. scand., 56:147$159,1977$. 
12. BUPNER, M. - Usage immoderē des medicaments: information et prēvention. Med. et Hyg., Geneve, 33(1136):245, 1975.

13. BUSH, P. J. \& RABIN, D. L. - Who's using nonprescribed medicines? Med. Ca: $\because$, 14:1014-1023, 1976.

14. CAMILLERI, J. A. - Civilization in crisis. Cambricge, Cambridge University Press, 1976.

15. CAPLAN, G. - Principles of preventive.psychiatry. London, Tavistock Publications, 1966.

16. CARMODY, J. et al. - Patterns of the use of benzodiazepines in Australia. Med. J.Aust., 2:666-668, 1977.

17. CHRISTIE, D. - "The analgesic abuse sundrome": an epidemiological perspective. Int. J. Epidem., 7:139-143, 1978.

18. COOPERSTOCK, R. - Sex differences in the use of mood modifying drugs. J.Hlth. soc. Behav., 12:238-244, 1971 .

19. DECRETO no 79.094 - 05 de janeiro de 1977. Reoulamenta a Lei no 6.360, de 23 de setembro de 1976, que submete a sistema de vigilância sanitäria, os medicamentos, insumos farmacêuticos, drogas, correlatos, cosmëticos, produtos de higiene, saneamento e outros. In: MINISTERIO DA SAODE. Legislação Federal do Setor Saüde. Brasilla, 1977. v.3, p. 958-997.

20. DENIKER, R. - La psychopharmacoloqie. Paris, Press Universitaires de France, 1966.

21. EIMES, P. C. et al. - Prescribing in Northern Ireland: study no 1, sleeping tablets. Ulster med. J., 45:166-177, 1976.

22. FINEPE constata fraude no setor farmacêtico. Folha de são Paulo, 6 jun. 1979 .

23. FISHER, E. \& CIAFARDO, R. - Farmacoterapia de las enfermedades nerviosas y mentales. Buenos Aires, Editorial Beta, 1971. 
24. FREEDMAN, A. M. et al. - Comprehensive textbook of psychiatry. 2nd. ed. Baltimore, Williams and Wilkins, 1975.

25. FREUD, S. - Inhibicion, sintoma y anaustia. In: Obras completas, Madrid, Editorial Biblioteca Nueva, 1968, v.2, p. $31-71$.

26. FREUD, S. - A ansiedade. In: - Conferências introdutōrias sobre osicanálise. Rio de Janeiro, Editora Imađo, 1976.

27. GODDARD, J. L. - The medical business. Sci. amer., 229:161-166, 1973.

28. GUIMARÃES, C. et al. - Programa de Saúde Mental. Rev. Saúde Publ., S. Paulo, 9:551-3, 1975.

29. HEDIGER, H. - La angustia del animal. In: HEDIGER, H. et al. La anqustia. Madrid, Tribuna de la Revista de Ocidente, 1960 , D. 13-50.

30. HEMMINKI, E. - The effect of a doctor's personal characteristics and working circunstances on the prescribing of psychotropic drugs. Med. Care, 12:351-357, 1974.

31. HINSIE, L. E. \& CAMPBELL, R. J. - Psychiatric dictionary 4th. ed., New York, Oxford University Press, 1970. p. 49-50.

32. HORDERN, A. - Psicofarmacologia: algunas consiceraciones histöricas. In: JOYCE, C. R. B. et al. - Psicofarmacologia: dimensiones y cerspectivas. Buenos Aires, Editorial Beta, 1970. p. 115-170.

33. HUXLEY, A. - Admirável munco novo. lla. ed. Pio ce Janeiro, Companhia Brasileira de Divulgação do Livro, 1969.

34. ILLICH, I. - A expropriacão da saūde: nemesis da redicina.

2a. ed. Rio de Janeiro, Nova Fronteira, 1975.

35. IMS - Mercado Farmacêutico: Brasil. Catálogos de 1972 a 1977. 
36. JOYCE, C. R. B. et al. - Personal Factors as a cause of differences in prescribing by general practitioners. Brit. J. prev. soc. Med., 22:170-177, 1968.

37. LANGNER, T. S. \& MICHAEL, S. T. - Life stres. and mental health: the Midtown Manhattan Study. London, Free Press, 1963.

38. LEI n9 6.360 - 23 de setembro de 1976. Dispõe sobre a vigilância sanitária a que ficam sujeitos os medicamentos, as drogas, os insumos farmacêuticos e correlatos, cosméticos, saneantes e outros produtos, e dà outras providências. In: MINISTERIO DA SAODE. Legislacão Federal do Setor Saúce. Brasilia, 1977, v.1, p. 162-179.

39. LORENZ, K. - Civilização e pecado. Rio de Janeiro, Ed. Artenova, 1974 .

40. MANEEIMER, D. I. et al. - Popular attitudes and beliefs about tranquilizers. Amer. J. Psychiat. , 130:1246-1253, 1973.

41. MAPES, R. E. A. - Psysician's drug innovation and relinguishment. Soc. Sci. Med., 11:619-624, 1977.

42. MELLINGER, G. D. et al. - Patterns of psychotherapeutic drua use among adults in San Francisco. Arch. gen. Psychiat., 25:385-394, 1971 .

43. MILES, D. L. - Multiple prescriptions and drug appropriateness. Hilth. Serv. Res., 12:3-10, 1977.

44. MOREIRA, M. J. C. et al. - Rlguras consideraçc̄es scbre o uso de ansiolíticos em nosso meio. Rev. Ass. bras. Psiauiat., $\underline{2}: 10-18,1979$.

45. MULLER, C. - The over medicated society: forces in the marketplace for medical care. Science, 176:488-492, 1972.

46. ORWELL, G. - 1984. 7a. ed. São Paulo, Companhia Editora Nacional, 1974. 
47. PNRRY, H. et al. - National patterns of psychotherapeutic crug̣ use. Arch. ren. Psychiat., 28:769-783, 1973.

48. PLUNKETT, R. \& GORDON, J. - Epicemiolocy and mental illness. New rork, Basic Books, 1960.

49. PÖLDINGER, W. - Compêndio de psicofarmacoterapia. Basle, Suiça, Serviço Científico Roche, 1968.

50. PORTARIA N8 20 de 6 de setembro de 1977. Instruçōes sobre proibição, limitação, fiscalização e controle de produção, do comércio e do uso de substâncias que determinem dependência física ou psiquica e medicamentos que as contenham. Diārio Oficial da União, 11 nov. 1977 - Seção I, Parte I, p. 15302-10.

51. PORTARIA No 26 de 26 de julho de 1974, do Serviço Nacional de Fiscalização da Medicina e Farmācia do Ministērio da Saúde. Diārio oficial da uniño, 14 de out. de 1974.

52. REMEDIOS mais consumidos podem prejudicar a saúde. O Estado de são paulo, 22 set. 1976, p. 15

53. ROCHE SCIENTIFIC SERVICE - From emotion to lesion. Basle, Suiça, Roche, 1969, p. 42-50.

54. RYCROFT, C. - Anxiety and neurosis. London, Penouim Books, 1970.

55. SCHULZ, P. - I'utilization de sources d'information sur les mēdicaments: revue de la littērature. Praxis, 65:1115-1120, 1976.

56. SECRETARIA DA ECONOMIA E PLANEJAMENTO - Subdivisão do Municipio de são Paulo em áreas homogêneas. São Paulo, 1977. (Estudos e Pesquisas, 13)

57. SELYE, H. - Stress: a tensão da vida. São Paulo, Ibrasa, 1959.

58. SILVERMAN, M. - The epidemiolooy of drug promotion. Int. J. Hlth. Serv., 7:157-166, 1977. 
59. SIVGARD, J. - La place du medicament dans I'economie de la santé. Thērapie, 32:529-552, 1977.

60. WAGHORN, J. M. - Influences affecting the increasing use of psy, hotropic drug, specially by woman. Hlth. Educ. J., 35: $231-237,1976$.

61. WALDRON, I. - Increased prescribing of Valium, Librium and other drugs: an exemple of the influence of economic and social factors on the practice of medicine. Int. J. Hlth. Serv. , 7:37-62, 1977 .

62. WANDREY, D. \& LEUTNER, V. - Los neuropsicofarmacos en la clinica y en la practica. Barcelona, Editorial Cientifico Medico, 1967.

63. WILSON, C. W. et al. - Influence of different sources of therapeutic information on prescribing by general practitioners. Brit. Med. J., 2:599-604, 1963.

64. WOTRING, C. E. \& SCHMELLING, D. - Mood altering drug abuse: the perceptions of middle age women concerning the use and abuse of prescription drugs. J. Drug Educ., 7:123-131, 1977.

65. VON GEBSATELL, V. E. - Prolegomena einer medizinischen Anthropologie. Citado In BENEDETTI, G. - La angustia desde el punto de vista psiquiátrico. In: __ - La angustia. Madrid, Tribuna de la Revista de Ocidente, 1960. p. 201. 
ANEXO 01 


\section{No executivo.}

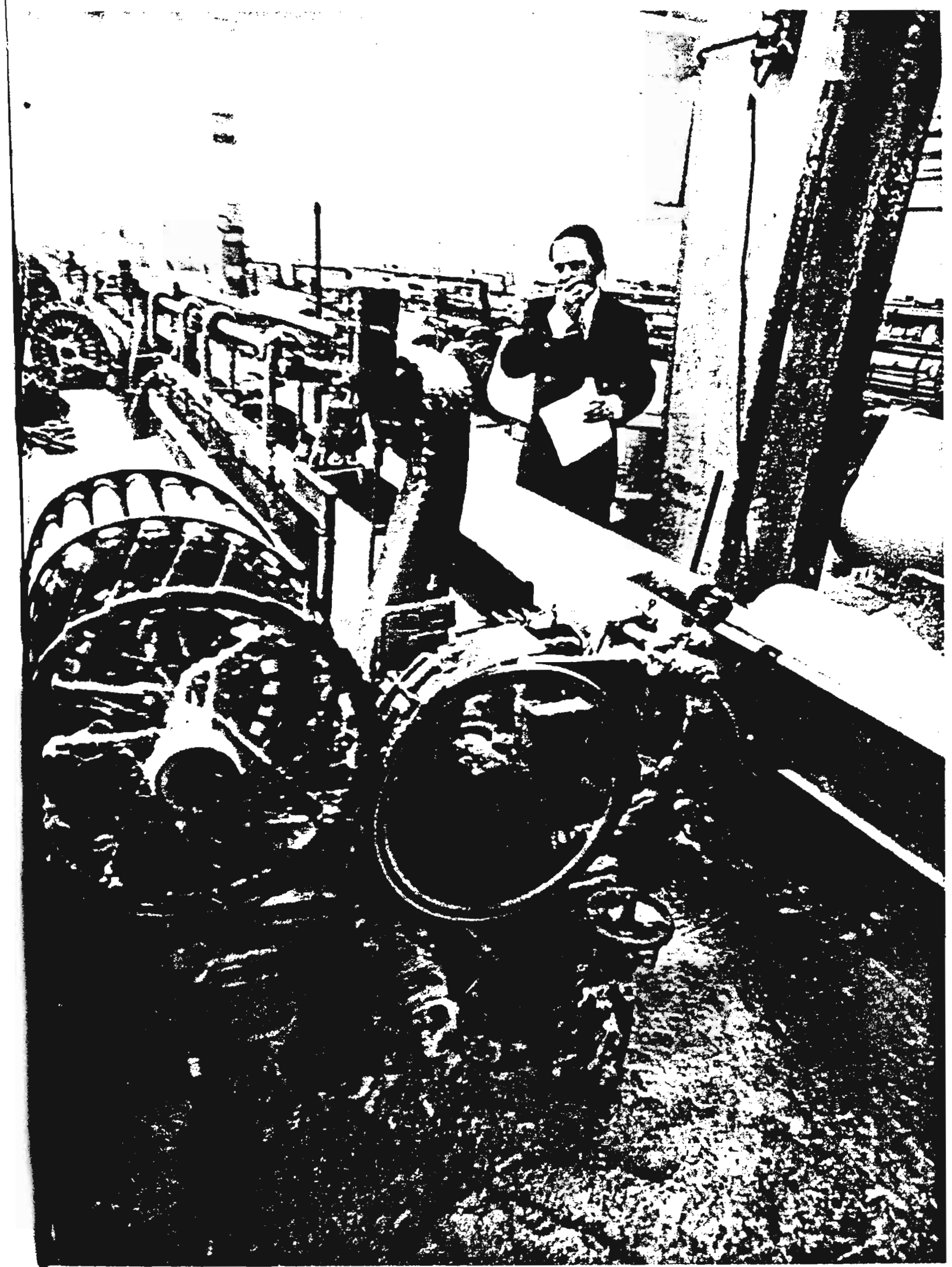

Wuardo ( 38 anos) vive em estado ansioso porque assumiu todas as responsabilidades da empresa e náo tem tempo de fazer tudo o que queria. 


\section{Nadona-de-casa.}

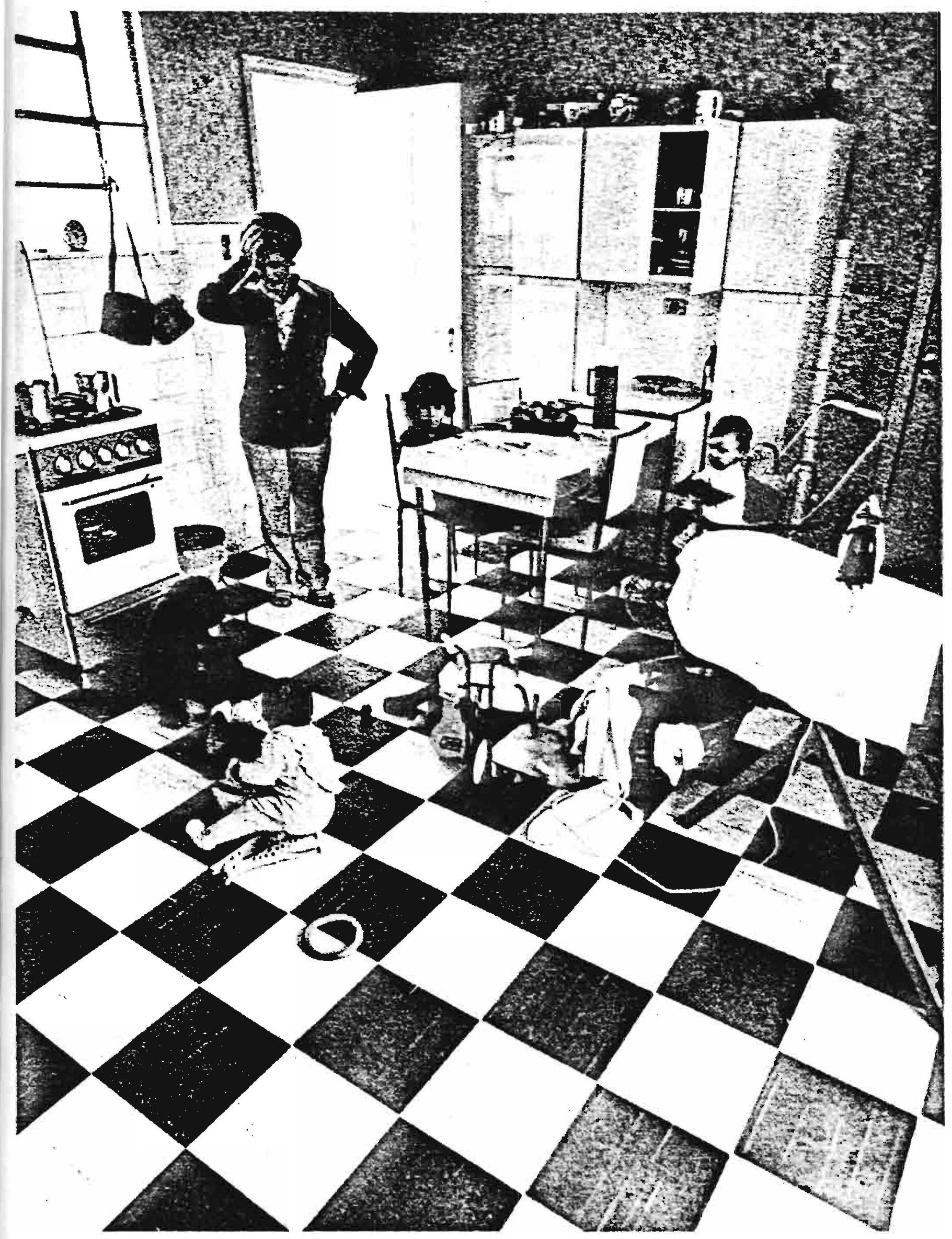

Da. Dirce ( 36 anos) vive em estado ansioso porque nằo consegue mais ser lavadeira, arrumadeira, cozinheira, costureira, babá, professora, administradora do lar, motorista das crianças, e uma esposa tranqüila ao mesmo tempo. 
No oveme

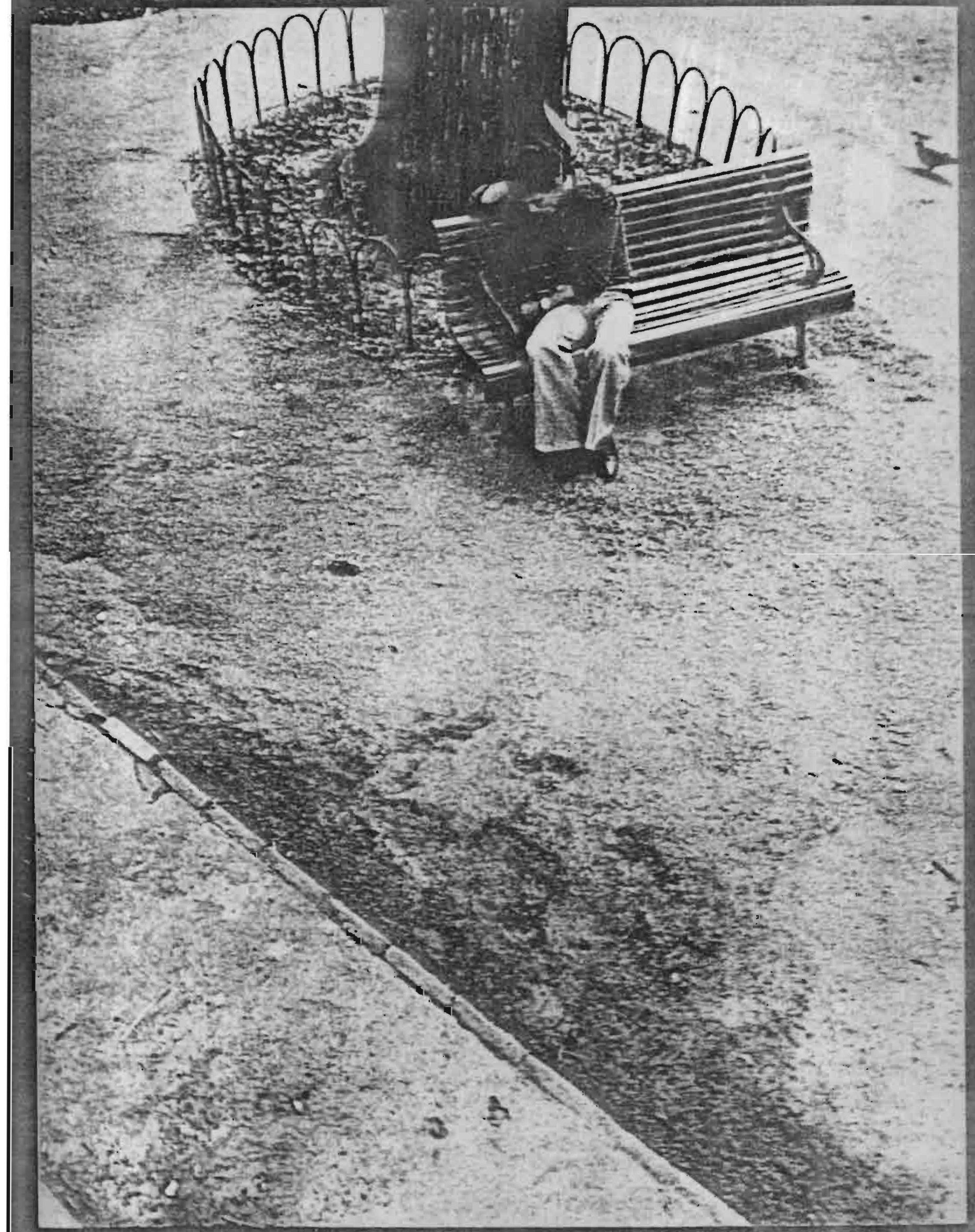

Gabriel (19 anos) vive em estodo ansíoso porque näo sente arracäo pelo que narmalmente darioprazer oum jovem da sua idade. 
Noadvilo.
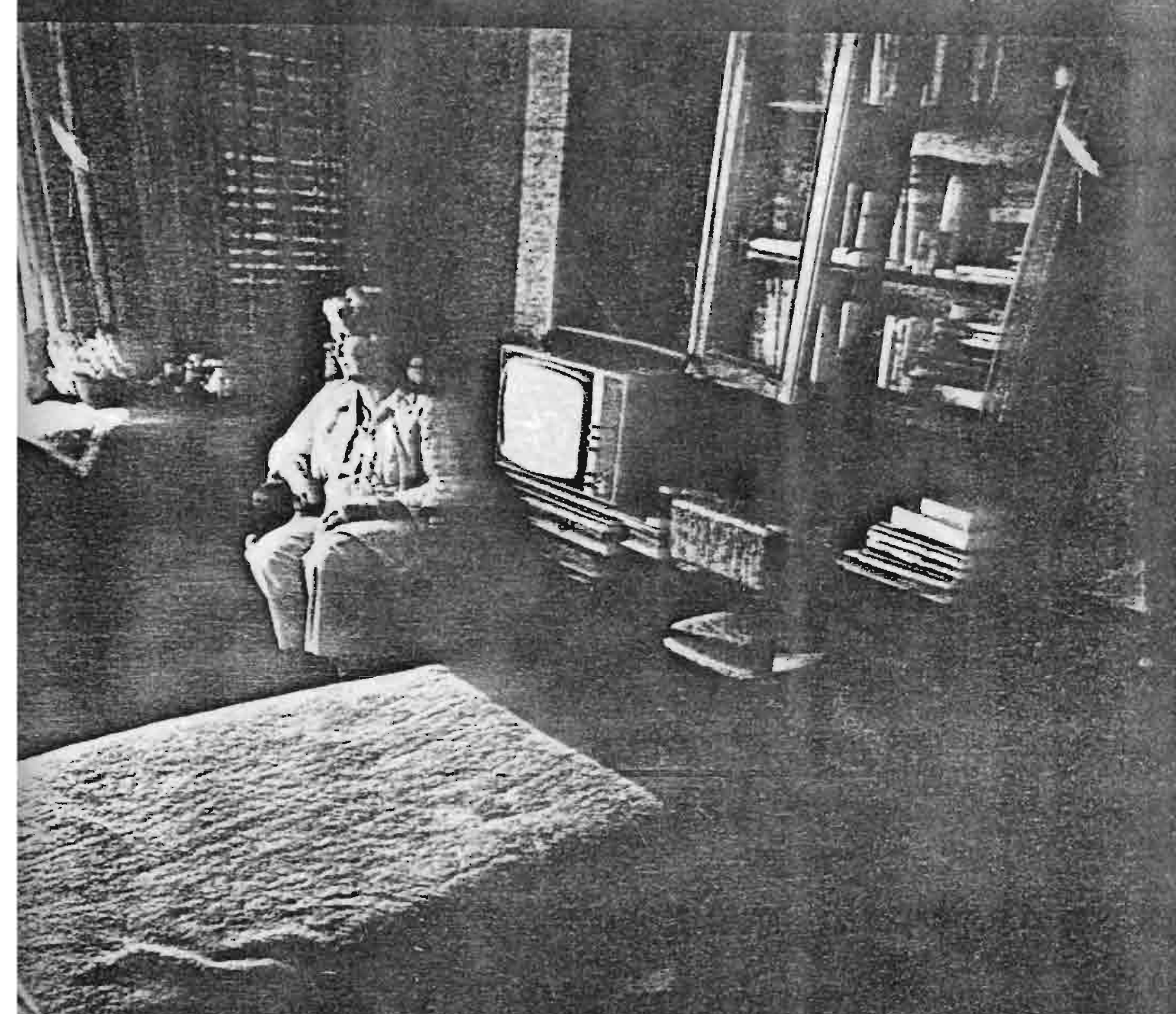

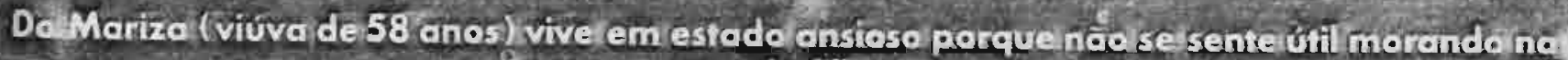
casado filio. 


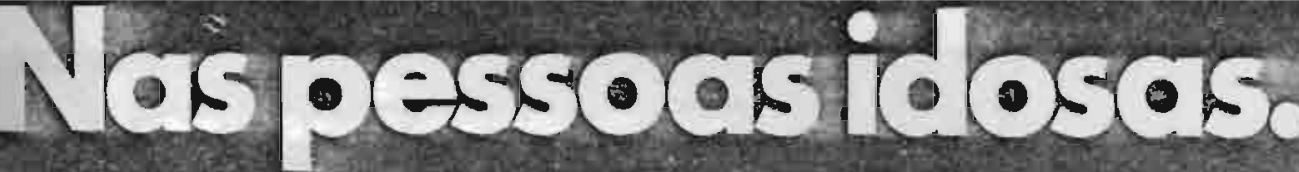

(F)

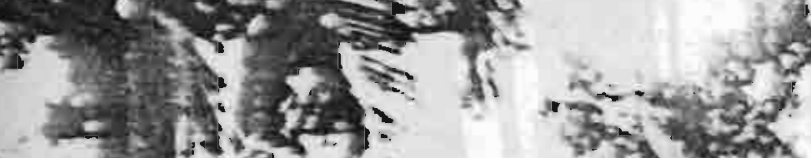

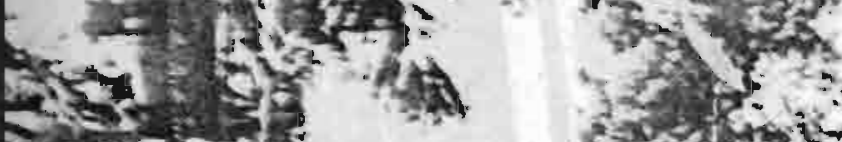

Q

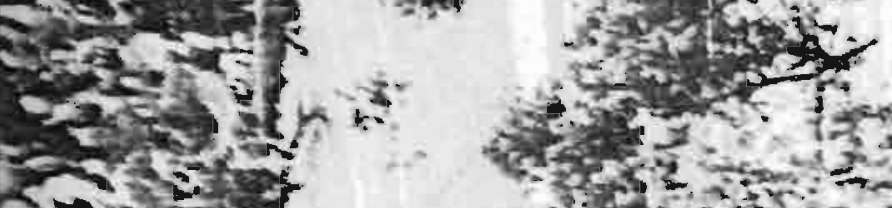

artint?

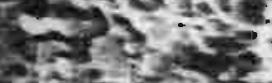

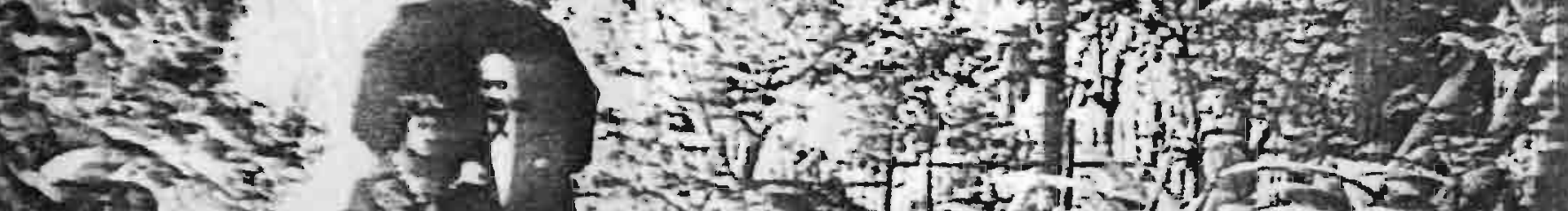

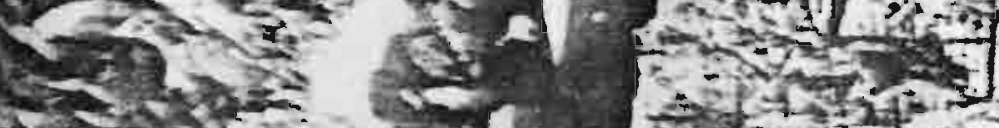

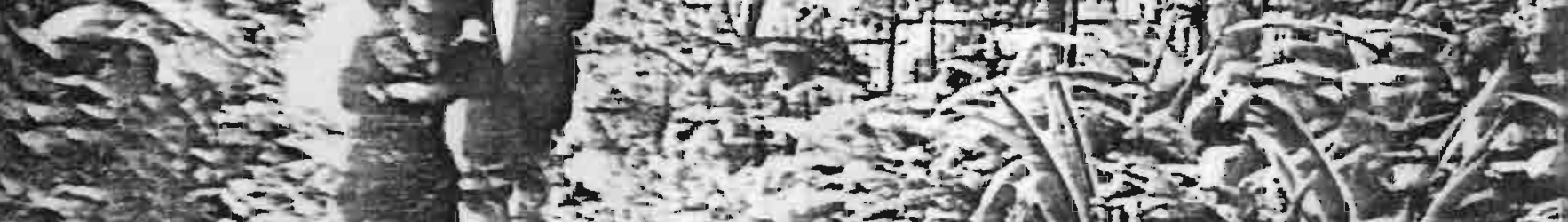

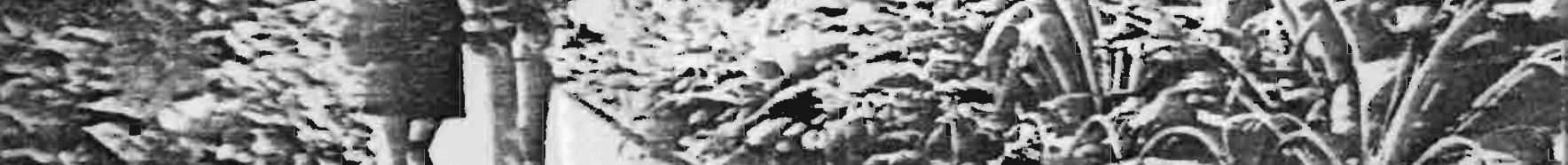

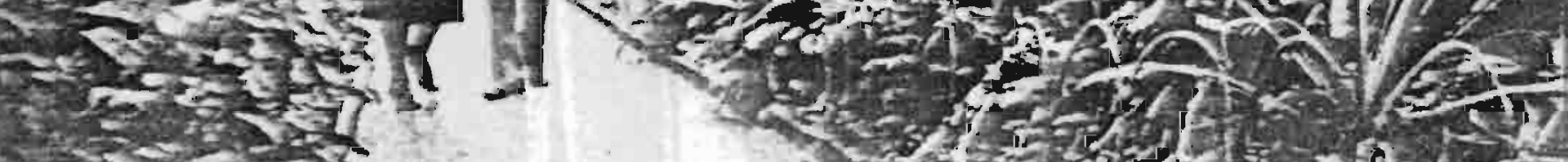

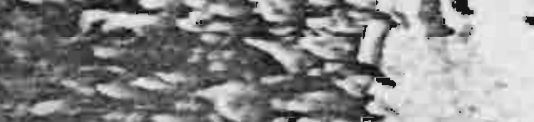

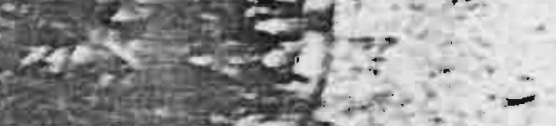

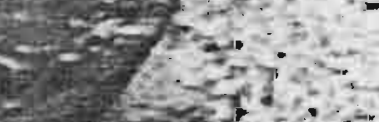

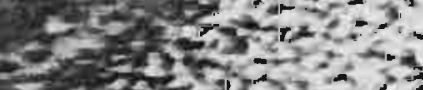

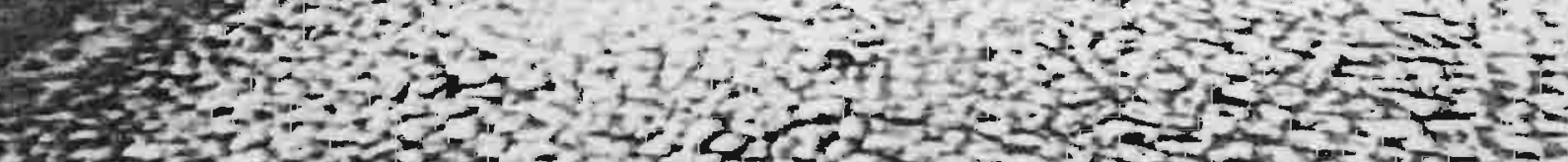

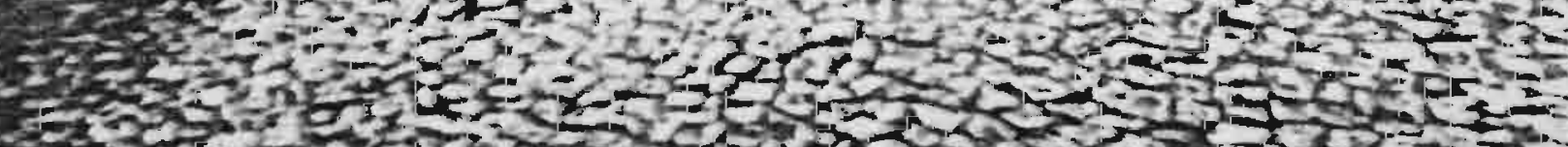

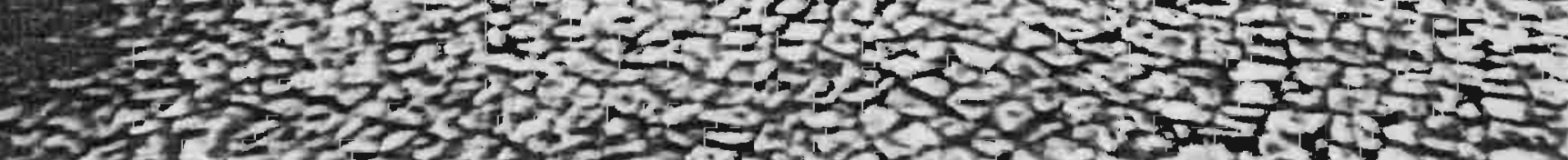

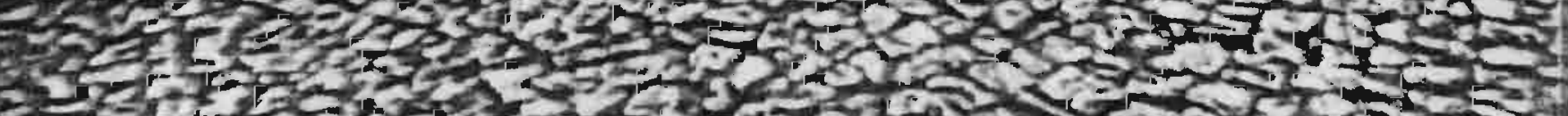

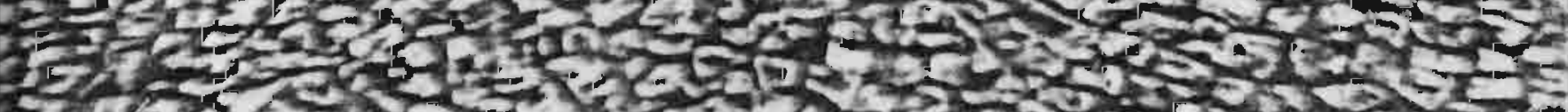

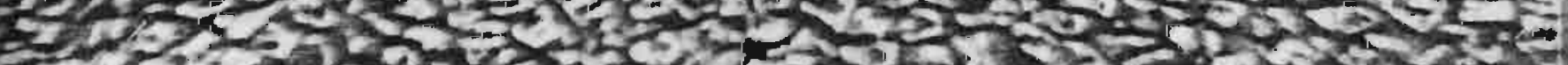

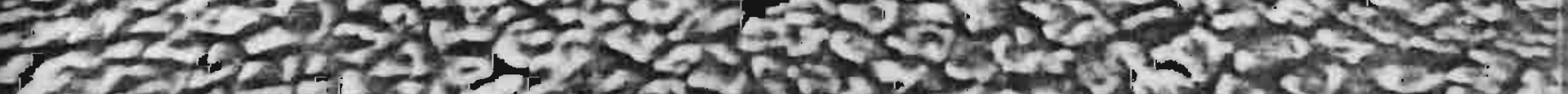

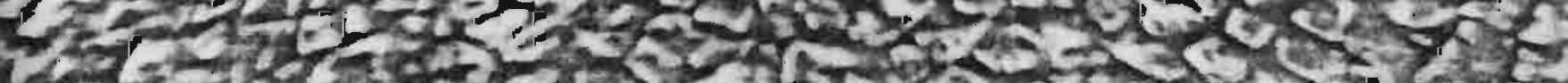

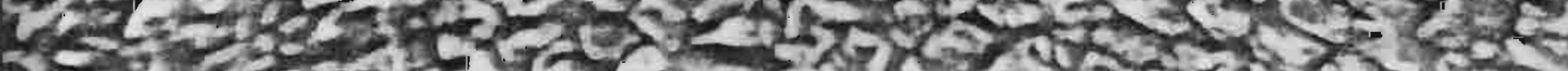

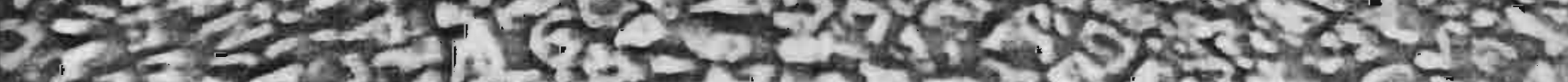

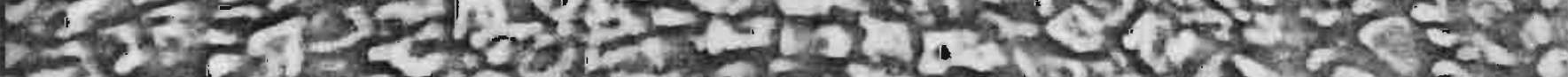

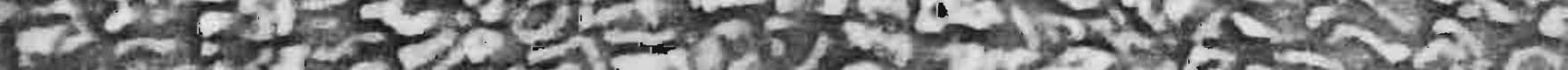

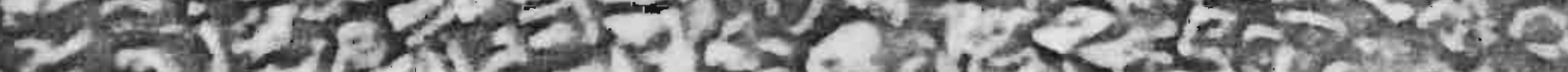

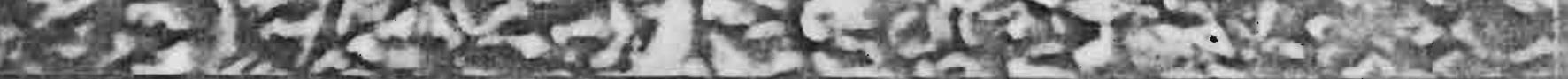

"Seu"Jose e Da. Ano (68.e67 anos) viven em esfado ansioso porque tem medo de se verem. sozinhos derepente: 


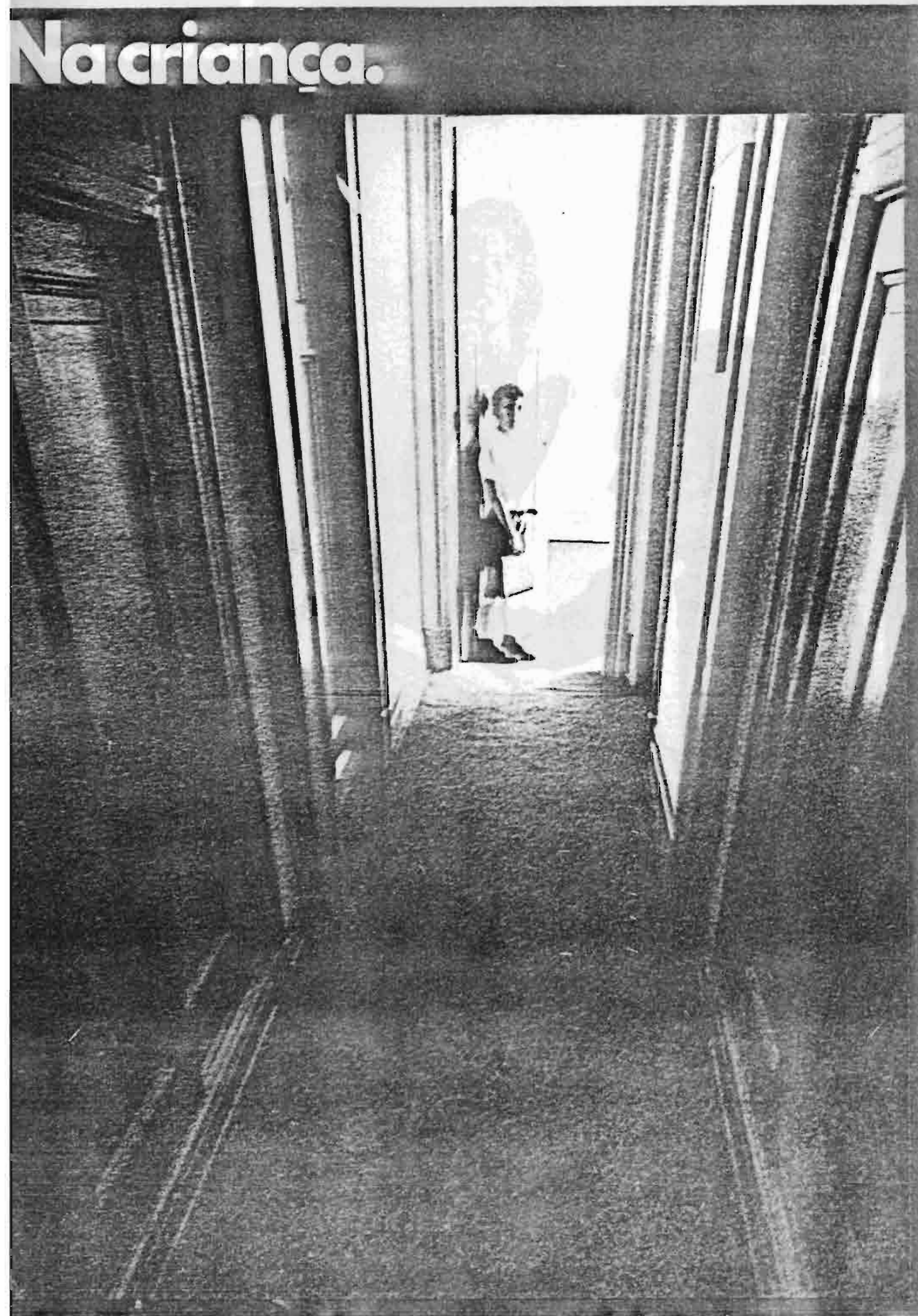

Fábio (10 anas) vive em este 3 ansioso porquetem medo de nao ir bem nos provas

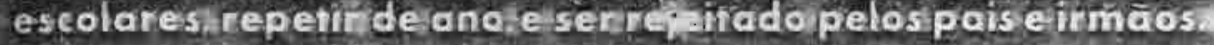


01 SE

02 LIE ERDADE

03 PENHA DE FRANÇA

04 NOSSA SENHORA DO 0

05 SANTA EFIGENIA

06 BRÁS

07 CONSOLAÇÃOO

08 SANTANA

09 VILA MARIANA

10 BELENZINHO

11 SANTA CECILIA

12 CAMBUCI

13 BUTANTA

14 LAPA

15 BOM RETIRO

16 MOOCA

17 BELA VISTA

18 IPIRANGA

19 PERDIZES

20 JARDIM AMERICA

21 SAUDE

22 TUCURUVI

23 CASA VERDE

24 INDIANOPOLIS
25 PART

26 VILA PRUDENTE

27 TATUAPE

28 JARDIM PAULISTA

29 SANTO AMARO

30 I BIRAPUERA

31 PIRITUBA

32 CAPELA DO SOCORRO

33 ALTO DA MOOCA

34 CERQUEIRA CESAR

35 BARRA FUNDA

36 VILA MARIA

37 ACLIMAÇÃO

38 VILA MATILDE

39 VILA MADALENA

40 BRASILANNIA

41 CANGATBA

42 JABAQUARA

43 JAGUÁRA

44 LIMAO

45 PINHEIROS

46 VILA FORMOSA

47 VILA GUILHERME

48 VILA NOVA CACHOEIRINHA 


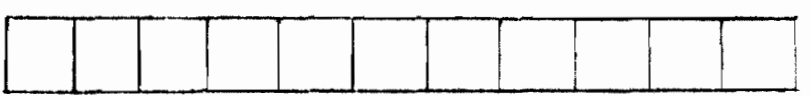

ENLCREYO $-8$ COMPL. BAIRRO:

ENTREVISTADOR:

I. Apresente-se, dizendo o porque da entrevista e porque essa casa foi selecionada. (Seguindo as instruçóes do trainamenta).

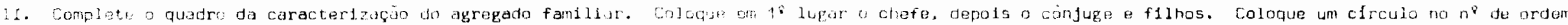
do arlisaristicto.

SOLRENUME

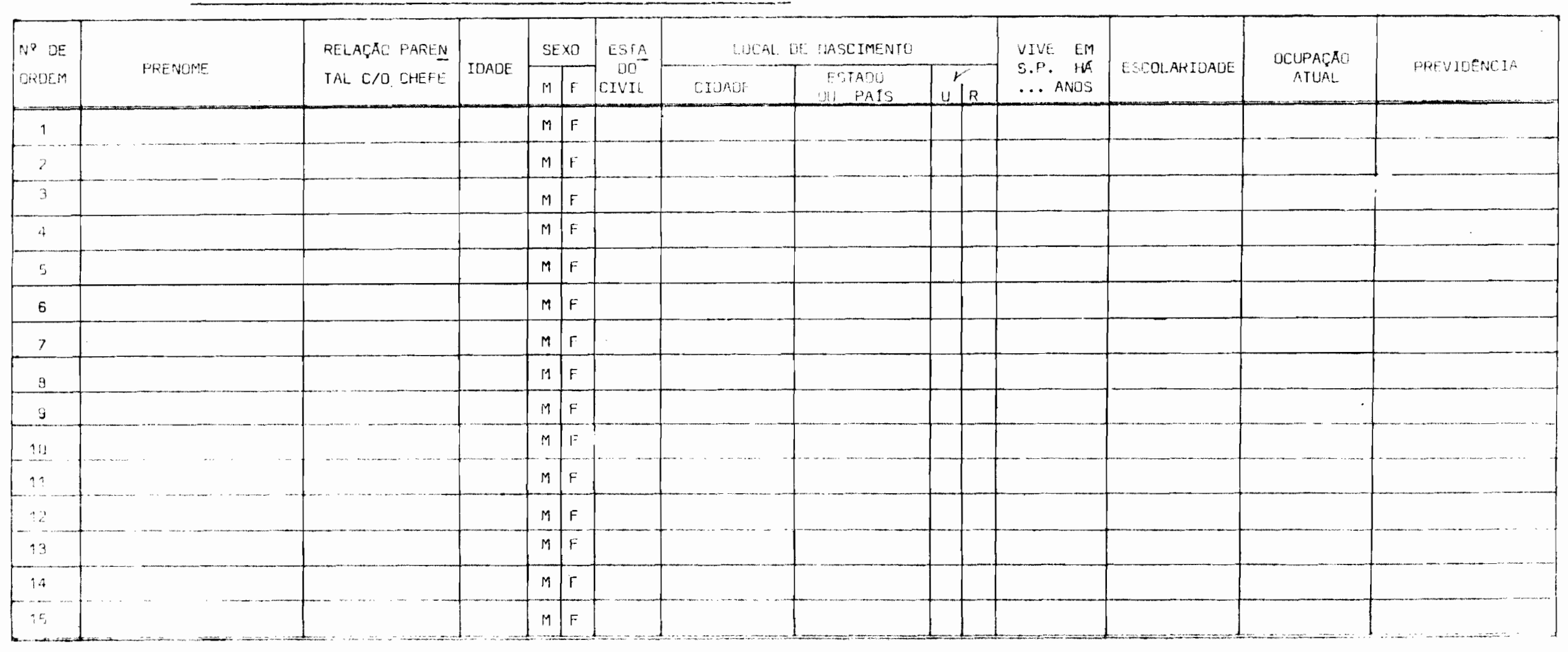

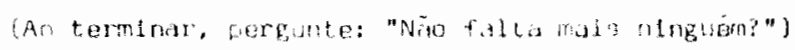




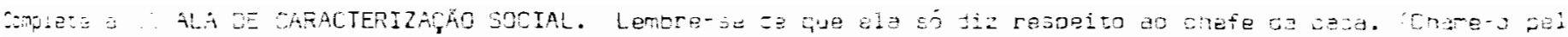
nates).

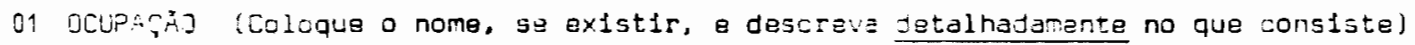

EXPLICACO:

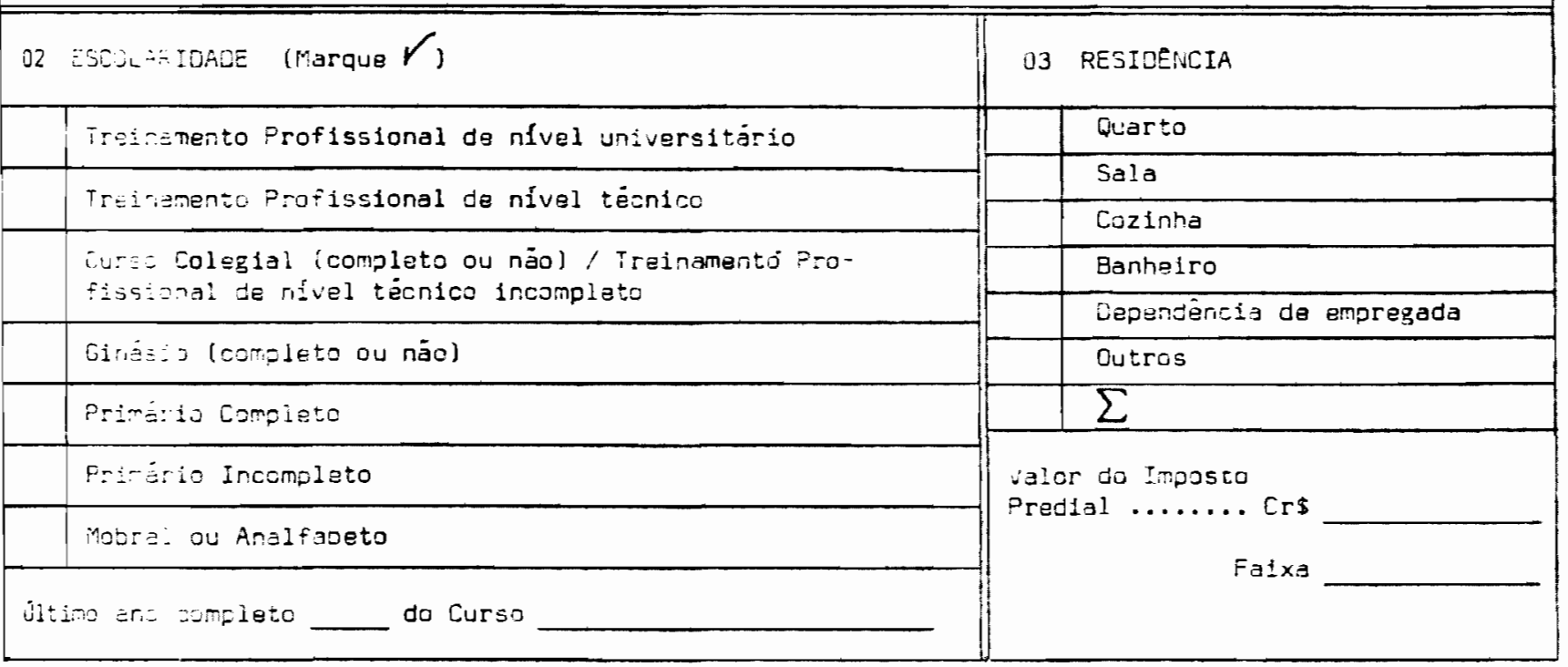

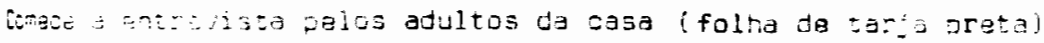




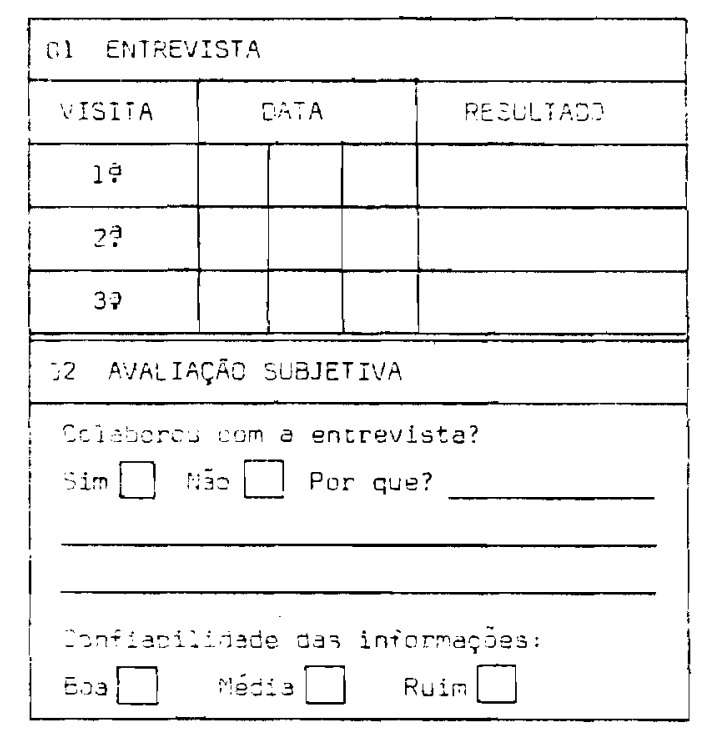

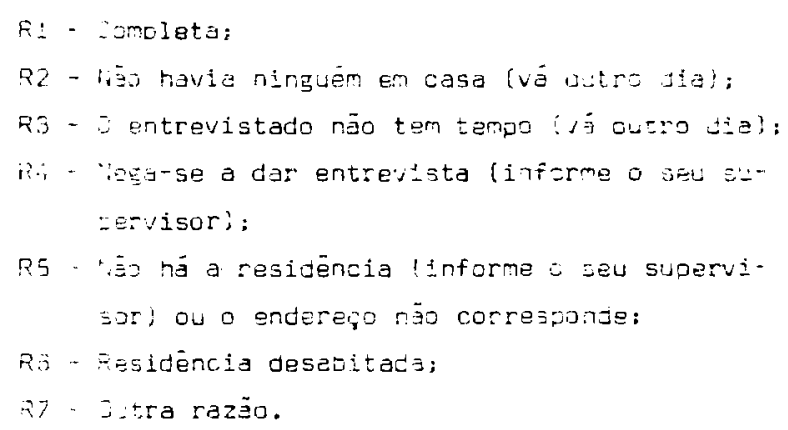

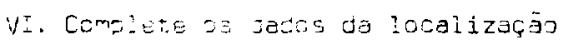

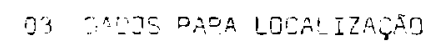
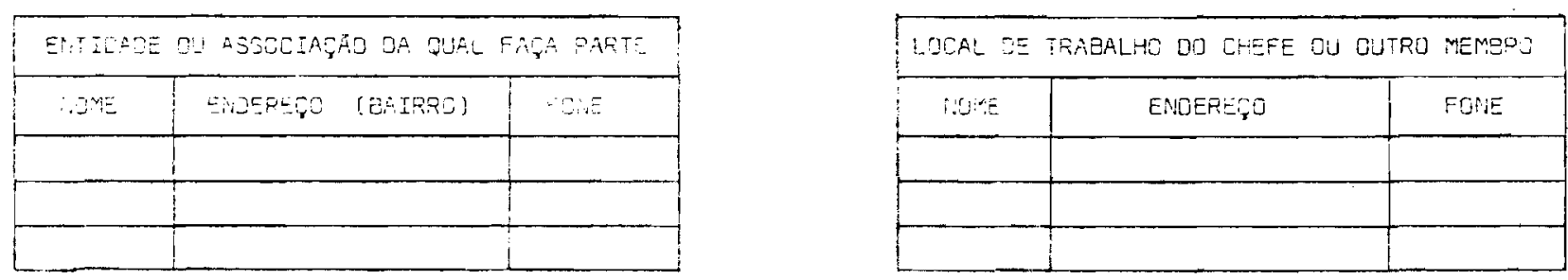

\begin{tabular}{|c|c|}
\hline WAI SE MLAP? & $\sin \square$ Loos? \\
\hline Na= $\square$ IEncra & $\begin{array}{l}\text { Sate }-1 \text { ' Lum podg inionmar } \\
\text { sobre o novo local ae noradie? } \\
\text { Nome: }\end{array}$ \\
\hline & Enderego: \\
\hline
\end{tabular}

Qual o horério pelhor para 100alizer os gue trabalnam fora?

\begin{tabular}{|l|l|}
\hline iN8 DE ORDEM & HOAKARIJ \\
\hline & \\
\hline & \\
\hline & \\
\hline
\end{tabular}

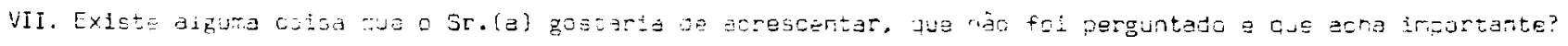

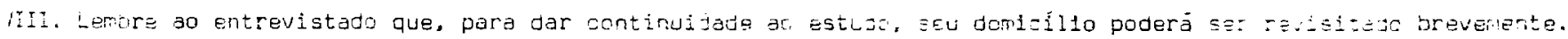
SBSEF: PUES: 


\section{AOULTOS}

M. TE DRDEM DOS QUE PRESTARAM IMFORMACEES:

:SSAO: OCUPAFTO ATUAL:

१:

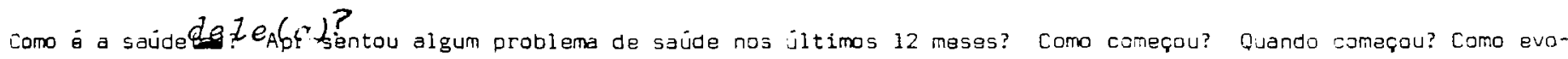
luiu?

Durante este ulltimo ano elela) foi alguma vez examinadola) por algum mëdiço ou esteve hospitalizadola) ? (Anotar nomes. locais e outros motivos]

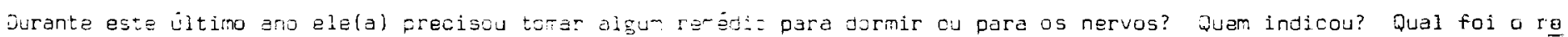

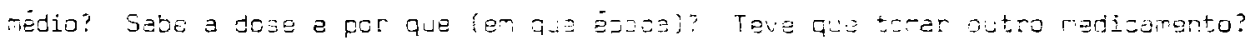

Ele(a) sofre dos nervos? Desde quando? (Cescrever er. dessines ninuciosos)

Ten ou teve desmaios, etaque de bichas ou convilsöes? Prezisou ser tratado? Con que idade?

Elelaj apresentou alguma mujança no seu comportamento, nas suas idéias ou na maneira ą r.ezaz as pessoas? Apresentou idélas ou comfortamentos que lhe pareceram absurdos ou eszzanhos? Quais? 


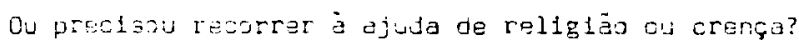

0. Ache que (nome) recisarla ter consultado médico ou tjtrada remédio para tratar de problemas de nervos? que médico? Que remájio?

1. Comic elela) é no trabalno?

2. Cono ala! a) in ns estudos?

3. Achu que eleia) cete demais? U. passou a faze-lo nos ultimos 12 .meses? (Descrever bem o que o(s) informantels) entendelm) por "dersiz":

4. D uso do álcool je lie causou problemas? isaúde física e mentai, no trecalno, com a fariliz, amigos ou vizinhos, con a Polícia) (Se esta for dositiva, $e$ a anterior negativa, volte à $n^{8} 13$

s.

. (nume)

\begin{tabular}{|l|l|}
\hline $11 \mathrm{~A}$ & Marque um $r$ (Jescrever em detalnes os motivos) \\
\hline & muaou de emprego nos ültimos 12 meses \\
\hline & perou de trabalhar nos últimos 12 meses \\
\hline & perdeu dias de serviço \\
\hline & tem se queixado multo ou parece 1risatisfeito \\
\hline & näo trabal ha \\
\hline & nenhuma das anteriores \\
\hline
\end{tabular}

\begin{tabular}{|l|l|}
\hline IZA & Marque um $/$ \\
\hline & néo estuda \\
\hline & $\begin{array}{l}\text { ten tido dificuldade para acompanhar o programa } \\
\text { nos últimos } 12 \text { meses }\end{array}$ \\
\hline & $\begin{array}{l}\text { pardeu aulas (cescrever ao lado porque) } \\
\text { teve problemas na escola (descrever eo lado por- } \\
\text { quel }\end{array}$ \\
\hline
\end{tabular}




\section{RETEIR OE ETREUISTA}

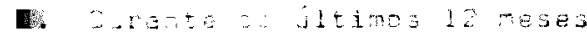

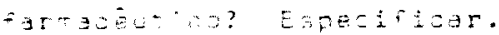

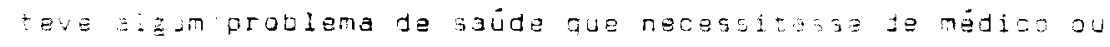

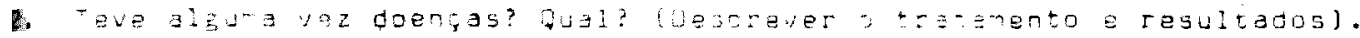

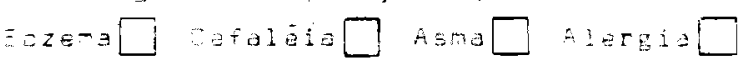

(3. Toma a:

4. 40,2 ans: $(n \in m e)$

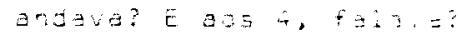

\begin{tabular}{l} 
(nome) \\
\hline \\
\hline \\
\hline
\end{tabular}

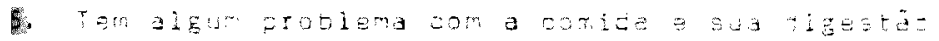

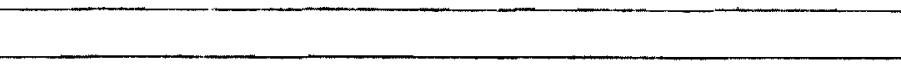

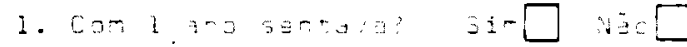

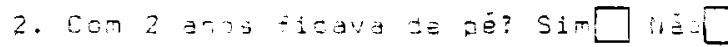

3. Dopoiz Je sentarlenzarlialar deixou

de $+3 z \bar{c}-10$ ?

Con que idade?

Sate por que:

1. Pouco $\square$ ou muit! ape:ito

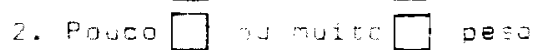

3. Recusa alimentar-a sen motivo justo? aug ?

4. vomiton $\square$ iareid Jastipajo $\square$

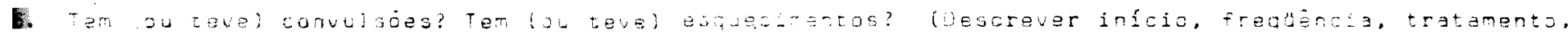
$0+0.1-$

zomo pesa nos objetos?

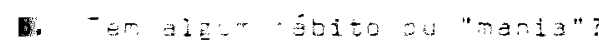

t.

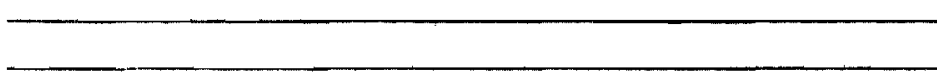

"gano" a tienderamento delelal?

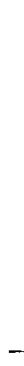

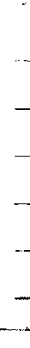




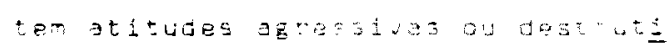
zj que coeguem a provocar recianazzes de dutras pej :as. como por exemplo. os vizinios? i. Tem atos aresinas

destrutivos $\square$ de refenta $\square$

2. Mente $\square$ Rouna $\square$ pór foga nas coisas

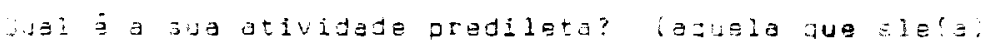
:yto de passor a rajoz parte do soj temol.

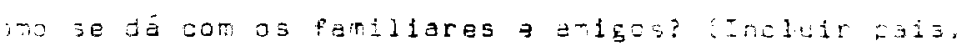
aris, zus. ets. ?

fala sozinholal? Er fug 203510 d ?

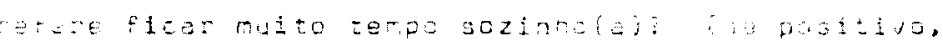
peificar a ativiala ?

nedos (de coisas, situaçöes, 2ess=as, enimsis)

rogativo, fazer iriventäriol

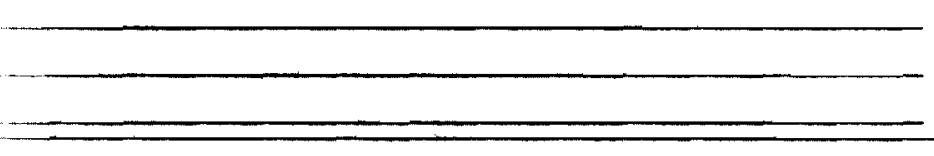

algum problema de sono?

SES DO ENTREVISTADOR:
2. Muto goedierte $\square$ Guizting $\square$ jemaiz $\square$

2. isslaja[ hjo se da $=2 m$ autras cridor.

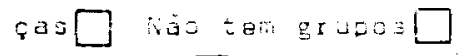

3. E infaic $\square$ Nis conversa $\square$

4. Faz colses sem sentida $\square$

5. Nāo consegue beincar ajequademente com binguesos $\square$

1. Tom meco de arimais $\square$ jojetos $\square$ de dormir cu atormecer sozintala) $\square$ de escuro $\square$ de outras crianças $\square$ de ajultas $\square$ de triszs $\square$ de separar-se da mà $\square$

(Esclarecer os termos médicos)

1. Nào peza na soro $\square$ Acorda $\square$ Enurese noturna $\square$ Terror roturno $\square$ Soniliaulo $\square \quad$ Sonambulismo $\square$ 
ROTEIRO DE ENTREVISTA

1. Durante os uitimos 12 meses teve algum prohlema de saude qua neceisitasse da médico ou farmacōutico? Especificar.

Teve alguma vez doei. as? Qual? (Descrever o tratamento e resultados)

Eczema $\square \quad \operatorname{cefalis} \square \quad \operatorname{Asma} \square \quad \operatorname{Alergie} \square$

(2)

3. Toma algum remédio regularmente?

Aos 2 anos.

andava? E aos 4 , falava?
1. Com 1 ano sentava? $\operatorname{sim} \square$ Näo $\square$

2. Com 2 anos ficava de pé? Sim $\square$ Näo $\square$

3. Depols de sentar/ficar de pé/andar/ falar/ delxou de fazè-10?

Com que ldade?

Sabe por que?

1. Pouco $\square$ ou musto $\square$ apetite

2. Pouco $\square$ ou muito $\square$ peso

3. Recusa alimentar-se sem motivo jus to? Qual?

Tem (ou teve) convulsōes? Tem (ou teve) "esqueci-

mentos"? (Descrever início, frequéncia, tratanen-

to. etc. J

Como pega nos otjetos, em geral?

1. Descoordenado, não consegue manusear nada sem deixar cair ou quebrar (desastrado)

2. Hiperativa

Tem hábito ou "mania"?

1. Ró 1 unhas $\square$ Chupa(ou chupou) dedos $\square$ Masturba-se demais $\square$ Encoprese $\square$ Gagueja $\square$

Como ä "génion ou temperamento delela)?

tem atitudes agresslvas ou disiurzios

que cheguem a provocar reclamaçós de outras pessoas, como os vizinhos?
1. Exige ser obedecido (é quem manda)

2. Dóc11 $\square$ Birrento $\square$ violento $\square$ Choräo $\square$ Agressivo $\square$ Isolado $\square$ Bonzinno Medroso

Outros:
1. Tem atos agressivos e distürbios $\square$

2. Mente $\square$ Rouba $\square$ Pöe fogo nas caisas $\square$

3. Mutto desobediente $\square$ Invejoso $\square$ 
: Wāo perguntar je a lo for regetida).

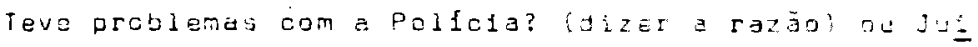
zado de Menores?

Tem alguma curiosidade especial ou grobemas ent reía çào do sexo?

\section{Como se dá con os fama iares linciúr pais, irmäos,} avös) e amigos?

Qual sua atividade predileta? (zavela que elela) go ta de passar a maior parte do terifo)

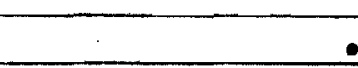

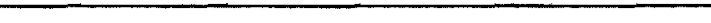

-

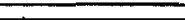

1. Nuriag terrina o que começa $\square$
Como vai na escola?
1. Falta nuito $\square$ irccarita $\square$ Expulso 1 ou 7 als vezes $\square$ Por quE?
2. Frequienta chasae ou escola especial
2. Muito obedient: $\square$ ou quietinho $\square$
2. Isolado $\square$ Nào se dá cam outras crian- gas $\square$ Não tent grupos $\square$
3. E Infeliz $\square$ ijo conversa $\square$
4. Faz ccisas sem sentiao $\square$ Näo coneg. gue brincar adequadamente com orircis dos [

Prefere ficar muito tampo sozirio(a): (se pasitivo, especificar qual a atividadel

$\ldots$

Convida ou é convidaco para festinhas, reuniões. brincadeiras, excursões en grupos con frequéncia?

Passou a se desculdar da higlene passoal?

Tem medos que o inpeder de $7 a z=t$ algute colse? ise negativo, fazer o invertèriol

Tem "manias"ou rituals que ofa) imazem ca tazer alguma coisa?

Mostra preocupaça Excessive oum reisijo, horério. dinheiro, arrumaça de suas roupas du sue higieng pessoal?

Tem elgum jroblema de sono?
1. Tem redo ae arimais $\square$ vbjetos de dormir (aidadornezer)sozinio(a) de escuro $\square$ je cuzas criangas $\square$ de aduitc $\square$ iz origas $\square$ de separa:-se $=0$ rä $\square$
1. Nào pege no eoñ acorde vuite durante o sono $\square$ Enureso noturna $\square$ iorror noturna $\square$ Senambulismo $\square$ soniloquio $\square$ 
ANEXO 04 
OBS:- Preencha este questionärio sempre que o entrevistado responder afirmativamente à questão 4 da folha de "entrevista de adultos".

1. Qual(is) o(s) nome(s) do(s) medicamento(s)?
a)
b)
c)

2. Quais os motivos ou situações que o (a) levam a usar a medicação? (exemplo: por falta de sono, por ficar angustiado, porque o médico recomendou, etc..)

3. Quais as épocas em que tomou esse medicamento?

4. Toma(ou) com regularidade ou com irregularidade? Com que frequéncia usou nos ültimos 12 meses e quais as doses aproximadas? (exemplo: 2 - 3 vezes por mês; 3 comprimidos nos dias em que se sente mal, etc..) 
5. Nos últimos 30 dias ainda tem tomado algum dos medicamentos ou começou a fazê-10? NĀO SIM

Quais? :

6. Em que doses?

7. Com que frequência usou a medicação nos ültimos 30 dias?
a) nenhuma vez;
b) uma vez;
c) mais de uma e menos de 5 vezes;
d) mais de cinco vezes, e
e) diariamente.

8. Quem indicou o nome e o uso do medicamento?
a) parente ou conhecido;
b) tomou por conta pröpria;
c) farmacēutico;
d) médico
d.1. psiquiatra
d.2. clínico geral
d.3. outro. Indicar a especialidade:

e) Outra pessoa. Quem?

f) Não sabe.

9. Como obtém o medicamento? (indicar local e forma de aquisição).

10. Hä necessidade de apresentar receita médica para comprä-lo na farmäcia ? ("a receita fica presa na farmäcia"). 
11. Quemi paga a medi cação?
a) o usuärio;
b) recebe gratuitamente. De que instituição?

12. Quais os efeitos que o entrevistado acha que os medicamentos usados tem?

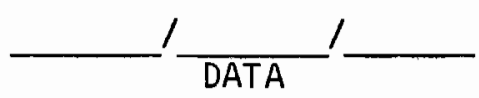


ANEXO 05 


\section{MANUAL DE CODIFICAÇÃO}

CARTÃO FAMILIAR

\begin{tabular}{|c|c|c|c|c|}
\hline ITEM & CODIGO & \multicolumn{3}{|c|}{ COLUNA } \\
\hline 1 - Identificação do cartão & 1 - Familiar & \multicolumn{3}{|c|}{$\frac{1}{1}$} \\
\hline \multirow[t]{5}{*}{2 - Identificação da entre- } & Fase & & $\frac{1}{2}$ & \\
\hline & Subdistrito & 3 & & 4 \\
\hline & UPA & 5 & 6 & 7 \\
\hline & Mês de sorteio & 8 & & 9 \\
\hline & Domicilio & $\overline{10}$ & $\overline{11}$ & $\overline{12}$ \\
\hline
\end{tabular}

3 - Entrevistadora

00 - Não informa

01 - Cässia

02 - Cynthia

03 - Deocélia

04 - Elma

05 - Isis

06 - José Carlos

07 - Josefina

08 - Lala (M. Candelária)

09 - Leane

10 - Lilian

11. - Maria Zimmerman (Maria)

12 - Maria Aparecida Borin

13 - Maria Artonia

14 - Maria José

15 - Marisa A. E. Simons

16 - Margare te 
cont inuação (3)

$$
\begin{aligned}
& 17 \text { - Meyre } \\
& 18 \text { - Regina } \\
& 19 \text { - Rosali/ Neiri } \\
& 20 \text { - Takako } \\
& 21 \text { - Valdomira (Mira) } \\
& 22 \text { - Thomäs } \\
& 23 \text { - Nanci }
\end{aligned}
$$

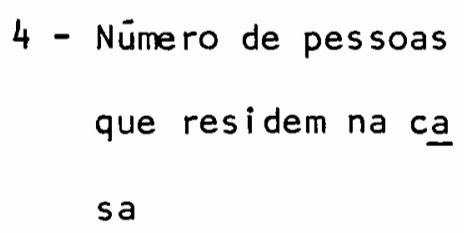

5 - Nümero de pessoas do sexo masculino

6 - Relação parental

0 - Não informa do informante

1 - Chefe

principal com o

2 - Cônjuge

chefe da casa

3 - Filho(a)/genros/noras

4 - Pais/sogros

5 - Irmāos/cunhados

6 - Netas/avös

7 - Sobrinho/primo ou ou tro parente

8 - Agregado sem laço de parentesco (empregada domés ti ca/amigo)

9 - Não é possível distin guir qual dos informantes foi o principal

7 - Quantos informan tes houve ao todo ? 
8 - Sexo do informante

principal
0 - Não informa

1 - Masculino

2 - Feminino

9 - Não é possível distinguir o informante prin cipal
9 - Idade do informante principal

10 - Grau de instrução do informante princi pal
00 - Não informa

99 - Não se aplica

o - Não informa

1 - Mobral/analfabe to

2 - Primärio incomple to

3 - Primärio completo

4 - Ginásio (completo ou não)

5 - Curso colegial (completo ou não)/treinamento pro fissional de nível técni co incompleto

6 - Treinamento profissional de nível técnico

7 - Treinamento profissional de nível universitário

9 - Não foi possível caracte rizar o informante prin= cipal
11 - Principal ocupação do informante
0 - Não informa/não sabe

1 - Empregado/autônomo

2 - Empregador

3 - Aposentado

4 - Desempregado

5 - Li cenciado

6 - Trabalhos Domésticos

7 - Estudante

8 - Sem ocupação

9 - Não se aplica/não foi pos sível caracterizar o informante principal 
12 - Número de pessoas com menos de 2 anos de idade

13 - Idade da pessoa mais 00 - I gnorado

velha que reside no 99 - Não se aplica domicílio

\begin{tabular}{lll}
14 - Idade da pessoa mais & $00-$ I gnorado \\
nova que reside no & $01-1$ ano ou menos de 1 ano \\
domicílio & $99-$ Não se aplica \\
\hline 15 - Tipo de família & 1 - Nuclear completa \\
& 2 - Nuclear incompleta \\
& $3-$ Pseudo-nuclear \\
& 4 - Elementar \\
& 5 - Nuclear mültipla \\
& 6 - Para-nuclear \\
& 7 - Elementar mūltipla \\
& 8 - Poli-nuclear \\
& 9 - Outros não classificados \\
& nos cödigos acima
\end{tabular}

16 - Idade do Chefe

00 - Não informa

17 - Sexo do Chefe

0 - Não informa

1 - Masculino

2 - Feminino

18 - Estado Civil do Chefe

00 - Não informa

11 - Solteiro de fato

12 - Solteiro com companheira

21 - Casado vivendo com o con juge

22 - Casado vivendo separado 
23 - Casado vivendo com o compa nhe i ro (a)

31 - Viüvo sem companheira

32 - Viüvo vivendo com o companhe i ro (a)

41 - Desquitado vivendo sō

42 - Desqui tado vivendo com com panhei ro(a)

43 - Desqui tado vivendo com o companheiro de quem se des qui tou

19 - Local de nascimento

do chefe

20 - Origem urbana ou ru

ral do chife
Ver listagem de locais de nasci

mento

$$
\begin{aligned}
& 0 \text { - Não informa } \\
& 1 \text { - Urbano } \\
& 2 \text { - Rural }
\end{aligned}
$$

$$
\begin{array}{ll}
21 \text { - Hä quanto tempo } 0 & 0 \text { - Não informa } \\
\text { chefe vive em Säo } & 1 \text { - Menos de } 6 \text { meses } \\
\text { Paulo? } & 2-\begin{array}{l}
\text { Menos de } 1 \text { ano e } 6 \text { ou mais } \\
\text { meses }
\end{array} \\
& 3-1 \text { a } 2 \text { anos } \\
& 4-3 \text { a } 5 \text { anos } \\
& 5-6 \text { a } 10 \text { anos } \\
& 6-11 \text { a } 20 \text { anos } \\
& 7-21 \text { anos e mais } \\
8 & - \text { Sempre viveu em São Paulo }
\end{array}
$$

22 - Grau de instrução do chefe
0 - Não informa

1 - Mobral ou analfabeto

2 - Primärio incompleto

3 - Primärio completo

4 - Ginäsio (completo ou não)

5 - Curso colegial (completo ou 
continuação (22)

não)/treinamento profisional de nível técnico incom ple to

6 - Treinamento profissional de nível técnico

7 - Treinamento profissional de nível universitärio

23 - Principal ocupação

0 - Não informa/não sabe

atual do chefe

1 - Empregado/autōnomo

2 - Empregador

3 - Aposentado

4 - Desempregado

5 - Li cenciado

6 - Trabalhos domésticos

7 - Estudante

8 - Sem ocupação

9 - Não se aplica

24 - Profissão do chefe

Escala OIT

$\overline{44} \quad \overline{45}$

25 - 0 chefe tem previden- 0 - Não informa

ciäria?

1 - Não

$2-\operatorname{sim}$

26 - Tipo de residência

0 - Não informa

1 - Casa individual

2 - Casa coletiva

3 - Apartamento individual

4 - Apartamento coletivo

5 - Favela

6 - Não è possível distinguir se se trata de casa ou apartamen to 
27 - Nümero de dependèn-

28 - Utilização de cozi

o - Não informa

nha e/ou banhei ro

1 - Cozinha e banheiro indivi duais

2 - Cozinha individual e banheiro coletivo

3 - Cozinha coletiva e banhei ro individual

4 - Cozinha e banheiro coletivos

29 - Nümero de dependências que excedem a unidade bäsica de habi tação (2 quartos, 1 cozinha, 1 banheiro, ou 1 quar to, 1 sala, 1 cozinha, 1 banheiro) 4 è o mínimo o - Não atinge a unidade bāsi ca

1 - Não atinge a unidade bäsi ca, mas tem"outras"depen= dēncias

2 - Resume-se à unidade básica

3 - Excede em 1 dependência a uni dade bäsica

4 - Excede em 2 dependências a unidade bäsica

5 - Excede em 3 dependências a unidade bäsica

6 - Excede em mais de 3 depen dênclas

9 - Näo hä informação

30 - 0 chefe è doente

1 - Não

$2-\operatorname{sim}$

31 - 0 cônjuge é doente

1 - Näo

$2-\operatorname{sim}$

9 - Não se aplica

32 - Nümero de menores

9 - Não se aplica

de 15 anos doentes 
33 - Número de outros adultos da família doentes

(exclui o chefe e o

cônjuge)

34 - Número de outros adultos agregados doentes

(empregados, pessoas

9 - Não se aplica

com estadia temporária)

35 - Nümero de doentes do sexo masculino (inclui os agregados)

36 - Nümero de doentes do sexo feminino (inclui os agregados)

37 - Classificação sōcioeconômica: profissāo do chefe

9 - Não informa

38 - Classi fi cação sōcioeconómica: escolarida de do chefe

9 - Não informa

39 - Classificação söcioeconómica: tipo de residência

9 - Não informa 
MANUAL DE CODIFICAÇĀO

CARTÃO INDIVIDUAL DE ADULTOS

ITEM

CODIGO

COLUNA

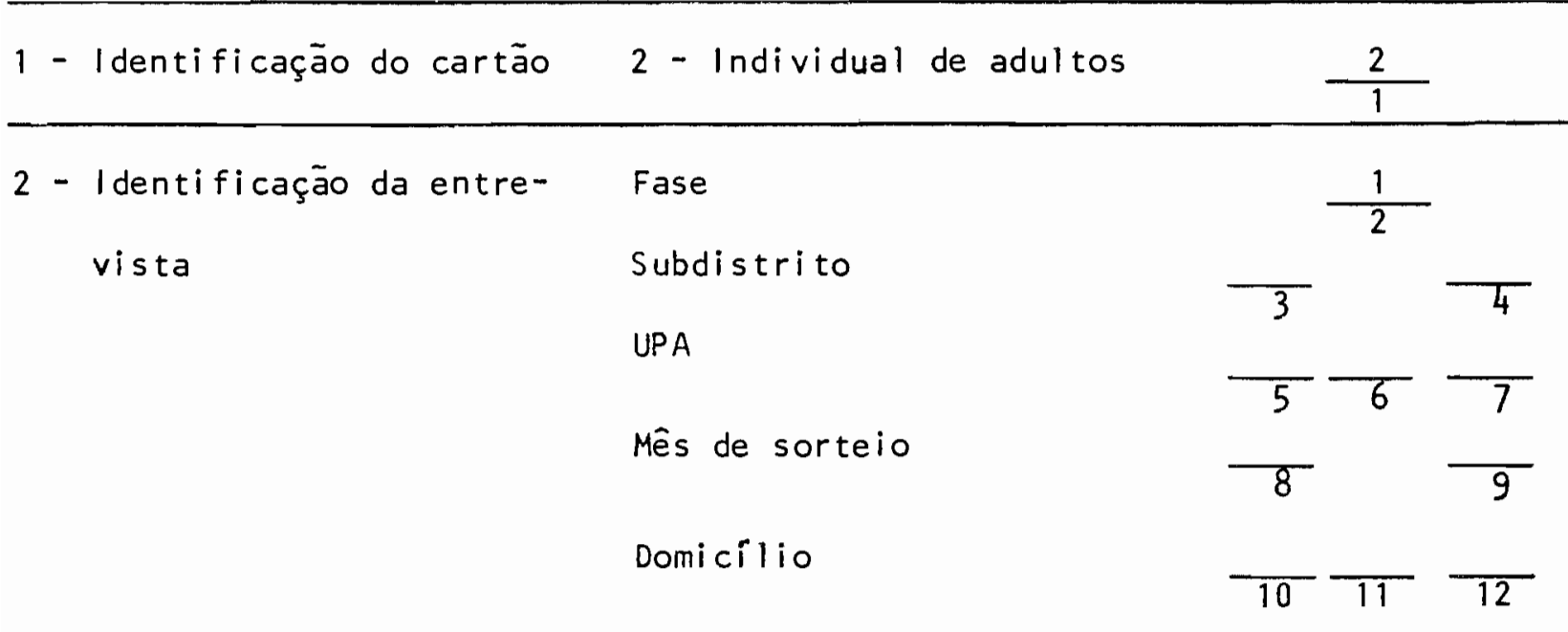

3 - Identificação do indiví

duo (No de Ordem)

4 - Relação parental do

o - Não informa

interessado com o chefe

1 - 0 pröprio chefe

2 - Cônjuge

3 - Filho (a)/genro/nora

4 - Pais/sogros

5 - 1 rmãos/cunhados

6 - Netos/avós

7 - Sobrinho/primo ou outro

parente

8 - Agregado $S / l$ aço de paren tesco

9 - Empregada doméstica 
$6-\operatorname{sexo}$

$$
\begin{aligned}
& 0 \text { - Não informa } \\
& 1 \text { - Masculino } \\
& 2 \text { - Feminino }
\end{aligned}
$$

7 - Estado Civil

00 - Não informa

11 - Solteiro de fato

12 - Soltei ro com companheira

21 - Casado vivendo com o cônjuge

22 - Casado vivendo separado

23 - Casado vivendo com companhei ro(a)

31 - Viüvo sem companheira

32 - Viüvo vivendo com companhe i ro(a)

41 - Desquitado vivendo sö

42 - Desquitado vivendo com companhei ro (a)

43 - Desqui tado vi vendo como companheiro de quem se desquitou

99 - Menor

8 - Local de nascimento Ver listagem de locais de nascimento

9 - Origem urbano/rural 0 - Não informa

1 - Urbano

2 - Rural

10 - Hä quanto tempo vive

0 - Não informa em São Paulo

1 - Menos de 6 meses 

ou mais

$3-1$ a 2 anos

$4-3$ a 5 anos

$5-6$ a 10 anos

6 - 11 a 20 anos

7 - 21 anos e mais

8 - Sempre viveu em São Paulo

11 - Grau de instrução

0 - Não informa

1 - Analfabeto/Mobral

2 - Primärio incompleto

3 - Primärio completo

4 - Gināsio incompleto

5 - Ginásio completo

6 - Colegial completo/incompleto

7 - Superior incompleto

8 - Superior comple to

9 - Não se aplica

12 - Ocupação principal

0 - Não informa/não sabe

1 - Empregado/autônomo

2 - Empregador

3 - Aposentado

4 - Desempregado

5 - Li cenciado

6 - Trabalhos domésticos

7 - Estudante

8 - Sem ocupação

9 - Não se aplica 


$$
\begin{aligned}
& 13 \text { - Ocupação secundāria } 0 \text { - Näo informa } \\
& 1 \text { - Estudante } \\
& 2 \text { - Trabalho esporádico } \\
& 3 \text { - Trabalho regular faito } \\
& \text { em horärio livre } \\
& 4 \text { - Trabalho regular feito } \\
& \text { em horärio fixo }
\end{aligned}
$$

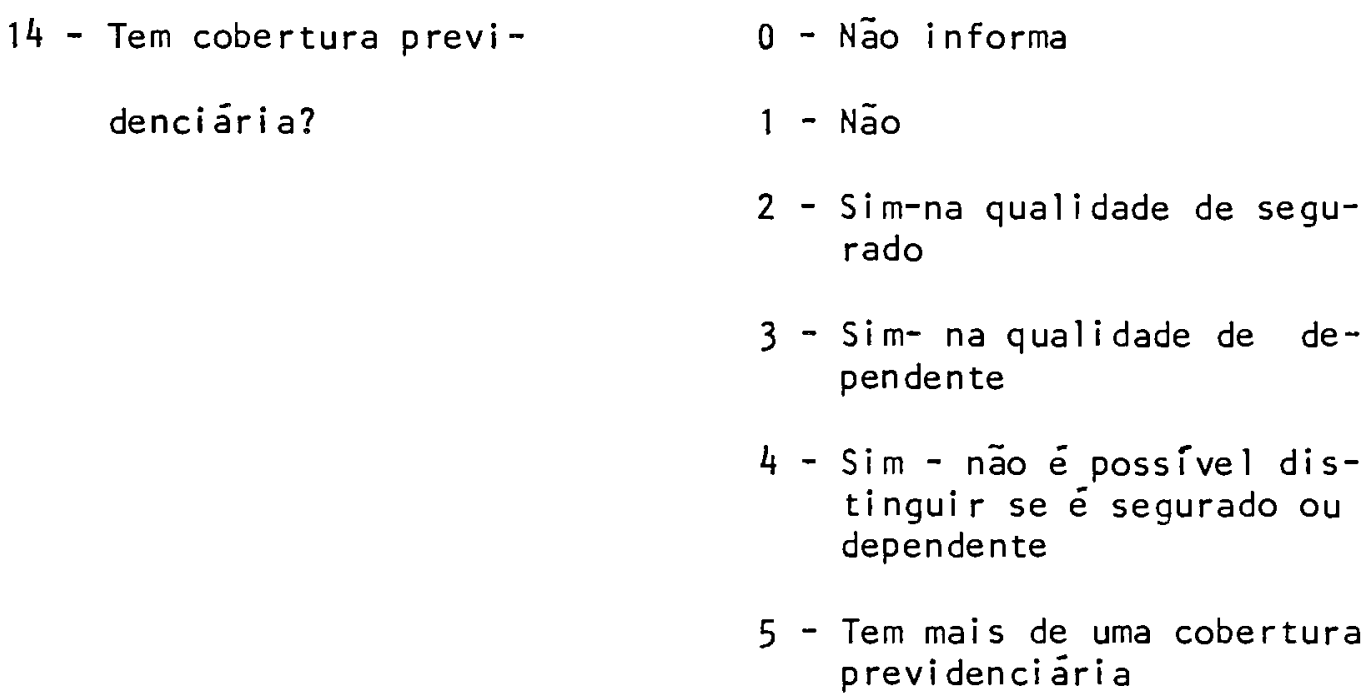

16 - Relação parental do

informante principal

com o interessado
0 - Não informa

1 - 0 pröprio

2 - Pais

3 - Cônjuges

4 - Filhos

5 - Sogros

6 - Genros/noras

7 - Cunhados/i rmãos

8 - Outros

9 - Empregado doméstico 
17 - Refere transtornos mentais nos ültimos 12 meses
1 - Não refere qualquer prob lema presumi ve imente classificado como mental

2 - Queixas somáticas de pre sumível etiologia psíqui ca

3 - Queixas de transtornos psíquicos mal definidos

4 - Queixa de quadro de tipo ansioso associado a trans torno somätico

5 - Queixa de quadro de tipo depressivo ou depressivoansioso

6 - Queixa de quadro ansioso ou conversivo

7 - Queixa de quadro de irritabilidade associado ou não com ansiedade

8 - Queixas de deficienncias intelectuais

9 - Queixas de quadros psíquicos de li nha psicótica

0 - Outros quadros não classificäveis nos ítens ante riores
18 - Refere problemas de saüde nos ültimos 12 meses
1 - Não refere problemas de saúde no período ou refere episōdios menores de curta duraçāo

2 - Queixas indefinidas ou mal especificadas

3 - Queixas do apare tho 10comotor

4 - Queixas do aparelho car dio-circulatörio

5 - Queixas do aparelho gas tro-intestinal

6 - Queixas do apare lho res piratörio

7 - Queixas do apare lho geni to urinário

8 - Queixas de patologia en dórrina 

apare Iho

0 - Sintomas não classifi cados nos ítens anteriores

19 - Recebeu assistência

0 - Não informa

mëdica ambulatorial

1 - Não recebeu

nos ültimos 12 me-

2 - Exames de admissão e/ ou rotina

ses por queixa somä

3 - Prë-natal

tica?

4 - Uma ou mais consultas por queixa somática

5 - Faz tratamento regular e periódico (varias consultas)

6 - Recebeu assistência sem especifi cação

7 - Faz tratamento regular de reabili tação

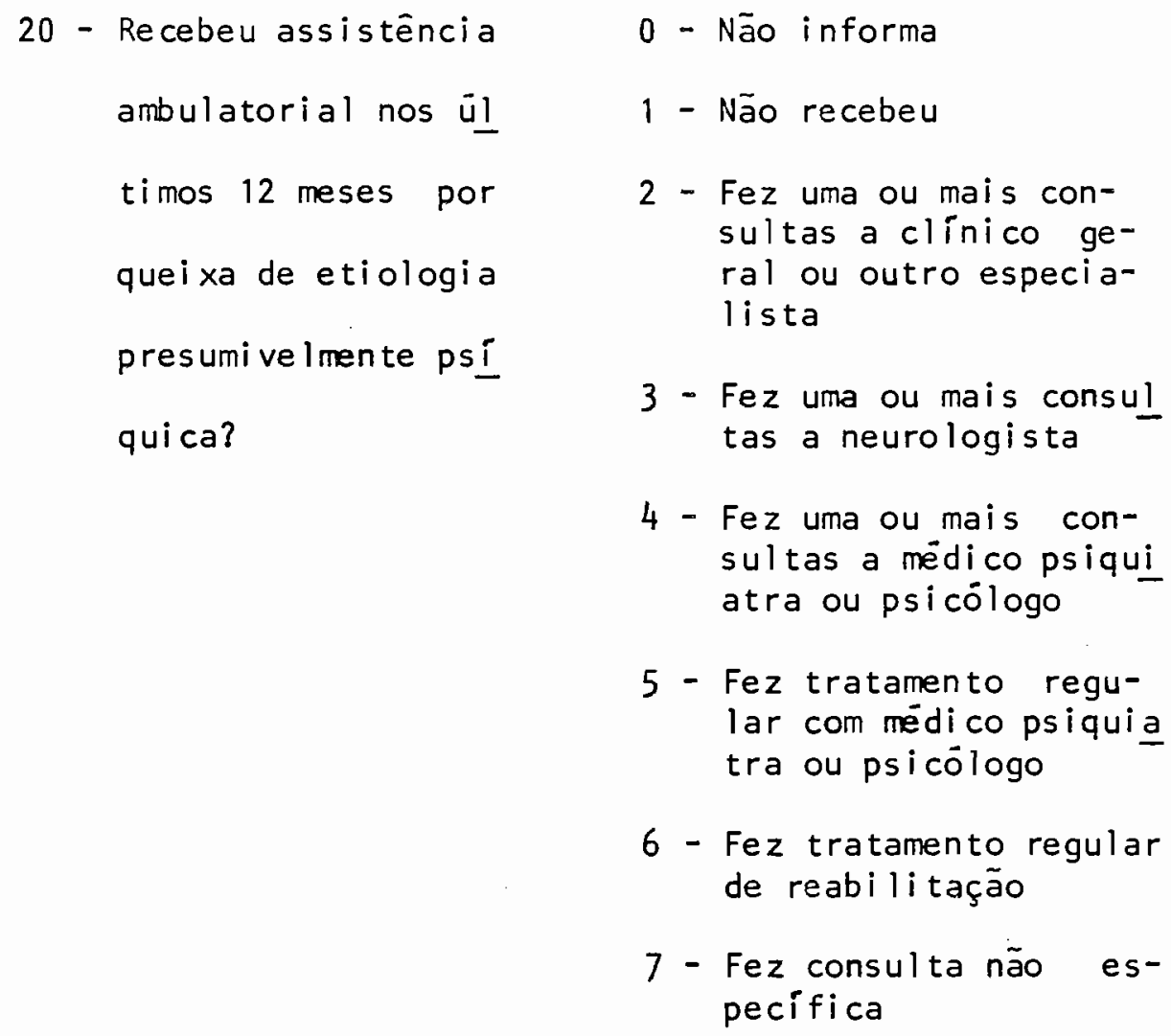


21 - Esteve hospitalizado

nos $\bar{l}$ timos 12 meses? o - Não informa

$1-$ Não

2 - Em maternidade

3 - Para diagnóstico ou traz mento clínico

4 - Para diagnóstico ou tratamento ci rúrgico

5 - Em hospital psiquiā trico

6 - Em instituiçōes pạ ra hospitalares psiquiätricos

7 - Esteve internado em -mais de um dos tipos de instituição acima

8 - Esteve internado em hospital geral -não sabe o tipo de tratamento
22 - Uso de medicação não psicotrópica nos ūiltimos 12 meses. o - Nāo informa

1 - Não usou

2 - Usou com regularida de orientado por mé di co

3 - Usou com regularida de orientado por leigo

4 - Usou com regularida de por auto-indicação

5 - Usou com regularida de - sem indi cação de quem indicou

6 - Usou i rregularmente (esporadi camente, em episódios isolados) indi cado por médi co

7 - Usou irregularmente (esporadi camente,em episódios isolados) indicado por leigo

8 - Usou irregularmente (esporadi camen te,em 
<3 - Quantas vezes apareceram

respostas negativas en-

tre os ítens 17 a 22 in

clusive (cōdigo 1)? (coㅇ

lunas 33 a 38 )

24 - Usou de medicação psico-

o - Não informa/não sabe

trópica nos ültimos 12

1 - Não usou

meses. Tipo

2 - Anticonvulsivante

3 - Hipnōtica

4 - Ansiolítica

5 - Antidepressiva

6 - Neuroléptica

7 - Associ ação entre 3-4-5-6

8 - Associação entre 2 e 3-4-5-6

9 - Fez uso de medicação psi cotrōpica - sem especifi cação

25 - Uso de medicação psico-

trópica. Frequēncia

(nos ültimos 12 meses)
0 - Não informa/não sabe

1 - Não usou

2 - Não usou nos ültimos 12 meses mas usou anteriormente

3 - Usou com regularidade

4 - Usou esporadica e episodi camen te

5 - Usou episodicamente asso ciado a situação de stréss

6 - Usou associado a tratamen tos clínicos 


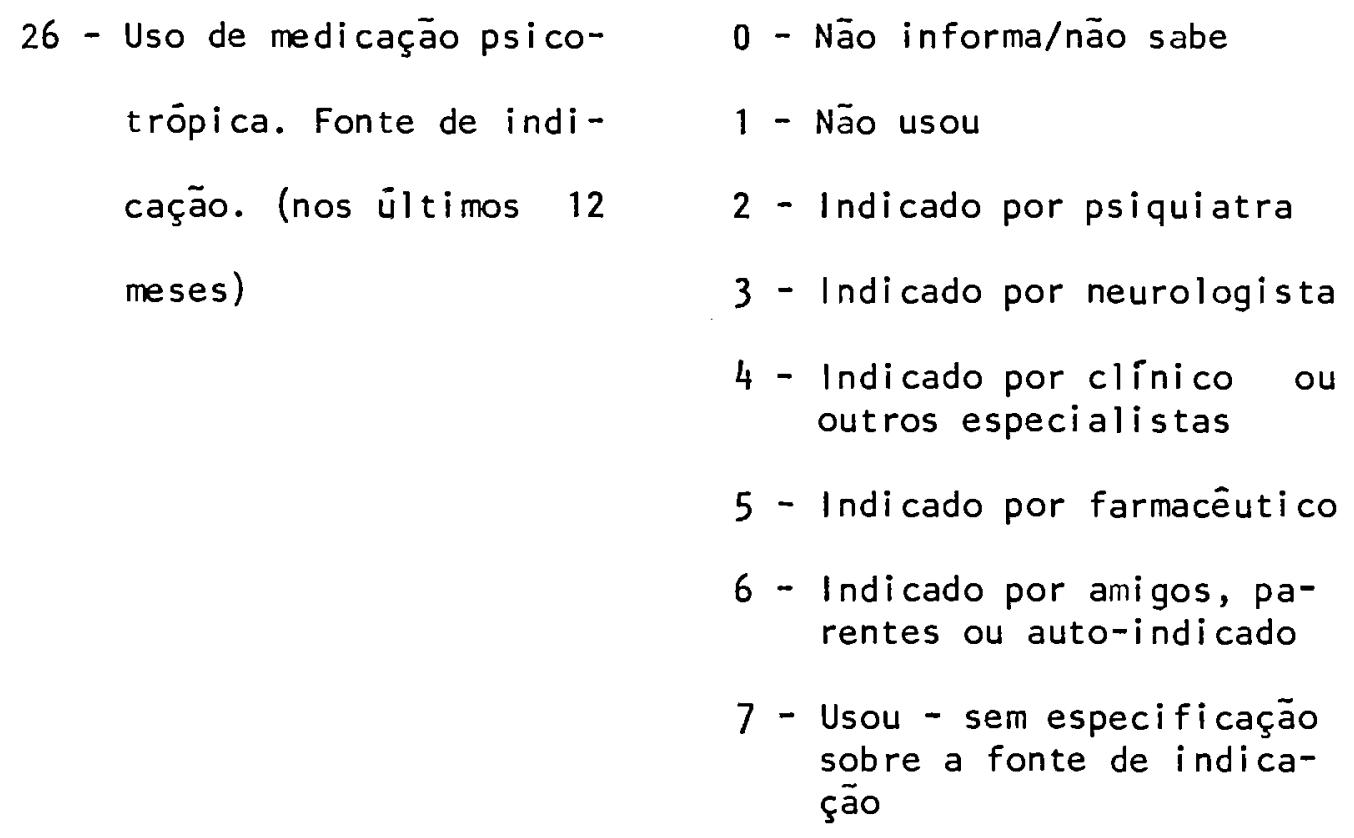

27 - Precisou ajuda externa

o - Não informa/näo sabe

nos ültimos 12 meses

1 - Não precisou/não recorreu

2 - Alguém do nücleo familiar

3 - Alguém da familia extens va

4 - Amigos, patrões, chefes,

5 - Farmacêutico

6 - Religioso,

7 - Sim - sem outra indicação

8 - $A A, N A$

28 - Precisaria ter recebido assistência para proble mas de nervos o - Não informa/não sabe

1 - Nāo

2 - Sim por mëdico psiquiatra (ou outros profissionais da àrea)

3 - Sim por outro especialista (inclusive clínico ge ral)

4 - Sim - sem indicação

5 - Informa jā estar em trata mento 
29 - Quantas vezes apareceu resposta negativa (código 1) entre os ítens 24 a 28 (inclusive)

(colunas 40 a 44)

30 - Uso de bebidas alcoōli cas nos ültimos 12 me ses o - Não informa/não sabe

1 - Habitualmente é abstinente

2 - Bebe ocasionalmente/social mente sem excessos

3 - Bebe esporadicamente em excessos

4 - Habitualmente bebe regular mente sem excessos

5 - Bebe regularmente sem excessos

6 - Bebia em excessos passando a fazê-lo moderadamente no período dos ültimos 12 meses

7 - Bebia em excessos tendo se tornado abstinente

8 - Bebe, não informa frequência ou quantidade

9 - Responde "Não"

31 - Avaliação do avaliador 1

9 - Nāo avaliou

32 - Avaliação do avaliador $2 \quad 9$ - Não avaliou

33 - Avaliação do avaliador 39 - Não avaliou

34 - Decisão

0 - Não Doente (N)

1 - Doente (S) 
MANUAL DE CODIFICAÇÃO

CARTAOO INDIVIDUAL DE MENORES DE 15 ANOS

ITEM

CODIGO

COLUNA

1 - Identificação do cartão 3 - Menores de 15 anos $\frac{3}{1}$

2 - Identificação da entre- Fase vista

Sub-Distrito

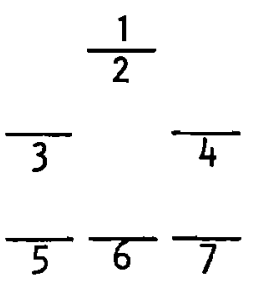

Mès do sorteio

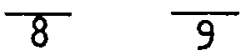

Domicílio

$\overline{10} \overline{11} \overline{12}$

3 - Identificação do indiví

duo (n: de ordem)

4 - Relação parental do in- 0 - Não informa

teressado com o chefe $\quad 1-$ Filho(a)

2 - Irmãos/cunhado

3 - Neto

4 - Sobrinho/primo

5 - Adotivo (de criação) SEM laço de parentesco

6 - Adotivo (de criação) COM laço de parentesco

7 - Empregado doméstico

5 - Idade

6 - Sexo

0 - Não informa

1 - Masculino

2 - Femino 
7 - Local de nascimento

Usar a listagem de locais de nascimen to

8 - Origem urbano-rural

$$
\begin{aligned}
& 0 \text { - Não informa } \\
& 1 \text { - Urbano } \\
& 2 \text { - Rural }
\end{aligned}
$$

$$
\begin{array}{ll}
9 \text { - Hä quanto tempo vi } & 0 \text { - Não informa } \\
\text { ve em São Paulo } & 1 \text { - Menos de } 6 \text { meses } \\
& 2 \text { - Menos de } 1 \text { ano e mais de } \\
& 6 \text { meses } \\
& 3 \text { - Entre } 1 \text { e } 2 \text { anos } \\
& 4 \text { - Entre } 3 \text { e } 5 \text { anos } \\
& 5 \text { - Entre } 6 \text { e } 10 \text { anos } \\
& 6 \text { - Mais de } 11 \text { anos } \\
& 8 \text { - Sempre viveu em } \mathrm{s.} \mathrm{Paulo}
\end{array}
$$

10 - Grau de instrução

0 - Não informa

1 - Analfabeto

2 - Primärio incompleto

3 - Primärio comple to

4 - Ginasial incompleto

5 - Ginasial completo

6 - Colegial incompleto

9 - Não se aplica (menores de 7 anos exclusive)

11 - Ocupação principal

0 - Não informa

1 - Estudante

2 - Não tem/sem ocupação

3 - Trabalho doméstico

4 - Trabalho externo

9 - Não se aplica (menores de 7 anos exclusive) 
16 - Procurou assistência

leiga por problemas

de saüde nos ültimos

12 meses?
0 - Não informa

1 - Não

2 - Farmacêutico

3 - Outros

4 - Associação entre 2 - 3

\section{7 - Recebeu assistência \\ 0 - Não informa \\ médica ambulatorial \\ 1 - Não \\ nos últimos 12 me- \\ 2 - Exames de rotina e/ou vacinaçōes \\ ses? \\ 3 - Uma consulta \\ 4 - Fez tratamento regular e periödico \\ 5 - Recebeu assistência am- bulatorial - sem outra indi cação \\ 6 - Faz tratamento regular de reabilitação \\ 7 - Associação entre 2 - 3 a 6}

18 - Esteve hospitalizado nos ültimos 12

meses? o - Não informa

1 - Não 2 - Para diagnóstico ou
tratamento clínico

3 - Para diagnóstico ou tratamento cirúrgico

4 - Em hospital ou clínica psiquiàtrica

5 - Em instituiçōes parahospitalares

6 - Esteve internado em mais de um dos tipos de instituições acima

7 - Esteve internado em hospital geral - sem outra indicação 


$$
\begin{aligned}
& 19 \text { - Apresentou algumas das } 0 \text { - Não informa } \\
& \text { seguintes doenças } \quad 1 \text { - Nenhuma } \\
& 2 \text { - Eczema } \\
& 3 \text { - Cefalea } \\
& 4 \text { - Asma } \\
& 5 \text { - Alergia (a drogas ou me- } \\
& \text { di camentos) }
\end{aligned}
$$

$$
\begin{aligned}
& 20 \text { - Antes dos ültimos } 12 \quad 0 \text { - Näo informa } \\
& \text { meses teve alguma do } \quad 1 \text { - Não há indicação } \\
& \text { ença } 2 \text { - Doenças infantis sem com- } \\
& \text { plicação } \\
& 3 \text { - Doenças infantis com com- } \\
& \text { plicação } \\
& 4 \text { - Desidratação } \\
& 5 \text { - Broncopneumonia } \\
& 6 \text { - Desnutrição } \\
& 7 \text { - Qualquer associação entre } \\
& 4-5-6 \\
& 8 \text { - Outras doenças } \\
& 9 \text { - Qualquer associação entre } \\
& 2,3,4,5,6,8
\end{aligned}
$$

21 - Tomou medi cação psi-

0 - Não informa

cotrópica - alguma

1 - Näo

vez?

2 - Sim indicado por leigo

3 - Sim indi cado por médi co

4 - Sim - não informa a fonte de indicação 
Fez uso de vitaminas $\quad 0$ - Não informa

nos ültimos 12 meses? 1 - Não

2 - sim - indicado por leigo

3 - Sim - indi cado por médico

4 - Sim - não informa quem indicou

23 - Fez uso de outros me

0 - Não informa

dicamentos nos ülti-

1 - Não

mos 12 meses?

2 - Sim - indicado por leigo

3 - sim-indicado por médico

4 - sim - sem indi caçäo

24 - Quantas vezes apare-

ceram respostas nega

tivas (cödigo 1) en-

tre os ítens 15 a $23 ?$

(col. 29 a 37)

$$
\begin{aligned}
& 25 \text { - Com que idade começou } 0 \text { - Não informa } \\
& \text { a andar? } 1 \text { - Antes dos } 12 \text { meses } \\
& 2-12 \text { a } 18 \text { meses } \\
& 3 \text { - } 19 \text { a } 24 \text { meses } \\
& 4 \text { - depois dos } 2 \text { anos } \\
& 5 \text { - só responde afirmativamen } \\
& \text { te a pergunta, sem preci } \overline{39} \\
& \text { sar a idade ("normal") } \\
& 6 \text { - Ainda não começou a andar } \\
& 7 \text { - depois de ter começado a } \\
& \text { andar deixou de fazê-lo }
\end{aligned}
$$

$$
\begin{array}{ll}
26 \text { - Refere problemas que } & 0 \text { - Não informa } \\
\text { atrasaram o desenvol } & 1 \text { - Não refere } \\
\text { vimento da marcha? } & 2 \text { - Neurológicas } \\
& 3 \text { - Ortopédicas }
\end{array}
$$


5 - Outros

6 - Não refere qual a possível origem do atraso

27 - Com que i iade come-

çou a falar?

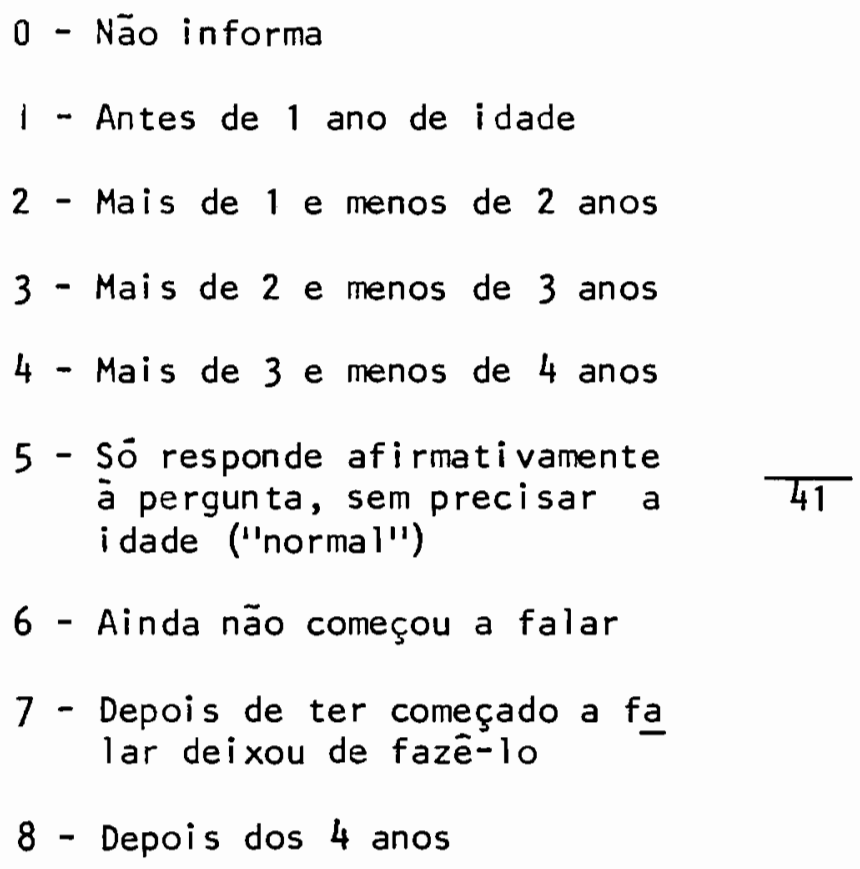

0 - Não informa

1 - Não refere

2 - Distürbios na pronuncia de letras ou sílabas

3 - Não forma frases

4 - Gagueja

5 - Outros

6 - Não começou a falar
29 - Refere distúrbios co miciais?
0 - Não informa

$1-$ Não

2 - Apresentou (apresenta) convulsōes febris

3 - Apresentou convulsöes, desmaios ou ausencias antes dos ültimos 12 meses

4 - Apresenta convulsões, desmaios ou ausências

5 - Apresenta distūrbios possivelmente comiciais mal carac terizados 
30 - Refere distúrbios da

motricidade?
0 - Não informa

1 - Não

2 - Incoordenação motora

3 - Hiperatividade motora

4 - Incoordenação mais hiperatividade

5 - Refere possíveis distürbios da motricidade mal caracterizados

31 - Estā na escola?

o - Näo informa

1 - Não

$2-\operatorname{sim}$

9 - Não se aplica

32 - Repetências de ano

0 - Não informa

1 - Não

2 - Repetiu de ano 1 vez

3 - Repetiu o mesmo ano mais de 1 vez e menos de 4

4 - Repetiu o mesmo ano mais de 4 vezes

5 - Repetiu 1 vez, anos diferentes

6 - Responde afi rmativamente mas não sabe precisar

9 - Não se aplica

33 - Frequenta classe es

$i$ - Não

pecial?

$2-\operatorname{sim}$

9 - Não se aplíca

34 - Refere distūrbios de

o - Não informa

sono?

1 - Nāo

2 - Sono agitado, ranger de dentes

3 - Terror noturno 


\begin{tabular}{|c|c|c|}
\hline continuação (34) & $\begin{array}{l}4 \text { - Soni loquio } \\
5 \text { - Sonambulismo } \\
6 \text { - Enurese } \\
7 \text { - Combinação de } 2,3 \\
8 \text { - Combinação de } 3,4,5,6 \\
9 \text { - Combinação de } 5,6\end{array}$ & \\
\hline $\begin{array}{l}35 \text { - Avaliação do avalia } \\
\text { dor } 1\end{array}$ & 9 - Não avaliou & 49 \\
\hline $\begin{array}{l}36 \text { - Avaliação do avalia } \\
\text { dor } 2\end{array}$ & 9 - Não avaliou & 50 \\
\hline $\begin{array}{l}37 \text { - Avali ação do avalia } \\
\text { dor } 3\end{array}$ & 9 - Não avaliou & 51 \\
\hline 38 - Decisão & $\begin{array}{l}0 \text { - Não doente (N) } \\
1 \text { - Doente (S) }\end{array}$ & 52 \\
\hline
\end{tabular}


I DENTI FI CAÇĀ

1. EPIDEMIOLOGIA DO USO DE TRANQUILIZANTES MENORES, HIPNOTTICOS E SEDATIVOS - TANCREDI

2. NO QUESTIONARIO

3. NO DE ORDEM DA PESSOA

4. QUEM DA A INFORMAÇĀO

0. Não informa

1. o próprio

2. pais

3. cōnjuges

4. filhos

5. sogros

6. genros/noras

7. cunhados/i rmãos

8. outros

9. empregado doméstíco

5. QUANTOS PRODUTOS REFERE

6. DENTRE OS PRODUTOS REFERIDOS ... NAOO SE ENQUADRAVAM ENTRE

OS PSICOTRÓPICOS

9. responde "não sabe", "não sabe o nome"

7. EM QUE CATEGORIA. SE ENQUADRAM OS PRODUTOS NÃO CONSIDERADOS PSICOTROPICOS

0 . responde "não sabe", "não sabe o nome"

1. ético

2. não ético

3. caseiro

8. a informação não é conclusiva

9. não se aplica 
8. NOME

9. DOSE

$$
\begin{aligned}
& 00 \text { - Não informa } \\
& 99 \text { - Não se aplica }
\end{aligned}
$$

10. APRESENTAÇÃO

$$
\begin{aligned}
& \text { 0. Não informa } \\
& \text { 1. comprimido } \\
& \text { 2. Sol ução } \\
& \text { 3. xarope } \\
& \text { 4. gotas } \\
& \text { 5. ampola }
\end{aligned}
$$

11. CATEGORIA

2\% PSICOTROPICO REFERIDO

12. NOME

13. DOSE

$$
\begin{aligned}
& 00 \text { - Não informa } \\
& 99 \text { - Não se aplica }
\end{aligned}
$$

14. APRESENTAÇAOO

15. CATEGORIA

3. PSICOTROPICO REFERIDO

16. NOME

17. DOSE

$$
\begin{aligned}
& 00 \text { - Não informa } \\
& 99 \text { - Não se aplica }
\end{aligned}
$$

18. APRESENTAÇÃO

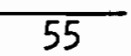

19. CATEGORIA

20. Segundo do informante, a venda se dá

0. não informa

1. com controle de receituärio

2. sem controle de receituärio

3. inconclusivo 
4. não sabe

5. não se aplica

21. Segundo o pesquisador, a venda se dä

0 . não informa

1. com controle de receituärio

2. sem controle de receituário

3. inconclusivo

9. não se aplica (não se sabe o nome)

22. Tomou nos ültimos 30 dias
0. não informa
1. não
2. $\mathrm{sim}$
3. inconclusivo
9. não se aplica

23. Padrão de uso nos últimos 30 dias

0 . näo informa

1. nenhuma vez

2. uma vez

3. mais de uma e menos de cinco vezes

4. mais de cinco vezes

5. diariamente

6. inconclusivo

9. não se aplica

24. Tomou no ültimo ano? (exclui os ültimos

0 . não informa 30 dias)

1. não

2. sim

3. inconclusivo

9. não se aplica

25. Padrão de uso no ano (exclui os últimos

0 . não informa

30 dias)

1. não tomou

2. episódico

3. esporädico

4. regular

5. inconclusivo

9. näo se aplica

26. Motivo(s) para o uso:

0 . näo informa/não sabe

1. queixas psíquicas

2. queixas somáticas de presumivel etiologia psíquica

3. associado a tratamento neurológico

4. associado a tratamento cardiológico 
5. associado a tratamento endocrinológico

6. associado a tratamento gastroenterológico

7. associado a outros tratamentos médicos

8. inconclusivo

9. não se aplica

27. Quem indicou?

00. não informa/não sabe

10. por conta pröpria

21. parente ou conhecido morando no mesmo domicílio

22. parente ou conhecido morando em outro domicílio

30. "farmacêutico"

40. médico psiquiatra

51. neurologista

52. clínico geral

53. cardiologista

54. ortopedista

55. gastroenterologista

58. outras especialidades

59. médico sem especi fi cação

60. outras pessoas

90. não se aplica 
10. Neuroléptico - SOl

11. Neuroléptico em dosagen antipsicótica

12. Neurolëptico em dosagem leve

13. Neurolēptico em associação antidistonica

20. Antidepressivo - sol

21. Antidepressivo puro

22. Antidepressivo em associação

30. Anticomicial

31. Anticomicial barbi túrico puro

32. Anticomicial barbi türico em associação

33. Anticomicial não barbitürico (puro ou em associação)

40. Tranquilizante menor benzodiazepinico - sol

41. Tranquilizante menor benzodiazepinico com receituärio controlado

42. Tranquilizante menor benzodiazepinico sem controle de receituärio (antidistonicos)

50. Tranquilizante menor não benzodiazepinico - Sol

51. Tranquilizante menor não benzodiazepinico com controle receituärio

52. Tranquilizante menor não benzodiazepinico sem controle receituärio

60. Hipnōtico - sol

61. Hipnötico com controle recei tuärio

62. Hipnōtico sem controle receituārio (antidistonico)

70. Sedativo - sol

71. Sedativo - associações com barbitüricos

72. Sedativo - associações com vegetais

73. Sedativo - associações com barbitúricos mais vegetais

74. Sedativo - associações com outras substâncias psicotrópicas

99. Não sabe o nome

00. Inconclusivo 